\title{
A NEW SPECIES OF THE PRIMITIVE DINOSAUR Thecodontosaurus (SAURISCHIA: SAUROPODOMORPHA) AND ITS IMPLICATIONS FOR THE SYSTEMATICS OF EARLY DINOSAURS
}

\section{Adam M. Yates}

Department of Earth Sciences, University of Bristol, Bristol, BS8 1RJ, UK

SYNOPSIS Juvenile sauropodomorph specimens from a Late Triassic/Early Jurassic fissure fill in Pant-y-ffynnon Quarry, South Wales are redescribed and named as a new species, Thecodontosaurus caducus. T. caducus can be diagnosed by the presence of pleurocoel-like pits on the neurocentral sutures of the sixth, seventh and eighth cervical vertebrae. It is further distinguished from the type species of the genus, $T$. antiquus, by the primitive shape of its proximal humerus and ilium. Data from this specimen are incorporated into a cladistic analysis of basal sauropodomorph relationships. It is found that Thecodontosaurus is basal to all other sauropodomorphs, with the exception of Saturnalia from the late Carnian of Brazil. As such Thecodontosaurus is a key taxon, with a novel combination of characters that has important implications for early dinosaur phylogenetics. Thecodontosaurus provides evidence that 'prosauropods' are paraphyletic with respect to Sauropoda and that Herrerasauridae lies outside the clade containing Sauropodomorpha + Theropoda.

KEY WORDS Thecodontosaurus, T. caducus, Cladistic analysis, Sauropodomorpha, Prosauropoda, Paraphyletic

\section{Contents}

Introduction

Systematic palaeontology

SAURISCHIA Seeley, 1888

SAUROPODOMORPHA von Huene, 1932

Genus THECODONTOSAURUS Riley and Stutchbury, 1836

Thecodontosaurus caducus sp. nov.

Description

Skull roof

Palate

Braincase

Mandible

Vertebral column

Forelimb

Hindlimb

Skeletal reconstruction

Cladistic analysis

Methods

Results

Prosauropod monophyly $\quad 26$

$\begin{array}{ll}\text { Acknowledgements } & \mathbf{3 1}\end{array}$

References $\quad 31$

Appendix 1: list of anatomical abbreviations 33

Appendix 2: list of characters $\quad 34$

Appendix 3: list of unambiguous synapomorphies $\quad \mathbf{4 0}$

Appendix 4: character-taxon matrix $\quad \mathbf{4 1}$ 


\section{INTRODUCTION}

The remains of several juvenile sauropodomorphs were found in Pant-y-ffynnon Quarry in South Wales by Professor K. Kermack and Dr P. Robinson in 1952. The material is part of an Upper Triassic assemblage found in fine-grained sandstone that filled a fissure in the Carboniferous Limestone of the Quarry. The sauropodomorph specimens include a disarticulated skull with associated forelimb elements and cervical series, isolated skull elements and several postcranial bones, including a partial hind limb. The skull was reconstructed and described as Thecodontosaurus sp. by D. Kermack (1984). The postcranial remains have been featured in skeletal reconstructions (Kermack 1984; Galton 1990; Upchurch 1997; Benton et al. 2000) but remain undescribed.

Thecodontosaurus was the first sauropodomorph dinosaur to be scientifically described (Riley \& Stutchbury 1836), but its anatomy has remained poorly known relative to other sauropodomorph dinosaurs. What is known is that, with an adult length of no more than $3 \mathrm{~m}$ (Benton et al. 2000), it is one of the smallest and most gracile members of the Sauropodomorpha. Some authors claim that it retained an obligatory bipedal posture during locomotion (Kermack 1984; Galton 1990, 2000; Benton et al. 2000) but it certainly did not retain a predatory lifestyle. It had the typical sauropodomorph dental specialisations that suggest it included a high proportion of vegetable matter in its diet (Galton 1985a; Crompton \& Attridge 1986).

The type species, T. antiquus Morris, 1843, was based on largely disarticulated bones found in a Late Triassic fissure fill deposit from Bristol in south-west England. Many of these bones were lost during the Second World War but hundreds still survive and these have been redescribed recently (Benton et al. 2000). More bones from another locality in south-west England are known (Whiteside 1983) and these are currently being prepared and studied.

The importance of Thecodontosaurus lies in its basal position within sauropodomorph phylogeny. It has either been thought of as the sister group of all other sauropodomorphs (Gauthier 1986) or as the basal member of a monophyletic Prosauropoda (Galton 1990). The only computerbased, cladistic analysis to include Thecodontosaurus found it to be part of a monophyletic prosauropod group but was unable to resolve the position of the genus within this clade (Benton et al. 2000).

In this paper, the Pant-y-ffynon prosauropod specimens are fully described and illustrated and their relationship to T. antiquus and other early sauropodomorphs is investigated using cladistic analysis. The implications of this analysis for early dinosaur systematics are discussed. In particular the case for prosauropod monophyly is examined in detail.

The abbreviations for the various institutions where material discussed in this paper is held are as follows:

\footnotetext{
AM = Amherst College Museum, Massachusetts, USA.

$\mathrm{BMNH}=$ Natural History Museum, London, UK.

BRSUG $=$ Department of Earth Sciences, University of Bristol, UK.

GPIT = Institut und Museum für Geologie und Paläontologie der Universität Tübingen, Germany.
}

HMN = Museum für Naturkunde der Humboldt Universität, Berlin, Germany.

PVL = Fundación 'Miguel Lillo', Tucumán, Argentina.

SMNS = Staatliches Museum für Naturkunde, Stuttgart, Germany.

\section{SYSTEMATIC PALAEONTOLOGY}

\section{SAURISCHIA Seeley, 1888}

\section{SAUROPODOMORPHA von Huene, 1932}

\section{Genus THECODONTOSAURUS Riley and Stutchbury, 1836}

TYPE SPECIES. Thecodontosaurus antiquus Morris, 1843; Late Triassic, Bristol, England.

DiAGNOSIS. Small, gracile sauropodomorphs with the following derived character states.

1. The basipterygoid processes are elongate and slender, with the length of the process, measured from its tip to the dorsal margin of the parabasisphenoid, being equal to the height of the braincase, measured from the dorsal margin of the parabasisphenoid to the top of the supraoccipital (convergent in 'Efraasia diagnostica').

2. The dentary is short and deep, occupying less than $40 \%$ of the total mandibular length, and with a maximum dorsoventral depth that is greater than $20 \%$ of its length (convergent in Saturnalia tupiniquim).

3. The epipophyses of the cranial cervicals are flat plates that overhang the caudal margins of the postzygapophyseal facets but do not form raised ridges on the dorsal surface of the postzygapophysis.

4. The proximal and mid-caudal neural spines are positioned at the extreme caudal end of their neural arches, filling the interpostzygapophyseal space (convergent in 'Efraasia diagnostica').

5. The ventral furrowing of the caudal centra is reduced so that it is only weakly present in the proximal caudals and is absent altogether from the mid and distal caudals.

REMARKS. The first two characters of the diagnosis are from Benton et al. (2000) while the last three are novel. The third character listed in Benton et al. (2000), 'caudal process of the iliac blade subquadratic' is also present in the basal saurischian Guiabasaurus candelariensis (Bonaparte et al. 1999), Neotheropoda (e.g. Dilophosaurus wetherilli Welles, 1984) and 'Efraasia diagnostica' (pers. obs. SMNS 12354, 12667). Consequently it is interpreted as a plesiomorphic characteristic of Thecodontosaurus.

\section{Thecodontosaurus caducus sp. nov.}

ETYMOLOGY. Latin, caducus, fallen. Refers to the fact that the holotype is an articulated specimen preserved in a fissure fill, indicating that the animal may have fallen into the fissure and died there.

HOLOTYPE. BMNH P24, a nearly complete but disarticulated skull, both mandibular rami, a complete series of cervical vertebrae, the proximal ends of both humeri, a proximal right scapula and both coracoids from one individual (Fig. 1). 


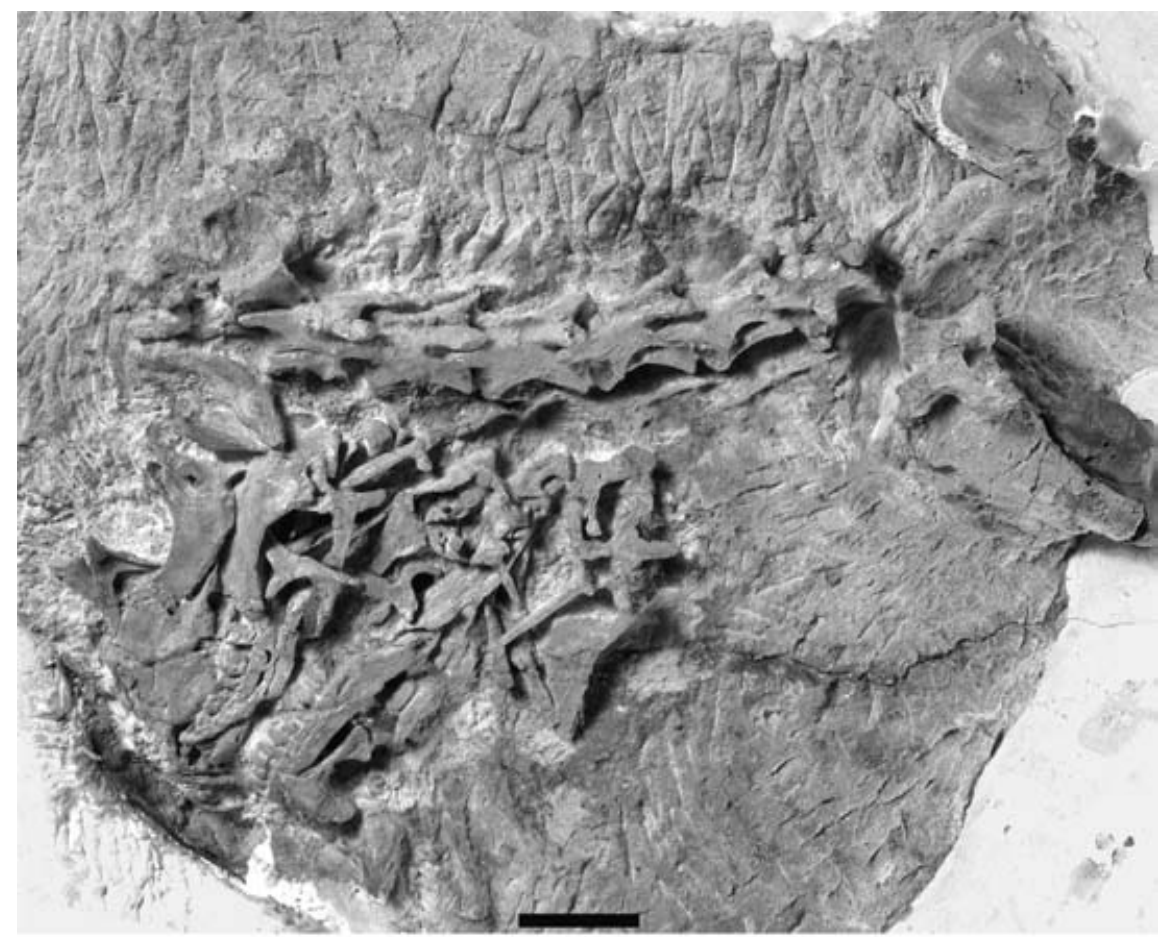

A

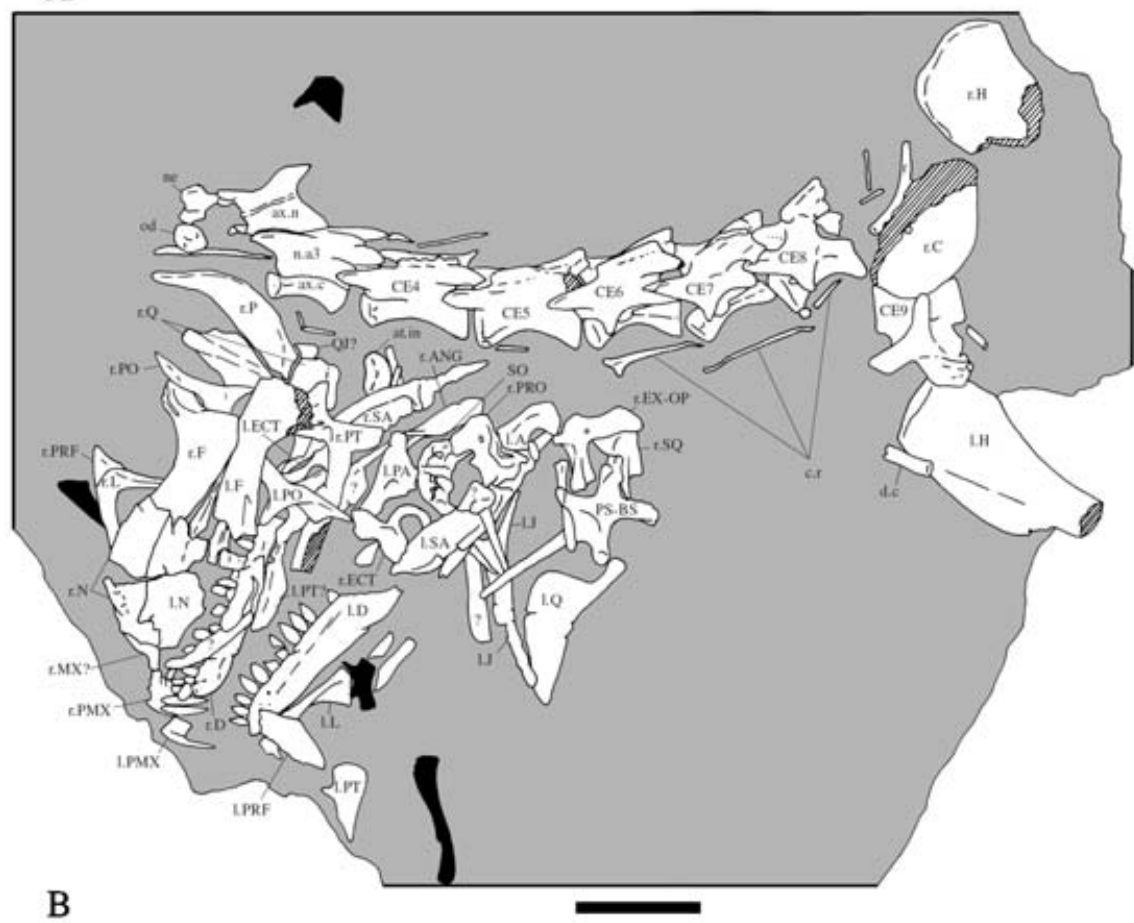

Figure 1 Thecodontosaurus caducus sp. nov., holotype, BMNH P24; skull and partial postcranial skeleton. 1A, photograph; 1B, interpretive line drawing. Solid black bones represent unrelated crocodylomorph and lepidosaur bones. For abbreviations, see Appendix 1. Scale bars $=20 \mathrm{~mm}$.

PARATYPES. BMNH P24/3, a right ischium; BMNH P39/2, a left coracoid; BMNH P59/5, a right quadrate; BMNH P64/1, a series of eight proximal-mid caudals; BMNH P65/21, a right ectopterygoid; BMNH P77/1, a series of distal caudal vertebrae, the right ilium, femur, tibia, fibula and pes; $\mathrm{BMNH}$ P126/1, a ?proximal pubis; BMNH P141/1, a basioccipital.
TYPE HORIZON AND LOCALITY. Late Triassic fissure deposits, Pant-y-ffynnon Quarry, near Bonvilston, South Wales. The age of the Mesozoic fissure deposits is difficult to determine. Given the faunal similarities between Pant-y-ffynnon and the Thecodontosaurus-bearing fissure fills from south-west England, they are likely to be of a similar age. The presence 

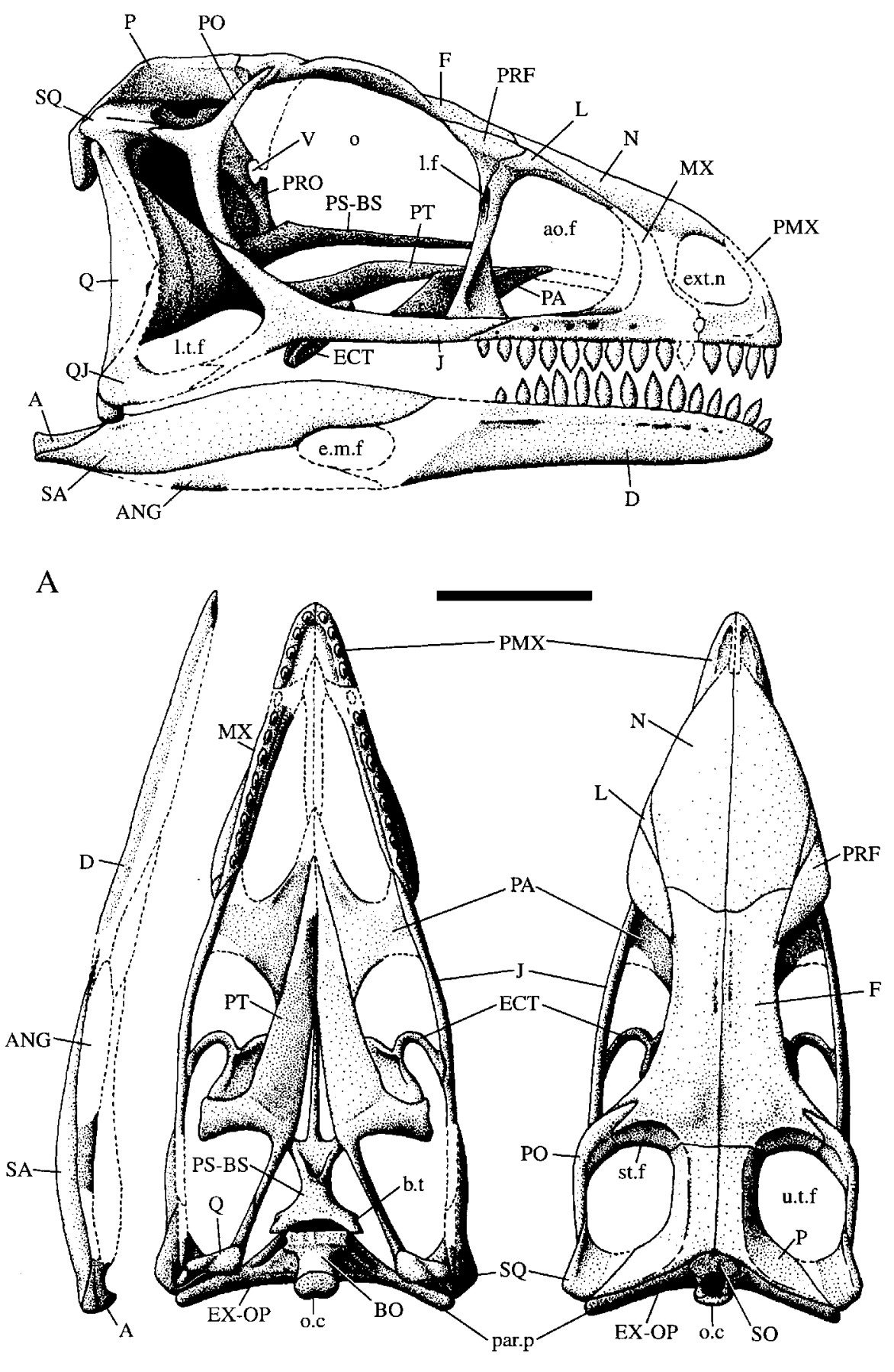

$\mathrm{D}$

B

$\mathrm{C}$

Figure 2 Thecodontosaurus caducus sp. nov., holotype, BMNH P24; reconstruction of skull. 2A, lateral view; 2B, ventral view; $\mathbf{2 C}$, dorsal view; 2D, ventral view of mandibular ramus. For abbreviations see Appendix 1 . Scale bar $=10 \mathrm{~mm}$.

of phytosaurs in the English fissure fills constrains their age to the Late Triassic (Benton et al. 2000) while palynomorphs may indicate a Rhaetian age (Whiteside 1983). A fuller account is given in Benton \& Spencer (1995).

DiAGNOSIS. A species of Thecodontosaurus with the following autapomorphy: pleurocoel-like pits on the neurocentral sutures of the sixth, seventh and eighth cervical vertebrae. $T$. caducus can be further distinguished from T. antiquus by exhibiting the plesiomorphic state for the autapomorphies of that species. These include a medial tubercle of the prox- imal humerus that does not project strongly (versus strongly projecting in T. antiquus) and a preacetabular process of the ilium that projects cranially (versus a downcurved preacetabular process in T. antiquus).

\section{DESCRIPTION}

The most complete specimen in the collection is the holotype, BMNH P24. Except where mentioned, the description of 
the skull, mandible and cervical vertebrae is based on this specimen.

The dorsal skull roof of this specimen is situated at the cranial end of the cervical series, while the elements from the left temporal region, mandible, palate and braincase are scattered for some distance to the left of the dorsal skull roof. All of the braincase elements have separated, indicating that suturing had not begun at the time of death, one of the many juvenile characteristics that can be seen in these specimens. The reconstruction of the skull presented here (Fig. 2) differs somewhat from that of Kermack (1984). This is partly because some bones have been re-identified and partly because missing, or damaged, parts were restored using shapes more similar to those known in other early saurischians.

\section{Skull roof}

\section{Premaxilla}

The medial surface of the right premaxilla is exposed. Its surface is damaged and the nasal process is missing. The main body of the premaxilla is quite short $(8 \mathrm{~mm}$ long and $6 \mathrm{~mm}$ high) and bears four teeth. Like juvenile Massospondylus carinatus (Cooper 1981) and Mussaurus patagonicus (Bonaparte \& Vince 1979), the height of the premaxillary teeth exceeds the height of the maxillary teeth. The crowns are simple subcylindrical spikes that bear a few weak serrations on the caudal carina (there are six such serrations on the second tooth). The first crown is the largest at $4.5 \mathrm{~mm}$ in height.

\section{Maxilla (Fig. 3)}

Only a fragment of the left maxilla is available for study. It is quite poorly preserved so details are hard to discern. The preserved portion, which is $25 \mathrm{~mm}$ long, consists of the

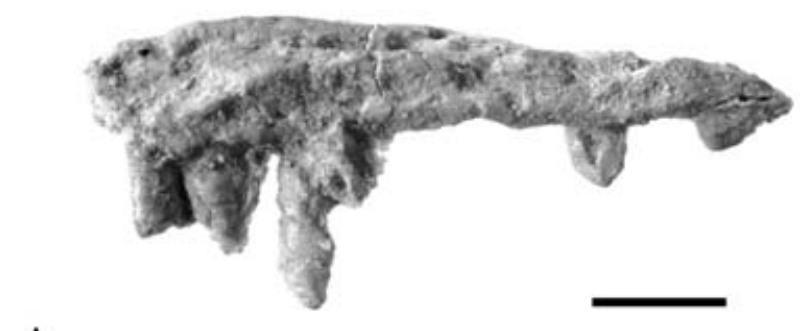

A

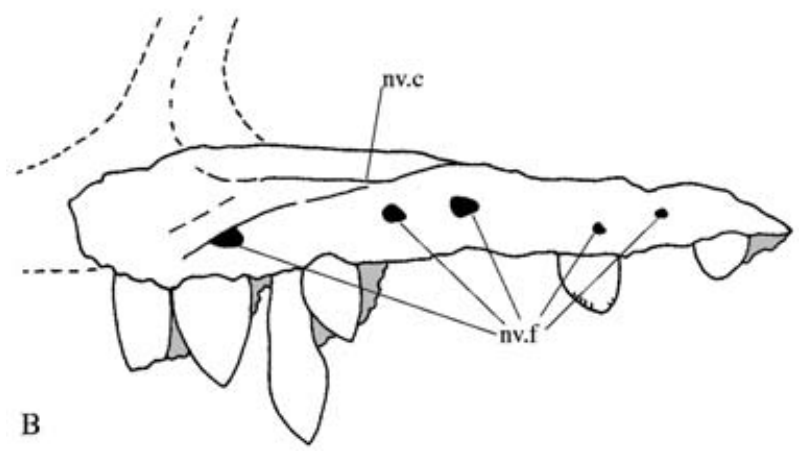

Figure 3 Thecodontosaurus caducus sp. nov., holotype, BMNH P24; left maxilla in lateral aspect. 3A, photograph; 3B, interpretive drawing. nv.c $=$ neurovascular canal, nv. $f=$ neurovascular foramen. Scale bar $=5 \mathrm{~mm}$. caudal ramus and what is probably the base of the ascending ramus. The ascending ramus itself and the rostral ramus are missing. The specimen is $4 \mathrm{~mm}$ high at the rostral end and tapers to a point at its caudal end. The number of alveoli cannot be determined but there are six teeth present and space for four more. On the lateral surface there appear to be five relatively large, neurovascular foramina. The caudal-most foramen is smaller than the more rostral foramina. In most other sauropodomorphs (e.g. Riojasaurus incertus: Bonaparte \& Pumares 1995; Plateosaurus engelhardti: pers. obs. of HMN MB. 1927.19.1, GPIT Skelett 1) the foramen at the caudal end of the row is distinctly larger than the rest of the maxillary foramina. This includes sauropods, where the caudal maxillary foramen is so enlarged it has been termed the pre-antorbital fenestra (Wilson \& Sereno 1998).

A sharp edge (the ventral rim of the external antorbital fenestra) delimits the lateral surface of the caudal ramus from the dorsal surface. The dorsal surface bears a short, longitudinal groove that extends from near the midpoint to a point above the fourth preserved tooth. This groove lies on the floor of the antorbital fossa and would have housed the maxillary nerve and associated vasculature (Witmer 1997). A similar groove has been reported in Plateosaurus engelhardti (Witmer 1997), Sellosaurus gracilis? (Galton 1985b) and Massospondylus carinatus (Gow et al. 1990). The groove becomes closed over by the jugal and the lacrimal to form a canal in ornithischians (Witmer 1997), whereas a foramen, or a series of foramina, pierce the dorsal or medial surface of the maxilla in sauropods and non-avian theropods (Witmer 1997). Therefore, a dorsally open canal for the maxillary nerve on the ventral surface of the antorbital fossa is potentially a synapomorphy uniting the traditional Prosauropoda into a monophyletic group.

The maxillary teeth are poorly preserved and those details that are present appear to be similar to the dentary teeth. The largest crown is $3 \mathrm{~mm}$ high.

Nasal

Both nasals have been fractured and distorted by compression against the underlying bones. Consequently many details are lost. However, the natural edge of the caudal margin is preserved and indicates that the suture with the frontals was concave, as it is in primitive dinosaurs such as Coelophysis bauri (Colbert 1989) and Lesothosaurus diagnosticus (Sereno 1991a). Some derived sauropodomorphs such as Plateosaurus engelhardti, have a caudally convex naso-frontal suture. There is no indication that there was a median nasal depression as is present in some specimens of Plateosaurus engelhardti (Galton 1984a) and 'Efraasia diagnostica' (Galton 1985b as Sellosaurus gracilis). The rostroventral process is missing from the main body of each nasal.

\section{Prefrontal}

The dorsal surface of the main body of the left prefrontal is exposed. It is a small, dorsally facing, elliptical plate, $11 \mathrm{~mm}$ long and $6 \mathrm{~mm}$ wide, that would have formed part of the skull roof behind the lacrimal. It is not enlarged, as it is in other basal sauropodomorphs such as Massospondylus carinatus (Cooper 1981) and Plateosaurus engelhardti (Galton 1984a). The right prefrontal is still articulated with the lacrimal. Most of the main body is missing, but a short, thin descending 

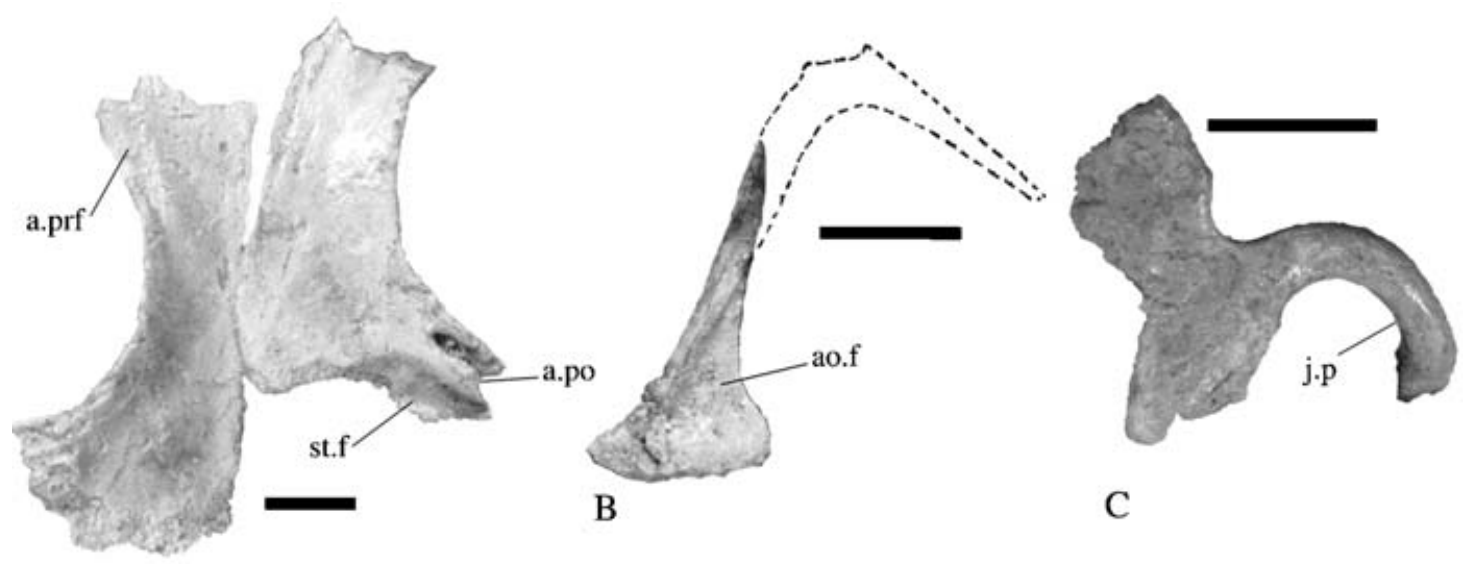

C

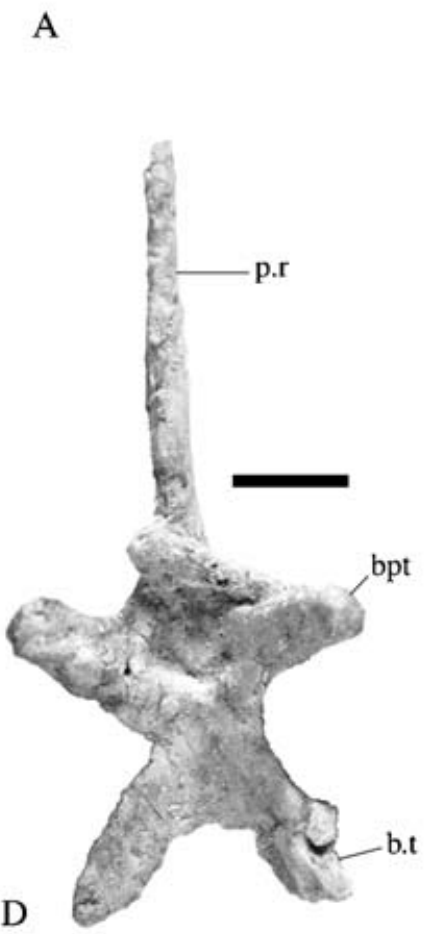

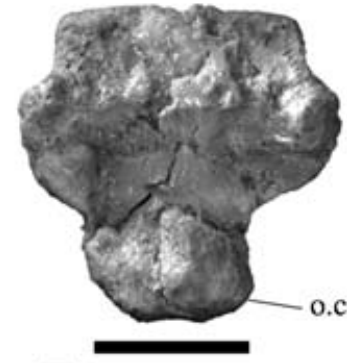

$\mathrm{E}$

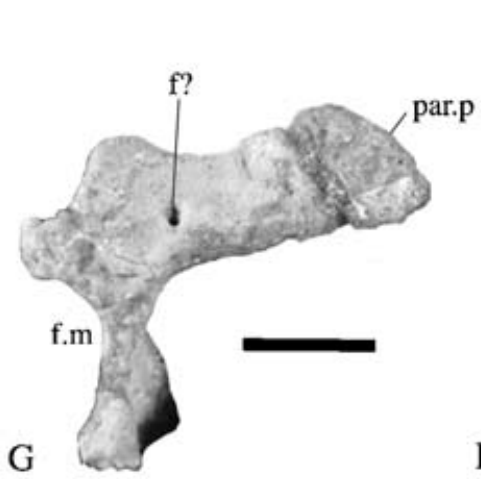

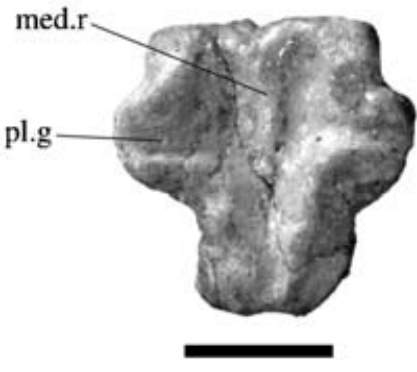

$\mathrm{F}$

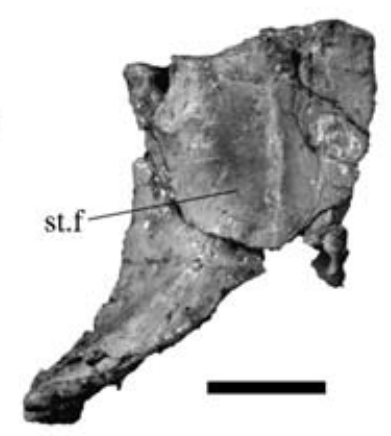

$\mathrm{H}$

Figure 4 Thecodontosaurus caducus sp. nov., holotype, BMNH P24; elements of the skull. 4A, pair of frontals in dorsal aspect; 4B, left lacrimal in lateral aspect (dorsal outline restored from right lacrimal); $4 \mathrm{C}$, right ectopterygoid in dorsal aspect; $4 \mathrm{D}$, parabasisphenoid complex in ventral aspect; $\mathbf{4 E}$, basioccipital in ventral aspect; $\mathbf{4 F}$, basioccipital in dorsal aspect; $\mathbf{4 G}$, right exoccipital-opisthotic complex in occipital view; $4 \mathrm{H}$, left parietal in dorsal aspect. For abbreviations see Appendix 1 . Scale bars $=5 \mathrm{~mm}$.

process arises from the caudolateral margin and extends about halfway down the medial side of the ventral ramus of the lacrimal. The dorsal exposure of the prefrontal is much greater than that of the lacrimal.

\section{Frontal (Fig. 4A)}

Both frontals are well preserved and are visible in dorsal view. Each frontal is longer than it is wide, with the maximum width developed at the caudal end. A deep, rostromedially inclined slot, for the reception of the frontal ramus of the postorbital, is incised into the tip of the caudolateral corner of the right frontal (this region is damaged in the left frontal). There is a faintly raised area medial to this slot, present on both frontals. The supratemporal fossa extends onto the frontals, producing a sharply defined, crescentic depression on the caudal margin of each frontal. The midsection of the frontals, which forms the roof over the orbits, is constricted transversely. The rostral end is expanded transversely, but not as greatly as the caudal. A facet for the articulation of the prefrontal occupies the rostral third of the lateral margin. Thus, the prefrontal does not restrict the frontal contribution to the orbital margin as it does in more derived sauropodomorphs such as Plateosaurus engelhardti (Galton 1984a) and Lufengosaurus huenei (Young 1941a). A row of foramina occurs on each side of the median frontal symphysis.

\section{Parietal (Fig. 4H)}

The parietals had separated before burial, indicating that they were not fused or tightly sutured together, which is a sign of immaturity. As in Plateosaurus engelhardti the parietals comprise a rectangular rostral portion that forms the caudal 
end of the dorsal skull roof and a caudolateral wing that sutures with the squamosal. The rostral end of the parietals forms a straight suture with the frontals in dorsal view. Faint ridges, on either side of the midline, mark the medial margins of the supratemporal fossae. Each ridge is confluent with the sharper ridge that bounds the rostral margin of the supratemporal fossa on the frontal. Medial to the ridges, the parietals form a flat, horizontal surface. Lateral to each ridge the parietal curves ventrally to meet the lateral walls of the braincase. The caudolateral wings are more steeply inclined than the lateral sides of the rostral end of the parietal. A scar marking the articulation with the squamosal occupies the distal half of the lateral surface of this wing. In lateral view the caudolateral wing curves ventrally so that the squamosal and, consequently, the quadrate head, would have been held below the level of the dorsal skull roof.

\section{Lacrimal (Fig. 4B)}

The bone identified by Kermack (1984) as the right squamosal is re-interpreted here as the right prefrontal and right lacrimal, exposed on their medial side. The lacrimal is an approximately $L$-shaped bone with a long ventral ramus $(26 \mathrm{~mm})$ and a short rostral ramus $(8 \mathrm{~mm})$. A narrow strip of the rostral ramus is exposed dorsolaterally on the skull roof, rostral to the prefrontal and lateral to the nasal. A sulcus extends up the dorsal half of the caudal face of the ventral ramus, medial to the ventral process of the prefrontal. A single lacrimal foramen is situated at the dorsal end of the sulcus. The rostral opening of the lacrimal foramen cannot be seen. The short rostral ramus sutures with the ascending ramus of the maxilla. The ventral ramus is quite narrow at its midpoint $(1 \mathrm{~mm})$ but flares rostrocaudally at its ventral end $(6 \mathrm{~mm})$. Dislocation has made it impossible to determine if the ventral end of the lacrimal contacted the caudal ramus of the maxilla.

As in other basal sauropodomorphs (e.g. Plateosaurus engelhardti: Galton 1984a) and the basal saurischian, Herrerasaurus ischigualastensis (Sereno \& Novas 1993), the lacrimal formed a lateral wall over the caudodorsal corner of the antorbital sinus, whereas the caudoventral corner of the sinus extended over the lateral surface of the lacrimal, to form a laterally facing fossa. In most basal sauropodomorphs (e.g. Plateosaurus engelhardti: Galton 1984a) this fossa is small and restricted to the rostroventral corner of the main ventral ramus of the lacrimal. In T. caducus, however, the fossa extends at least half way up the ventral ramus. This condition is probably the plesiomorphic one, since it is also seen in neotheropods and the basal saurischians Herrerasaurus ischigualastensis (Sereno \& Novas 1993) and Eoraptor lunensis (Sereno et al. 1993).

\section{Jugal}

Both jugals are obscured below overlying bones. Only parts of the lateral side of the left jugal are visible. It is estimated to be about $30 \mathrm{~mm}$ in length. The suborbital portion of the jugal is a slender, medio-laterally compressed bar that is $30 \mathrm{~mm}$ deep in the mid-orbital region. In keeping with the relatively large size of the orbit of this juvenile, the postorbital ramus is placed far back along the jugal (the rostral end of its base is approximately $23 \mathrm{~mm}$ from the rostral end of the jugal). The postorbital process is triangular with a relatively broad base. The ventral margin of the jugal is gently arched upwards. No details of the maxillary, lacrimal, postorbital and quadratojugal articulations are visible.

\section{Postorbital}

The left postorbital is visible in lateral view, while the medial side of the right postorbital is exposed. The postorbital is triradiate with long jugal and frontal rami and a short squamosal ramus. The frontal ramus is steeply inclined anterodorsally from its junction with the other rami to the frontal. The ramus also curves medially to articulate with the frontal but this curvature is not as strong as in Plateosaurus engelhardti (Galton 1984a). The frontal ramus becomes broader towards its rostral end, which is slightly forked. The supratemporal fossa extends onto the dorsomedial surface of this ramus as it does in other basal saurischians such as Herrerasaurus ischigualastensis (Sereno \& Novas 1993) and Plateosaurus engelhardti (Galton 1984a). The squamosal ramus was a short, slender and pointed process that was probably horizontally oriented. The jugal ramus is an elongate strap that is mediolaterally compressed and gently bowed caudally. Bones overlying both of the postorbitals obscure the articulation facets for the jugals.

\section{Quadratojugal}

Neither of the two quadratojugals can be positively identified; however, a small plate of bone protruding from beneath the right quadrate head is likely to be the main body of the right quadratojugal.

\section{Quadrate (Fig. 5)}

Both quadrates of BMNH P24 and an isolated right quadrate, BMNH P59/5, can be viewed in their medial and caudal aspect. The main body of the quadrate consists of two laminae set at right angles to each other. Where the two laminae meet along the caudal edge, a sharp keel is formed. This keel extends dorsally to the small knob-like quadrate head. A large semi-circular lamina extends rostromedially

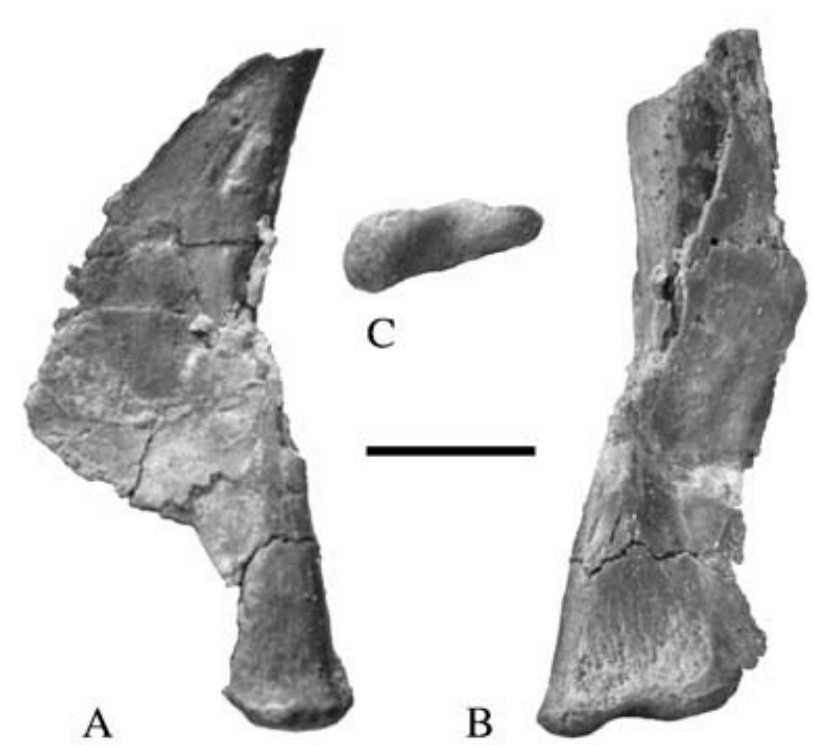

Figure 5 Thecodontosaurus caducus sp. nov., BMNH P59/5; right quadrate. $\mathbf{5 A}$, medial, $\mathbf{5} \mathbf{B}$, caudal; $\mathbf{5} \mathbf{C}$, mandibular condyle. Scale bar $=5 \mathrm{~mm}$. 
and forms the pterygoid wing, while the narrower, rostrolaterally directed lamina thickens ventrally to form the shaft that bears the quadrate condyles. The base of the pterygoid wing is long, occupying more than $70 \%$ of the length of the quadrate. This is a primitive character state that is also seen in 'Efraasia diagnostica' (Galton 1985b as Sellosaurus gracilis) but not in more derived sauropodomorphs such as Plateosaurus engelhardti (pers. obs. of SMNS 12950), Coloradisaurus brevis (from photographs of PVL 3967) or most sauropods (e.g. Camarasaurus lentus: Madsen et al. 1995). Unlike most other early saurischians (e.g. Herrerasaurus ischigualastensis: Sereno \& Novas 1993; Liliensternus liliensterni: pers. obs. of HMN MB.R.2175.7.4; Sinraptor dongi: Currie \& Zhao 1993; 'Efraasia diagnostica': pers. obs. of SMNS 12668; Plateosaurus engelhardti: pers. obs. of GPIT Skelett 1) the quadrate foramen is not deeply incised into the lateral margin of the rostrolateral lamina. If a quadrate foramen was present, it would have been a narrow gap between the quadrate and quadratojugal such as in Lesothosaurus diagnosticus (Sereno 1991a) and Heterodontosaurus tucki (Weishampel \& Witmer 1990). The articular surface is narrowly triangular in ventral view with the long axis oriented transversely and the apex pointing laterally. An oblique sulcus running antero-medially divides the articular surface into two condyles, of which the more medial is taller.

\section{Squamosal}

The bone lying under the caudal end of the basisphenoid and the paroccipital process of the right exoccipital-opisthotic complex appears to be the left squamosal exposed in dorsomedial aspect (identified as part of the ?opisthotic by Kermack 1984). The squamosal head is subrectangular in dorsal view unlike the triangular shape that is usual amongst dinosaurs, including other basal sauropodomorphs such as Plateosaurus engelhardti (Galton 1984a). Like other dinosaurian squamosals the complete bone would have consisted of four rami, however, only two of these can be seen in this specimen. The rostromedially directed parietal ramus is short, slender and distinctly raised above the dorsal surface of the squamosal head. The rostrolaterally directed postorbital ramus has broken away. Caudal to the base of the parietal ramus, the base of a slender, caudoventrally directed, quadrate ramus can be seen. The overlying paroccipital process of the right exoccipital-opisthotic complex obscures the caudal ramus of the squamosal.

\section{Palate}

\section{Pterygoid}

Most of the right pterygoid is exposed in ventral and medial views, while only a fragment of the transverse flange remains of the left pterygoid. The pterygoid is a complex bone, consisting of three main projections: the rostral ramus, the quadrate ramus and the transverse flange. The rostral ramus was the longest of these, measuring $25.5 \mathrm{~mm}$ long as preserved. It is an elongate triangular plate that, in life, would have faced ventromedially and formed a large part of the palate. Its medial margin is almost straight, with the rostral end forming a median symphyseal surface. The medial margin is flared upwards in this region so that when the two pterygoids were in contact a low, dorsally projecting, median crest was formed. The base of the transverse flange forms the caudolateral margin of the rostral ramus.
The pterygoid is bent downwards sharply along this line so that the transverse flange faces more or less rostroventrally. The flange itself is a short, subrectangular process that is directed laterally in ventral view. Judging from the shape of the cross-section of the left pterygoid fragment, the transverse flange was gently curved about the transverse axis so that the caudodorsal surface was concave. It is $11 \mathrm{~mm}$ long along its caudal margin. The quadrate ramus is a short, vertical, triangular plate that is $7 \mathrm{~mm}$ long and is directed dorsally and laterally. It flares distally from its narrow, waist-like junction with the rest of the pterygoid, at the caudomedial corner of the rostral ramus and the transverse flange. Perhaps the most significant feature of the pterygoid is the absence of a caudomedial flange that hooks around the basipterygoid process to contact its counterpart medially. Most dinosaurs have such a flange (e.g. Plateosaurus engelhardti: pers. obs. of HMN 24; Lesothosaurus diagnosticus: Sereno 1991a; Sinraptor dongi: Currie \& Zhao 1993) although it is reduced to a small dorsomedially oriented hook, or is absent altogether, in eusauropods (Wilson \& Sereno 1998).

\section{Ectopterygoid (Figs 4C, 6)}

The right ectopterygoid is visible in dorsal view, while the ventral view can be seen in an isolated right ectopterygoid (BMNH P65/21). The main body is twice as long as it is wide (10 mm long) with a sinuous medial margin. A deep concavity occupies the ventral surface and closely resembles the ventral pneumatic fossa of neotheropods. The jugal process is slender and strongly recurved. In this respect the ectopterygoid resembles that of a neotheropod more than any other sauropodomorph.

\section{Palatine}

A flat, roughly quadrangular sheet of bone exposed between the right pterygoid, the left ectopterygoid and the supraoccipital is probably the left palatine, exposed latero-

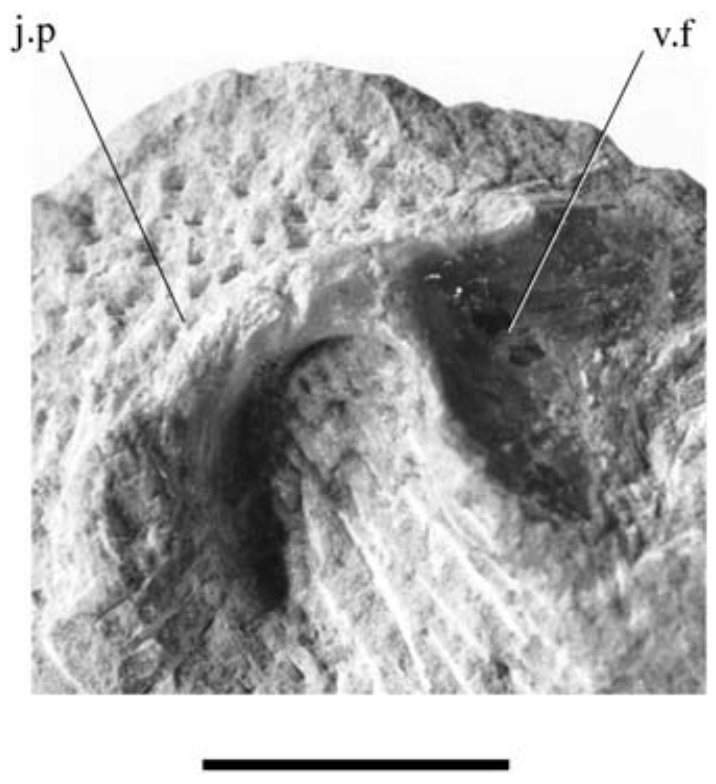

Figure 6 Thecodontosaurus caducus sp. nov., BMNH P65/21; right ectopterygoid in ventral aspect. j. $p=$ jugal process, $v . f=$ ventral fossa. Scale bar $=5 \mathrm{~mm}$. 


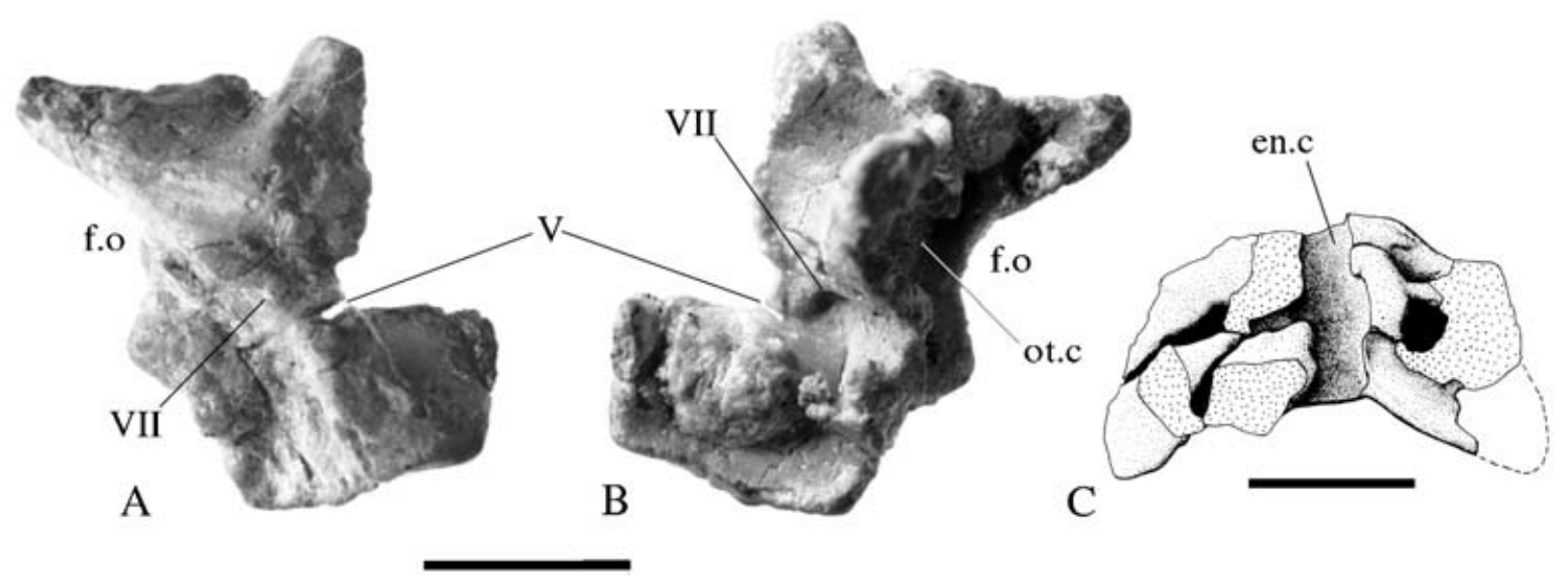

Figure 7 Thecodontosaurus caducus sp. nov., holotype, BMNH P24.7A, right prootic in lateral aspect; 7 B, right prootic in medial aspect; 7 C, supraoccipital in cranial aspect. For abbreviations see Appendix 1 . Scale bars $=5 \mathrm{~mm}$.

dorsally. The ventro-lateral margin bears a deep, narrow sulcus for the reception of the medial side of the maxilla. Little else can be said except that the caudal palatine margin (the rostral border of the palatine fenestra) is quite straight and not as strongly emarginate as it is in Plateosaurus engelhardti (Galton 1984a).

\section{Braincase}

\section{Supraoccipital (Fig. 7C)}

The inner surface of the crescent-shaped supraoccipital is exposed. Like Anchisaurus polyzelus (Galton 1976) and 'Efraasia diagnostica' (Galton 1985b), but unlike most other basal sauropodomorphs, the bone is much wider than it is high. The ventral margin is concave and would have formed the dorsal margin of the foramen magnum. The dorsal margin is evenly arched and is not peaked at the midline as it is in Plateosaurus engelhardti (Galton 1984a). The caudal end of the endocranial cavity forms a deep dorsoventrally orientated median sulcus running up the midline of the inner face. This sulcus is flanked by two pairs of facets, the dorsal pair of which face rostrally and would have articulated with the prootics while the ventral pair face rostrolaterally and would have contacted the opisthotic-exoccipital complexes. On each side, a deep, narrow channel extends laterally between these two facets, from the endocranial cavity to the dorsolateral margin of the supraoccipital. This channel may have allowed the passage of the vena capitis dorsalis.

\section{Exoccipital-opisthotic complex (Fig. 4G)}

The occipital face of the right complex is exposed, with limited lateral exposure. A tongue-shaped paroccipital process projects laterally and slightly dorsally. A conspicuous foramen exits from the middle of the occipital surface of the bone, at the base of the paroccipital process. This foramen is not present in the braincase of T. antiquus, neither is it present in Plateosaurus engelhardti (Galton 1984a), thus the position of this foramen on the paroccipital process may be a juvenile characteristic or a specific autapomorphy. Below the base of the paroccipital process a vertical sheet of bone descends to articulate with the basioccipital. The caudoventral corner of this sheet projects to form the dorsolateral corner of the occipital condyle. This sheet forms the lateral margin of the foramen magnum. Its lateral surface is pierced by two foramina for rostral and caudal rami of the hypoglossal nerve (cranial nerve XII). A deep narrow sulcus, the metotic fissure, extends caudodorsally from a point rostral to these foramina. This fissure is bordered rostrodorsally by a thin crista interfenestralis.

\section{Prootic (Figs 7A, B)}

Both prootics are preserved, the right one of which has been freed from the matrix. Each bone is roughly rectangular in lateral view. The ventral margin formed a relatively straight contact with the dorsal margin of the lateral wall of the parabasisphenoid complex, in front of the fenestra ovalis. The rostral margin bears a deep notch midway along its length. This is an incompletely closed foramen for the exit of the trigeminal nerve (cranial nerve V). Exiting though the centre of the prootic is a foramen for the facial nerve (cranial nerve VII). The facial nerve foramen lies against a crescentic ridge that extends from the ventral margin to a point halfway up the caudal margin and separates a depressed caudoventral region from the rest of the prootic. Most of the caudal margin of the prootic forms the rostral rim of the fenestra ovalis. Above this rim the caudodorsal corner was produced into a short, caudally projecting, triangular process that would have overlapped the rostral face of the opisthotic-exoccipital complex. The dorsal margin, where it would have contacted the skull roof, forms a dorsally and laterally concave saddle. Medially, a tall process, standing $6 \mathrm{~mm}$ from the medial surface, arises from the centre of the bone. This process curves caudally to enclose a roughly pyramidal space that housed the inner ear. This cavity is open caudally, immediately adjacent to the rostral rim of the fenestra ovalis.

\section{Basioccipital (Figs 4E, F)}

There are two basioccipitals in the sample, one from BMNH P24, while BMNH P141/1 is an isolated specimen. Both have been freed from the matrix, permitting all aspects to be observed. The occipital condyle still bears a small notochordal pit, another indication of juvenility. In ventral view the parabasisphenoid contact forms a raised transverse ridge, which is the basioccipital contribution to the basal tubera. 

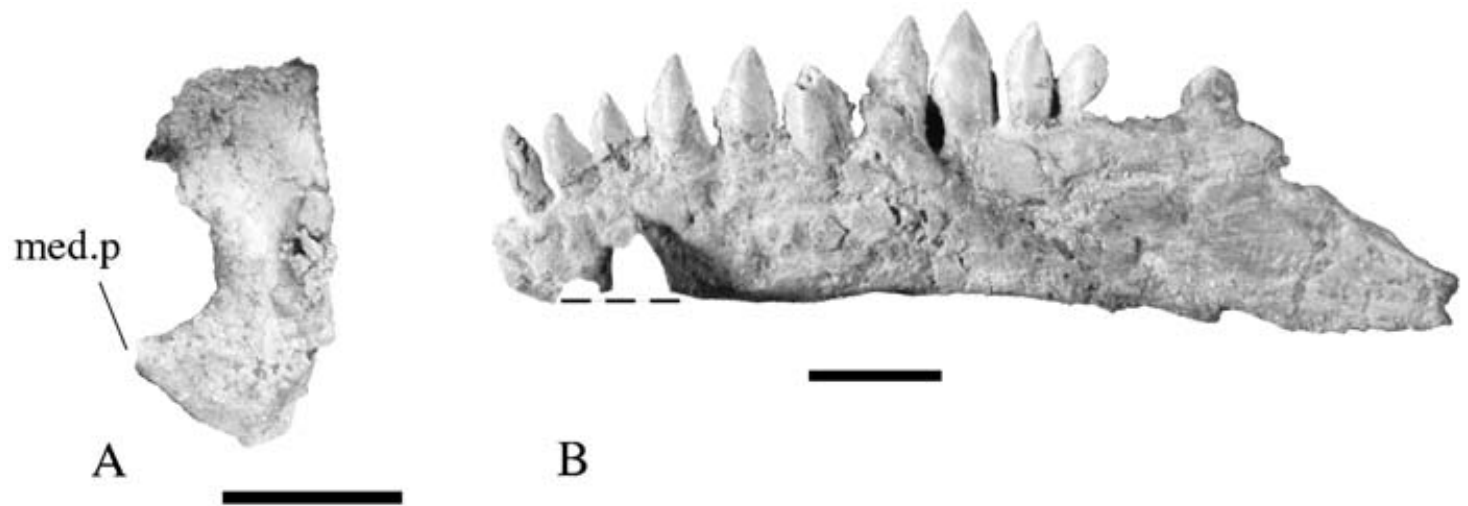

B

Figure 8 Thecodontosaurus caducus sp. nov., holotype, BMNH P24; mandibular elements. 8A, left articular in ventro-medial aspect; 8B, left dentary in lateral aspect. med. $p=$ medial process. Scale bars $=5 \mathrm{~mm}$.

Unlike many sauropodomorphs, such as Plateosaurus engelhardti (pers. obs. of HMN MB.1927.19.1), Massospondylus carinatus (pers. obs. of a cast of SAM 1314) and Camarasaurus lentus (Madsen et al. 1995), this raised area is undivided by a median excavation. Dorsally there is a broad midline sulcus that forms the caudal floor of the endocranial cavity. Two short perilymphatic grooves extend laterally from either side of the endocranial floor, above the basal tubera. A low but sharp median ridge on the braincase floor extends from between the perilymphatic grooves to the contact with the basispenoid. Similar, although weaker, ridges can also be seen in Thecodontosaurus antiquus (pers. obs. of uncatalogued BRSUG material), Plateosaurus engelhardti (pers. obs. of SMNS 6014) and Massospondylus carinatus (Gow 1990).

\section{Basisphenoid-parasphenoid complex (Fig. 4D)}

The parabasisphenoid complex is exposed in ventral aspect. In ventral view the main body comprises a flat central area from which the basipterygoid processes project rostrally and the basal tubera project caudally. The elongate, peglike basipterygoid processes extend ventrolaterally as well as rostrally. Unlike many other sauropodomorphs, such as 'Efraasia diagnostica' (pers. obs. of SMNS 12667), Plateosaurus engelhardti (Galton 1984a), Coloradisaurus brevis (from photographs of PVL 3967), Brachiosaurus brancai (Janensch 1935-36) and Camarasaurus lentus (Madsen et al. 1995), there is no interbasipterygoid web of bone. There is, however, a rostrally open fossa at the base of the cultriform process (the 'blind pocket' of Gow 1990) that is bordered caudally by a scarp-like wall that spans the interbasipterygoid space. It is from this feature that the interbasipterygoid web of more derived taxa almost certainly evolved. The cultriform process is a slender, laterally compressed, blade-like structure.

On the lateral surface there is a small elliptical foramen for the internal carotid artery set in a deep fossa located between the basal tubera and the base of the basipterygoid process. Dorsal to this fossa the ventral margin of the fenestra ovale forms a semicircular embayment in the dorsolateral margin of the bone. Compared to the adult braincase of T. antiquus (Benton et al. 2000), the fenestra ovale was relatively larger, which is almost certainly related to the juvenile nature of the specimen.

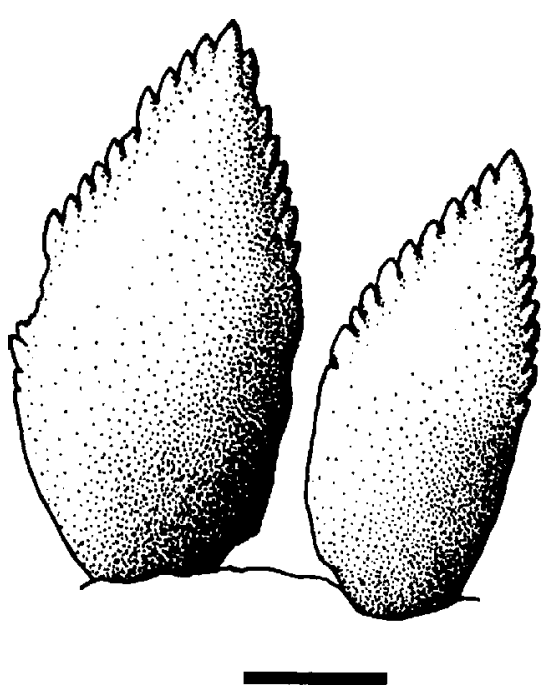

Figure 9 Thecodontosaurus caducus sp. nov., holotype, BMNH P24; eighth and ninth teeth from the left dentary. Scale bar $=1 \mathrm{~mm}$.

\section{Mandible}

\section{Dentary (Fig. 8B)}

The labial surface of the left dentary is exposed, while the lingual side of the right is partially exposed. The left dentary clearly bears 12 alveoli, all of which, except the eleventh, bear teeth (Fig. 9). The first alveolus is inset a short distance, less than the width of an alveolus, from the rostral tip. The dentary is short relative to the reconstructed length of the mandible, with the dentigerous portion occupying no more than $43 \%$ of the mandibular length $(27 \mathrm{~mm})$. Correlated with its brevity, the dentary is deeper, relative to its length, than in other basal sauropodomorphs. This feature is also found in the dentaries of T. antiquus (Benton et al. 2000). The labial surface of the dentary is flat and is not marked by a strong ridge below the caudal end of the tooth row, as it is in other early sauropodomorphs such as Riojasaurus incertus (Bonaparte \& Pumares 1995), Anchisaurus polyzelus (Galton 1976) and Plateosaurus engelhardti (Galton 1984a). A row of neurovascular foramina exits from the lateral side of the dentary below the dentigerous margin. In lateral view the ventral margin is straight while the dentigerous margin is 
gently curved ventrally at its rostral end. However, since the ventral margin is not concave, the dentary tip cannot be regarded as ventrally curved as it is in Coloradisaurus brevis (from photographs of PVL 3967) and Plateosaurus engelhardti (Galton 1984a).

\section{Surangular}

Both surangulars are exposed medially. The left surangular is the more completely exposed of the two. It is a sheetlike bone that is $35 \mathrm{~mm}$ long and $6 \mathrm{~mm}$ deep at its deepest point. The thickened and medially inflected dorsal margin forms a gently convex surface in lateral view that was not developed into a strong coronoid peak as it is in Coloradisaurus brevis (from photographs of PVL 3967), Plateosaurus engelhardti (Galton 1984a) and macronarian sauropods (Wilson \& Sereno 1998). A short, medial projection from the dorsal margin braced the rostral end of the articular. Behind the medial process there is a slender caudally projecting process that would have covered the ventrolateral surface of the retroarticular process. The anteroventral margin is too poorly preserved to judge the size of the external mandibular fenestra.

\section{Angular}

Only a small section of what is probably the right angular can be seen under the right prearticular and it does not offer any details for description other than that it appears to be quite narrow relative to the surangular.

\section{Prearticular}

The lateral (internal) surface of the right prearticular (identified as the right angular by Kermack 1984) is exposed. It is a thin, elongate, sheet-like bone that is slightly curved laterally along its ventral margin. It is deeper caudally in the region of the glenoid socket, where it is $5 \mathrm{~mm}$ deep. Rostrally it forms a long, dorsoventrally shallow process that is at its narrowest at the midpoint, where it formed the ventral border of the internal mandibular fenestra.

\section{Articular (Fig. 8A)}

The ventral side of the left articular is exposed. It has two flattened surfaces, one facing ventro-laterally and the other ventro-medially, that meet along the ventral midline to form a sharp keel. The ventro-lateral surface is narrower than the ventro-medial surface, although it becomes broader at its caudal end. A weakly defined, shallow fossa occupies the expanded rostral end of the ventro-medial face. The medial edge of the glenoid fossa forms a deep semicircular notch along the dorsal margin of the articular in medial view. The retro-articular process is quite primitive when compared to other basal sauropodomorphs such as 'Efraasia diagnostica' (Galton 1985b), Plateosaurus engelhardti (Galton 1984a), Coloradisaurus brevis (Bonaparte 1978), Lufengosaurus huenei (Young 1941a) and Massospondylus carinatus (Gow et al. 1990). Unlike these taxa, which have a long, low prong-like retro-articular process, that of T. caducus is short, deep and bears a pointed medial process. The medial process is a primitive feature that can be seen in Herrerasaurus ischigualastensis (Sereno \& Novas 1993) and many neotheropods (e.g. Allosaurus fragilis: Madsen 1976; Tyrannosaurus rex: Carr 1999).
Table 1 Dimensions of the cervical vertebrae (in $\mathrm{mm}$ ).

\begin{tabular}{lllll}
\hline & $\begin{array}{l}\text { Length } \\
\text { of neural } \\
\text { arch }\end{array}$ & $\begin{array}{l}\text { Length of } \\
\text { centrum }\end{array}$ & $\begin{array}{l}\text { Width of } \\
\text { anterior } \\
\text { cranial face }\end{array}$ & $\begin{array}{l}\text { Height of } \\
\text { anterior } \\
\text { cranial face }\end{array}$ \\
\hline Axis & 16.3 & 10.7 & 6.2 & 5.1 \\
CE3 & 20.6 & 14.5 & 6.8 & 5.2 \\
CE4 & 24.2 & 15.8 & 8.0 & 6.9 \\
CE5 & 24.4 & 16.9 & - & 6.2 \\
CE6 & 23.1 & 15.2 & - & 6.6 \\
CE7 & 22.0 & 14.9 & - & - \\
CE8 & 18.7 & 14.1 & - & 6.8 \\
CE9 & 16.9 & 14.4 & 8.4 & 8.0 \\
CE10 & 16.5 & 12.7 & 8.5 & 8.4 \\
\hline
\end{tabular}

$\mathrm{CE}=$ cervical vertebra.

\section{Splenial and coronoid}

No splenial or coronoid can be confidently identified, although they are probably included amongst a number of simple flat bones, that are poorly exposed and remain unidentified.

\section{Vertebral column}

\section{Cervical vertebrae (Table 1)}

Ten cervical (CE) vertebrae are preserved and, given that the tenth is quite like a dorsal vertebra in its morphology, this was almost certainly the last cervical. Although no dorsal vertebrae are preserved with which to compare the cervicals, it can be determined that the neck was elongated as it is in other saurischians. The centra of CE3-9 are all longer than the axial centrum, a condition seen in other sauropodomorphs and neotheropods.

Thecodontosaurus caducus differs from other sauropodomorphs, except Riojasaurus incertus, in not having midcervical centra that are at least three times as long as wide. The cervical vertebrae show strong indications of immaturity. These are the lack of fusion between any of the individual elements of the atlas-axis complex and the presence of plainly visible neurocentral sutures on the postaxial cervicals. Indeed the neural arches have parted from their centra in CE3, 6 and 7. Lack of sutural closure in the cervical vertebrae was found to be characteristic of immature crocodilians by Brochu (1996) and is almost certainly indicative of immaturity in dinosaurs as well.

The cervical ribs are poorly preserved, but it is clear that, like other saurischians, they are longer than their respective vertebrae, and that in life they lay parallel to the cervical column.

\section{Atlas (Fig. 10C)}

All elements of the atlas-axis complex are incompletely ossified, remain separate from each other, and have become scattered from their original positions. Thus it is difficult to distinguish the atlantal intercentrum from the axial intercentrum and the odontoid. The element identified by Kermack (1984) as the atlantal intercentrum is here thought to be too rounded and not transversely wide enough to be that element, and is re-interpreted as the odontoid. The element identified as the axial intercentrum is re-interpreted here as the atlantal intercentrum. It is a low, broadly U-shaped bone 


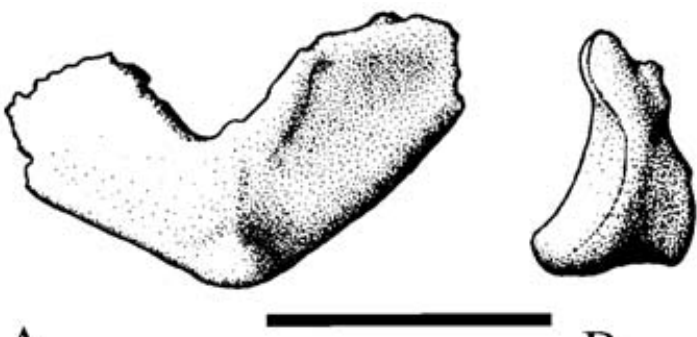

A B

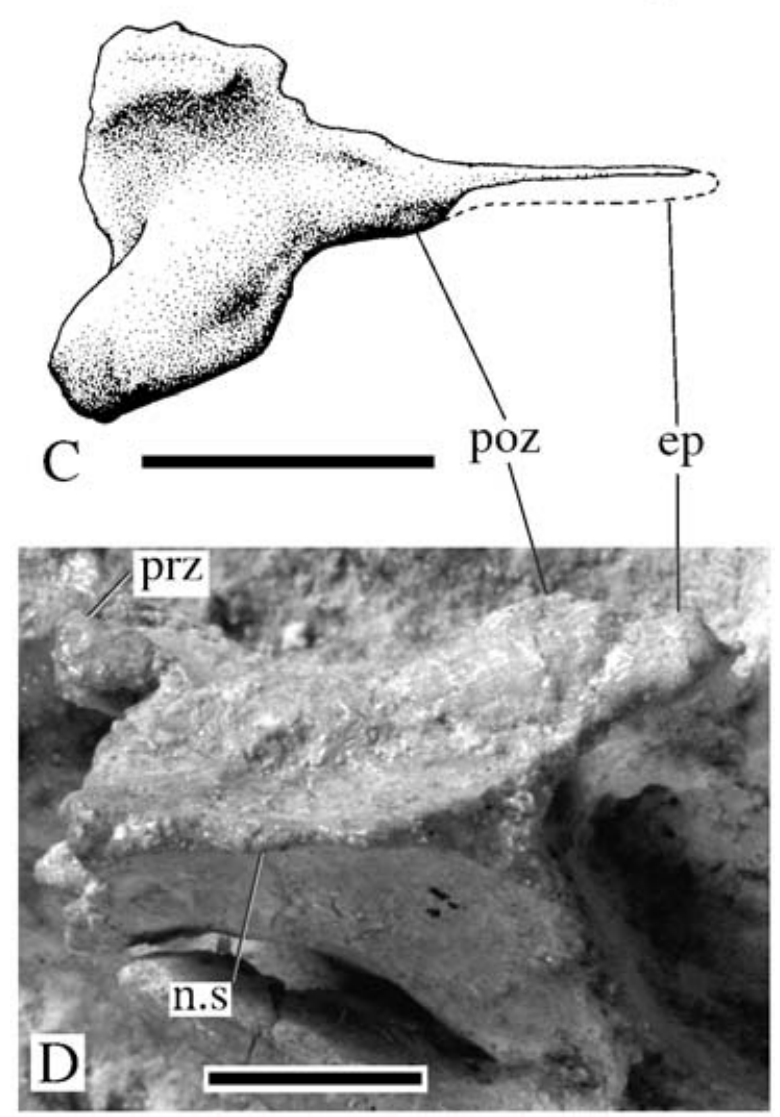

Figure 10 Thecodontosaurus caducus sp. nov., holotype, BMNH P24; elements of the atlas-axis complex. IOA, axial intercentrum in cranial aspect; IOB, axial intercentrum in left lateral aspect; IOC, right neurapophysis in medial aspect; IOD, axial neural arch in dorsal aspect. For abbreviations see Appendix 1 . Scale bars $=5 \mathrm{~mm}$.

in cranial view. In ventral view the cranial margin is convex, while the caudal margin is straight. The right neurapophysis can be viewed medially, rostrally and dorsally. The bone consists of two subrectangular processes, the pedicel and the prezygapophysis, and an elongate prong-like postzygapophysis. The vertically oriented pedicel forms the lateral wall of the neural canal. The prezygapophysis joins the dorsal edge of the pedicel at a roughly right angle, to from a roof over the top of the neural canal. The slender postzygapophysis extends caudally from the junction of the pedicel and the prezygapophysis. A thin, pointed epipophysis continues caudal to the postzygopophyseal facet, but it is not as elongated as it is in some basal sauropodomorphs such as Plateosaurus engelhardti (von Huene 1926) and Coloradisaurus brevis (Bonaparte \& Pumares 1995). In these taxa, the at- lantal epipophyses extend as far back as the cranial margin of the axial postzygapophyses. The odontoid is small and rounded. The dorsal surface is flattened, while the ventral and cranial surfaces are strongly convex. The lateral surface bears a small, round depression.

\section{Axis (Figs 10A, B, D)}

The probable axial intercentrum is a small, crescentic element with a strongly concave dorsal margin in cranial view and a pointed cranially directed process, developed on the midpoint of the ventral margin. The element is craniocaudally flattened and is only $2.9 \mathrm{~mm}$ long at its thickest point. The axial centrum is a simple spool-shaped element that is $11 \mathrm{~mm}$ long and $5 \mathrm{~mm}$ wide. A probable juvenile characteristic is the lack of any form of parapophysis at the cranial end of the centrum. Like other sauropodomorphs (e.g. Riojasaurus incertus: Bonaparte \& Pumares 1995; Plateosaurus engelhardti: pers. obs. of GPIT Skelett 1; Camarasaurus lentus: Madsen et al. 1995), but in contrast to other basal dinosaurs, the axis is not ventrally keeled. The axial neural arch covers a wide neural canal that is $75 \%$ the width of the cranial face of the axial centrum. The size of the foramen magnum relative to the size of the animal decreases through ontogeny (Dodson 1975) and we can expect the width of the axial neural canal to be strongly correlated with that of the foramen magnum. Thus the relatively wide axial neural canal is probably a juvenile characteristic. The prezygapohyses are small, dorsolaterally facing facets mounted on tab-shaped processes that project from the cranial margin of the neural arch, similar to the axial prezygapophyses of neotheropods, but unlike those of Herrerasaurus ischigualastensis (Sereno \& Novas 1993) and other sauropodomorphs (e.g. Camarasaurus lentus: Madsen et al. 1995). In these taxa the prezygapophyses are simple raised areas that do not project cranially. Below the prezygapophyses at the antero-ventral corners of the arch there are weakly developed tubercles that represent the diapophyses. In dorsal view, the lateral margins of the neural arch flare abruptly outwards at the level of the postzygapophyses. Thus, like other saurischians, the postzygapophyses are set wider from the midline than the prezygapophyses. The axial neural spine is damaged dorsally but it appears to be a long, low rectangular process that extends for the full length of the neural arch. Stout epipophyses project a short distance from the caudal margin of the postzygapophyses.

\section{Cervicals 3-5 (Figs 11A, B, C)}

The first three postaxial cervical vertebrae are similar to one another. Their neural arches are low, flat-sided and flattopped structures. Cranially projecting prezgapophyses overhang the cranial face of the centrum by as much as a third of the length of the centrum. The prezygapophyses meet caudally to form a $U$-shaped space, of which the caudal half is floored by a thin interprezygapophyseal lamina. Thus a cranially open, $U$-shaped fossa is developed at the cranial end of the dorsal surface of the neural arch. A long neural spine extends from the vertex of this fossa to the caudal margin of the arch. The spines have broken off at their bases, so their height cannot be determined. Wide, tongueshaped postzygapophyses project posterolaterally from posterodorsal corners of the neural arch and overhang the caudal face of the centrum by a few millimeters. Their dorsal 

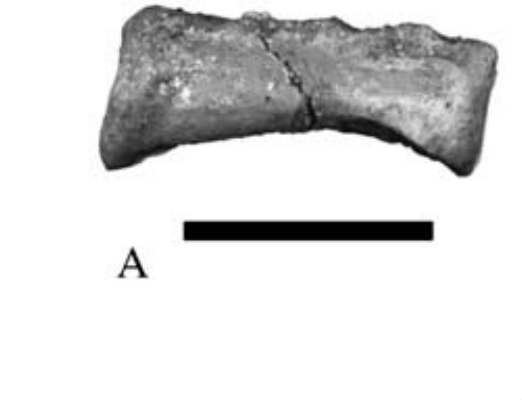

B
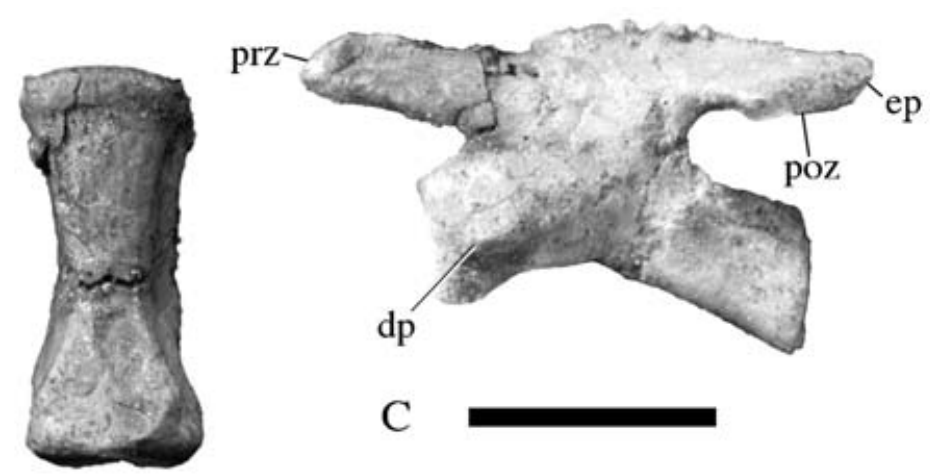

$\mathrm{C}$
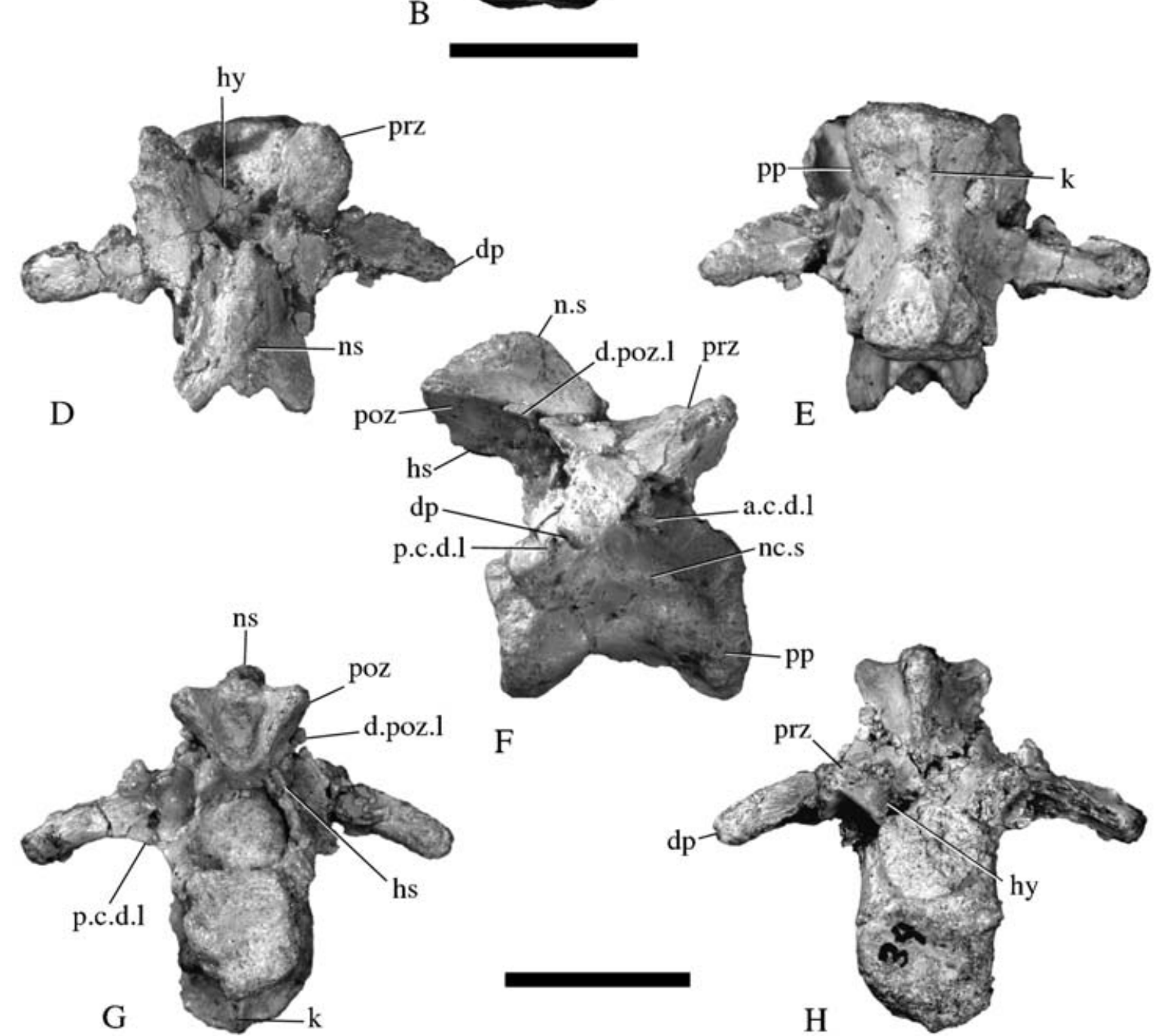

Figure 11 Thecodontosaurus caducus sp. nov., holotype, BMNH P24; cervical vertebrae. 11A, centrum of CE3 in right lateral aspect; $\mathbf{1 1 B}$, centrum of $\mathrm{CE}_{3}$ in ventral aspect; 11C, $\mathrm{CE}_{4}$ in left lateral aspect; 11D, CE10 in dorsal aspect; 11E, CE10 in ventral aspect; 11F, CE10 in right lateral aspect; 11G, CE10 in caudal aspect; $\mathbf{1 1 H}, \mathrm{CE}_{10}$ in cranial aspect. For abbreviations see Appendix 1. Scale bars $=10 \mathrm{~mm}$.

surfaces remain flat and horizontal along their length as they do in T. antiquus (Benton et al. 2000). The caudal edge projects a short distance beyond the caudal edge of the ventrally-facing articulation facet, producing a stubby, caudally-projecting epipophysis. Such overhanging, postaxial epipophyses have been thought to diagnose the Theropoda (Sereno \& Novas 1993), but they are also present in Plateosaurus engelhardti (pers. obs. of GPIT Skelett 1), which suggests that they diagnose the Saurischia and have been subsequently lost in later sauropodomorphs. There is no development of any lamina on these neural arches. The diapophysis is not visible on CE3 while it is borne on a small tubercle on the anteroventral corner of the arch in CE4 and CE5. The neurocentral articulation was weakly sutured in CE3 so that the two elements separated prior to burial. The centra of these vertebrae are elongate, amphicoelous spools that increase in length from CE3 to CE5. The caudal face is set distinctly lower than the cranial face in 

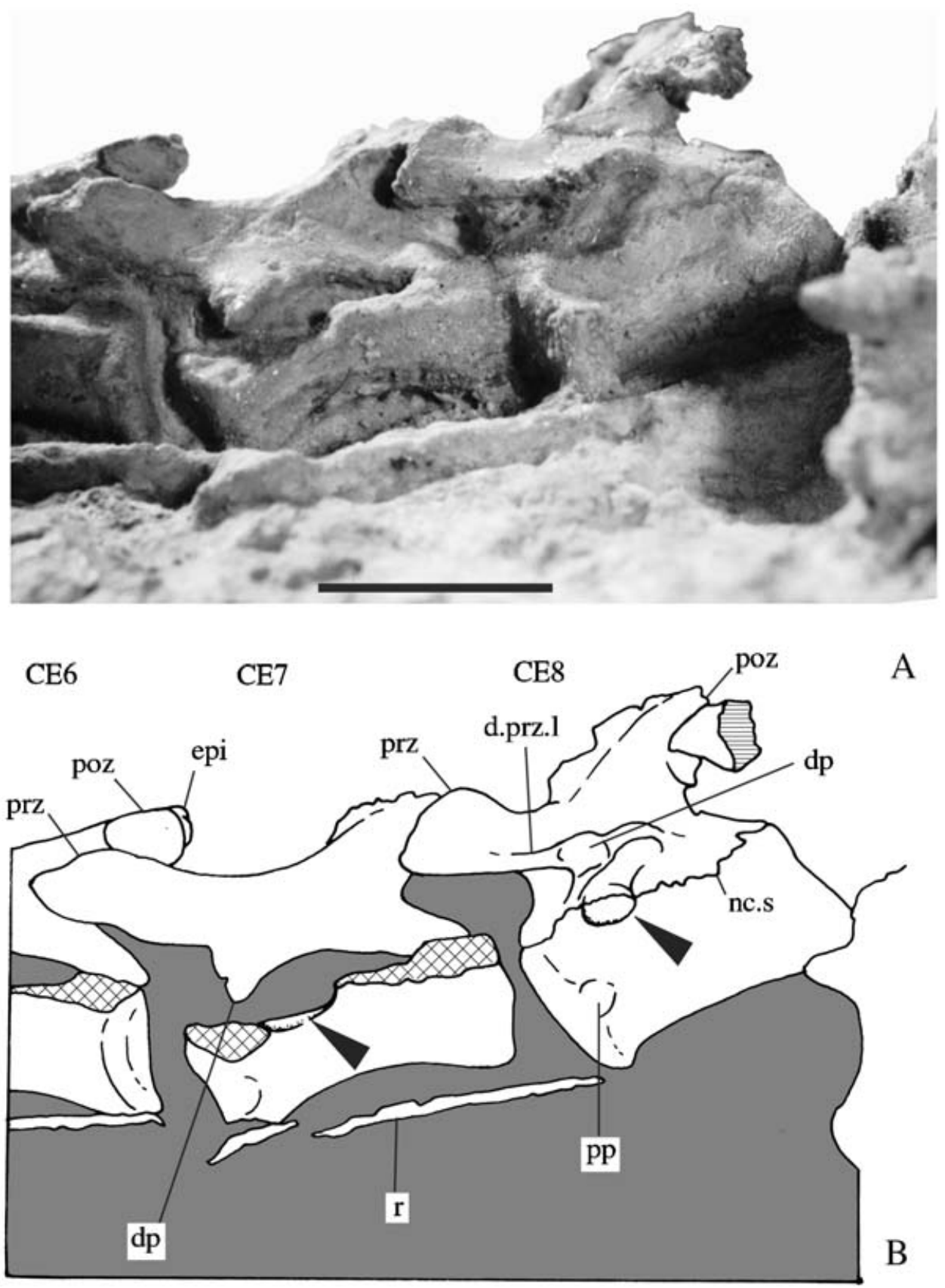

Figure 12 Thecodontosaurus caducus sp. nov., holotype, BMNH P24. 12A, cervical vertebrae 6, 7 and 8 in left ventrolateral aspect; 12B, interpretive line drawing of 12A, showing the pseudopleurocoels (arrowed). Cross-hatching = exposed sutural surfaces, horizontal hatching $=$ surfaces of broken bone. For abbreviations see Appendix 1 . Scale bar $=10 \mathrm{~mm}$.

CE4 and CE5 producing an upward bend in this region of the neck. Poorly developed parapophyses occur on the anterodorsal corners of the centra in CE4 and CE5, just below the diapophyses. The ventral surfaces of the centra are rounded transversely without any trace of the longitudinal keel that is commonly present in early dinosaurs (e.g. Herrerasaurus ischigualastensis: Sereno \& Novas 1993).

\section{Cervicals 6-7 (Fig. 12)}

These vertebrae are similar to CE4 and CE5, differing mainly in that the diapophyses are now borne on short, slender and pointed processes. These processes, which arise from near the anteroventral corners of each neural arch, are strongly pendent as well as being directed slightly forwards. The centra are shorter than that of CE5 and show signs of having borne small simple pleurocoel-like pits developed on the neurocentral suture just caudal to the diapophyses. The large elliptical spaces that are present below the neural arches are artefacts caused by the separation of the neural arches from the centra and lateral rotation of the latter relative to the former. Nevertheless, a distinct sharp-edged depression developed on the contact surfaces of the centra would have formed small elliptical pits just caudal to the diapophyses 
when the elements were correctly articulated. Stout epipophyses with planar dorsal surfaces are also present on these vertebrae, but unlike those of more cranial vertebrae, they do not overhang the postzgapophyseal facet.

\section{Cervical 8 (Fig. 12)}

The centrum of the eighth cervical is noticeably shorter than the centra of CE3-7 but it is still longer than the axial centrum. A small elliptical pleurocoel-like pit is located on the neurocentral suture below the transverse process. The cranial projection of the prezygapophysis is less marked than in the previous postaxials, while it is angled dorsally, indicating that the neck had an upward bend at this point. The transverse process, with its terminally placed diapophysis is centrally located and is directed laterally, unlike the vertebrae cranial to it. Three laminae radiate from the transverse process: the prezygapophyseal, the cranial centro-diapophyseal and the caudal centro-diapophyseal. The diapo-postzygapophyseal lamina is not expressed. 'Efraasia diagnostica' (pers. obs. of SMNS 12667), Plateosaurus engelhardti (pers. obs. of GPIT Skelett 1) and Massospondylus carinatus (Cooper 1981) also lack a diapo-postzygapophyseal lamina, so this condition might diagnose the Sauropodomorpha. Sauropods that do possess a diapo-postzygapophyseal lamina in all of their cervical vertebrae (Wilson 1999), have apparently reverted to the primitive condition.

\section{Cervicals 9 and 10 (Figs 11D-H)}

These are the last two cervical vertebrae. Like CE8, the centra of these two are shorter than those of CE3-7, but are longer than the axial centrum. The centrum of CE10 is the first to bear a sharp ventral keel. The parapophysis forms an oval tubercle halfway up the cranial margin of the centrum in lateral view. As they do not reach the neurocentral suture in the last cervical, it can be deduced that the parapophyses were located on the centrum of the cranial dorsals, as they are in Plateosaurus engelhardit (von Huene 1926). Both sets of zygapophyses are angled upwards in lateral view. The diapophysis is borne on a laterally projecting, elongate, pendent transverse process. A diapo-postzygapophyseal lamina now connects the base of the transverse process with the postzygapophysis, thus creating a posterior semiconical fossa, or chonos (Welles 1984). The postzygapophyseal facet is curved at its ventral end so that there is a narrow laterally-facing ledge that is connected with its counterpart by an interpostzygapophyseal lamina. This structure is a weakly developed hyposphene. The tenth cervical has a space, the hypantrum, to receive the hyposphene of CE9. The neural spine of each of these vertebrae is placed caudally, so much so that it projects into the interpostzygapophyseal space in dorsal view.

\section{Caudal vertebrae (Fig. 13)}

There is a series of eight proximal-mid caudals (BMNH P64/1) and 13 distal caudals (BMNH P77/1). Although these vertebrae are not very big (they probably come from a similar-sized individual as the holotype if not from the holotype itself) the neurocentral sutures are completely closed. This indicates that, like crocodilians, the closure of the neurocentral sutures proceded from caudal to cranial (Brochu 1996). The more proximate vertebrae of the first series have short laterally projecting transverse processes, while they are reduced to mere longitudinal ridges in the eighth. By comparison with other basal sauropododomorphs (Plateo-

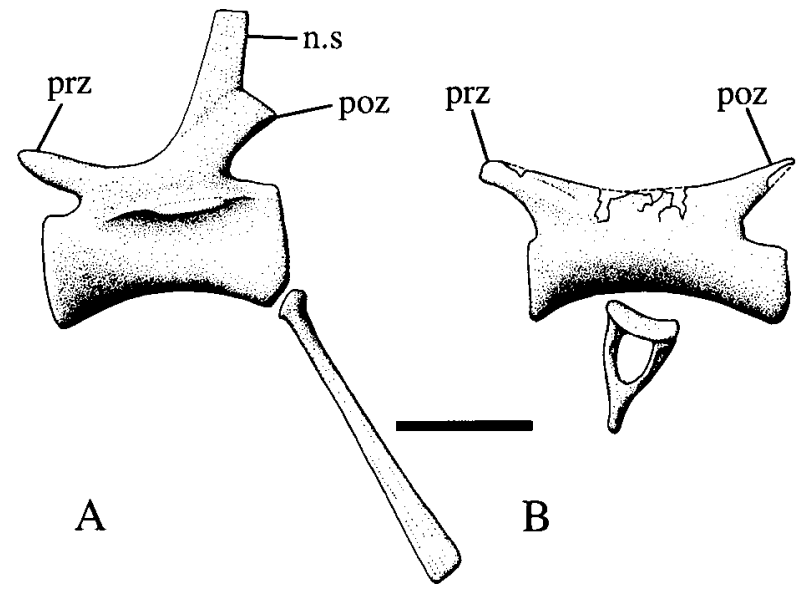

Figure 13 Thecodontosaurus caducus sp. nov., BMNH P77/1; caudal vertebrae. 13A, mid caudal (CA20?) and associated chevron in left lateral aspect; 13B, distal caudal in left lateral aspect with associated chevron in proximal aspect. For abbreviations see Appendix 1.

Scale bar $=5 \mathrm{~mm}$.

saurus engelhardti: pers. obs. of GPIT Skelett 1; Lufengosaurus huenei: Young 1941a), in which the most distal transverse process occurs in caudal 27 , it is probable that BMNH P64/1 represents caudals 20-28. The ventral surfaces of the centra are flattened and the longitudinal sulcus bordered by two ridges, which is usually present in sauropodomorphs, is absent. This is a derived condition shared with T. antiquus. Caudal 20 has a centrum that is $12 \mathrm{~mm}$ long and $6 \mathrm{~mm}$ high at its proximal end. Such an elongate CA20 is a primitive character state, the caudal centra of all other sauropodomorphs do not develop such proportions until CA27-30 (Young 1941a; pers. obs. of GPIT Skelett 1). The neural spines are proximo-distally short and placed far back on the neural arches, between the postzygapophyses. Thus, the U-shaped interpostzygapophyseal space, which is present in most dinosaurs, is filled by the base of the neural spine. This is a derived condition that T. caducus shares with T. antiquus. The length of the associated chevrons is equal to the height of their respective vertebrae. The proximal ends of the chevrons are bridged-over, while the distal ends are slightly expanded in the proximo-distal plane.

The distal series of caudals consists of elongate centra with reduced neural arches that lack transverse processes and neural spines. The prezygapophyses are small tongue-shaped processes that do not project far from the centra, unlike those of herrerasaurids (Novas 1993) and neotheropods (Chiappe et al. 1996). The postzygapophyses are similar in size and shape.

\section{Forelimb}

\section{Scapula}

Only a fragment from the proximal ventral corner of the right scapula of the holotype remains. It does not differ significantly from those of other early dinosaurs.

\section{Coracoid}

The medial surface of the right coracoid of the holotype is exposed, while the holotype's left coracoid and another isolated left coracoid (BMNH P39) have been freed from the matrix. The coracoid is an elongately oval plate that is $25 \mathrm{~mm}$ 


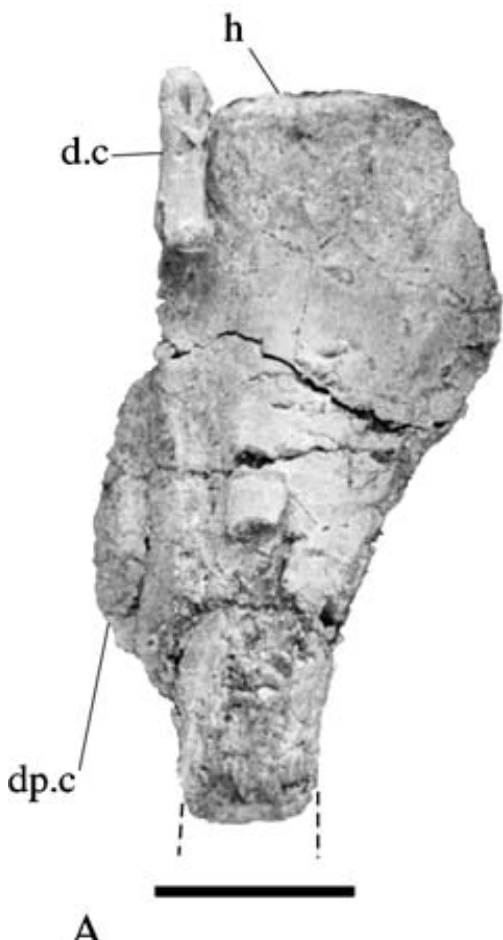

A

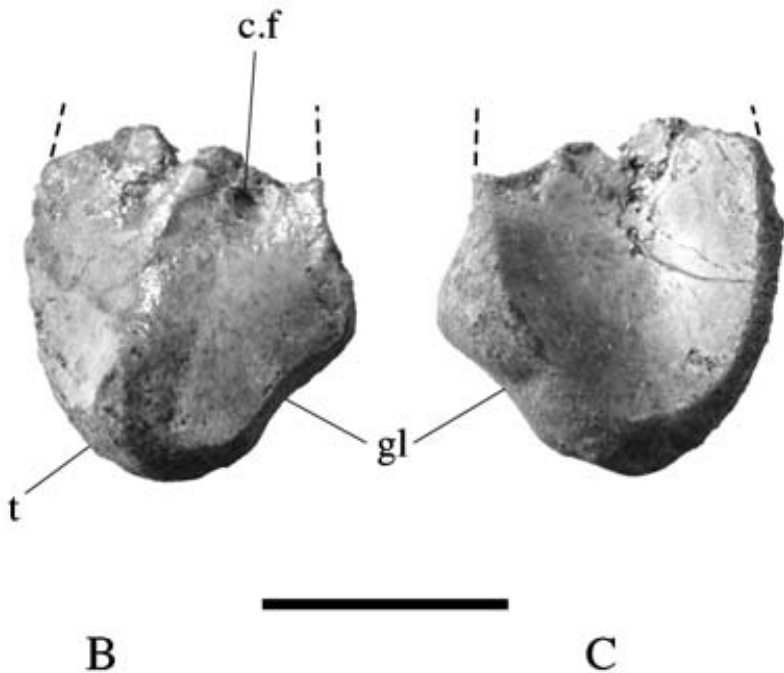

B

Figure 14 Thecodontosaurus caducus sp. nov. 14A, proximal left humerus of BMNH P24, holotype, in caudal aspect; 14B, incomplete left coracoid of BMNH P39/2; lateral view and 14C, medial aspect. For abbreviations see Appendix 1 . Scale bars $=10 \mathrm{~mm}$.

long and $15 \mathrm{~mm}$ high in P24. The long axis of the coracoid is parallel to its suture with the scapula. The glenoid region is greatly thickened compared to the cranial and caudal margins of the bone. The ventral margin is rounded and lacks a notch separating the glenoid from the pointed cranioventral corner that can be seen in some early sauropodomorphs, such as Lufengosaurus huenei (Young 1941a). There is, however, a laterally projecting tubercle developed at the cranioventral extremity of the bone.

\section{Humerus (Fig. 14)}

The left humerus (BMNH P19/7) could not be located, so this description is based entirely on the two proximal humeral fragments preserved in the holotype. The proximal humerus is a craniocaudally flattened structure capped by a narrow head $(19 \mathrm{~mm}$ wide) that is gently convex in the medio-lateral plane. The medial corner of the head does not project as strongly as it does in T. antiquus. In that species the strong medial projection of the humeral head causes the margin of the humerus, underneath the medial tuberosity, to be greatly arched, as it is in crurotarsans (Sereno 1991b). An elongate deltopectoral crest extends $30 \mathrm{~mm}$ down the lateral margin, from the proximolateral corner. Distal to the deltopectoral crest, the shaft narrows sharply to a cylindrical structure that is $7 \mathrm{~mm}$ in diameter.

\section{Hindlimb}

Except where mentioned, all of the hindlimb and pelvic elements described here come from a single, partially articulated specimen (BMNH P77/1).

\section{Ilium (Fig. 15)}

The ilium is closer in shape to those of other basal sauropodomorphs than it is to the ilium of T. antiquus. In the latter species the ilium is low and elongate, especially caudally, whereas in T. caducus it is tall, short and has a rhomboidal shape. The preacetabular blade is a pointed structure that is directed cranially without any ventral curvature as it is in all other basal sauropodomorphs, except $T$. antiquus. The elongate pubic peduncle is craniocaudally flattened so that the transverse width of the articular facet for the pubis $(5.5 \mathrm{~mm})$ is greater than its craniocaudal length $(3 \mathrm{~mm})$. This articular facet is as long as it is wide in T. antiquus and most other sauropodomorphs. The lateral acetabular margin of the pubic peduncle forms a sharp ridge that is confluent with the supra-acetabular crest. The supra-acetabular crest appears to reach its widest point at the base of the public peduncle, a derived condition amongst archosaurs, but the closely adpressed femur may have crushed the supra-acetabular crest between the pubic and ischial peduncles. Nevertheless the supra-acetabular crest is widest over the pubic peduncle of $T$. antiquus and other sauropomorphs that are more derived than Saturnalia tupiniquim, so it is simplest to infer that the supraacetabular crest of BMNH P77/1 is not damaged. The medial wall of the acetabulum is extensive, with a gently concave ventral margin. Such an incompletely perforate acetabulum is a primitive character that is rare amongst dinosaurs but is seen in Herrerasaurus ischigualastensis (Novas 1993), Guaibasaurus candelariensis (Bonaparte et al. 1999) and Saturnalia tupiniquim (Langer et al. 1999). The ischial peduncle is a short rounded process. The postacetabular blade is short and, like T. antiquus, 'Efraasia diagnostica' and neotheropods, it has a subrectangular caudal margin in lateral view. The medial shelf that joins to the last sacral rib 


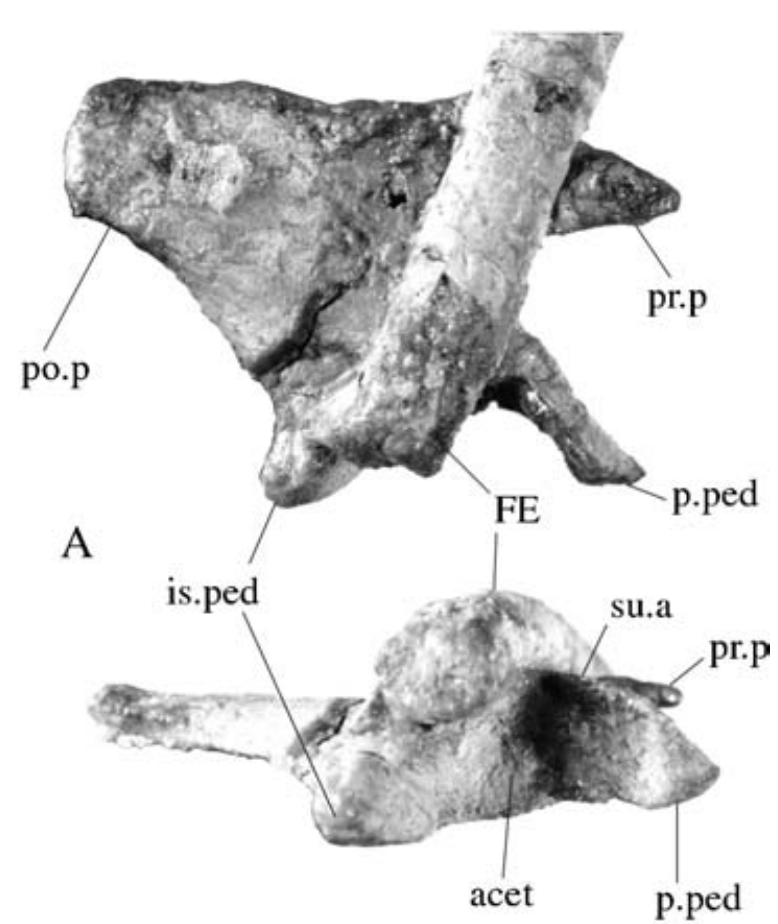

B

Figure 15 Thecodontosaurus caducus sp. nov., BMNH P77/1; right ilium. 15A, lateral aspect; 15B, ventral aspect. For abbreviations see Appendix 1. Scale bar $=10 \mathrm{~mm}$.

and forms the medial margin of the brevis fossa is absent, as is the brevis fossa itself. Other basal sauropodomorphs, such as Saturnalia tupiniquim, T. antiquus and 'Efraasia diagnostica', have large brevis fossae. It is probable that as T. caducus matured and the connection between the sacral ribs and the ilium began to suture firmly, the medial shelf of the postacetabular blade would have ossified. For this reason it is assumed that the absence of a brevis shelf may be more an indication of immaturity than a diagnostic character of the species.

\section{Pubis}

There is only one fragment of a possible pubis that may belong to T. caducus (BMNH P126/1). However, the referral is dubious because the specimen comes from an individual that was distinctly larger than the other specimens. The fragment includes what might be the iliac peduncle and some of the obturator plate, including part of the margin of an obturator foramen. No other details can be gleaned from this specimen.

\section{Ischium (Fig. 16)}

Kermack (1984) misidentified an isolated, right ischium (BMNH P24/3), as the distal end of the scapula of the holotype. It is, however, too expanded at its distal end to be a scapula. It is nearly complete and measures $40 \mathrm{~mm}$ along its greatest dimension. The proximal half forms a plate that, in life, would have been angled dorsolaterally from the symphysis along its ventral margin. A thin obturator plate expands ventrally at the proximal end. A short longitudinal sulcus is developed on the dorso-lateral margin where it

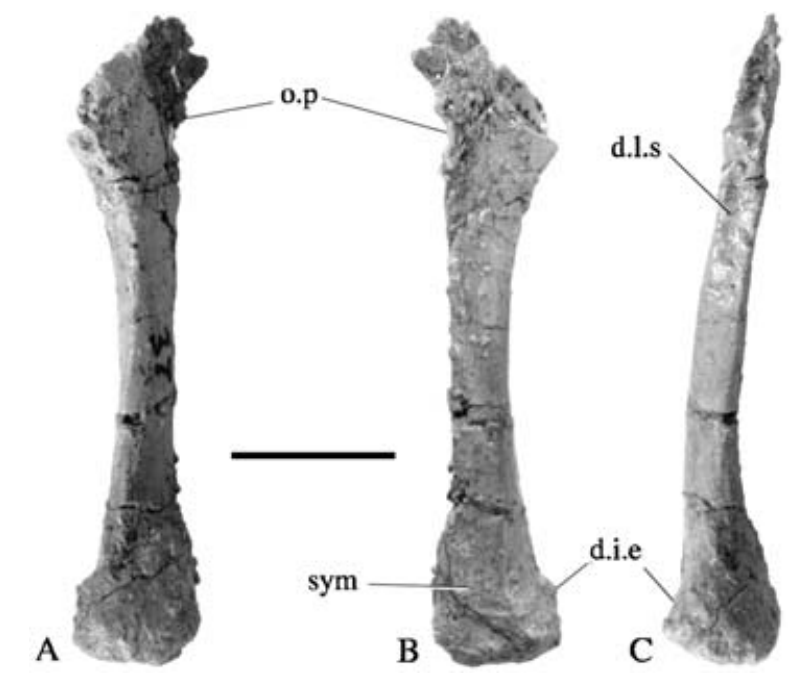

Figure 16 Thecodontosaurus caducus sp. nov., BMNH P24/3; right ischium. 16A \& 16B, lateral aspect; 16C, dorsal aspect. For abbreviations see Appendix 1 . Scale bar $=10 \mathrm{~mm}$.

curves upwards to form the iliac peduncle. Such a sulcus may diagnose Neotheropoda + Sauropodomorpha, since it is seen in other sauropodomorphs (e.g. Saturnalia tupiniquim: pers. obs. of MCP 3844 - PV; Plateosaurus engelhardti: pers. obs. of GPIT Skelett 1; Dicraeosaurus hansemani: pers. obs. of HMN material) and neotheropods (e.g. Lilliensternus lilliensterni: pers. obs. of HMN MB.R.2175.7.4). The distal half forms a shaft that is triangular in cross-section with a keeled ventral edge and a flat dorsal face. This is diagnostic of Saurischia (see discussion below). The distal end is expanded both mediolaterally and dorsoventrally. In distal view the conjoined ischial expansions would have been as wide as high, unlike Plateosaurus engelhardti, where the conjoined expansions are higher than they are wide (von Huene 1926).

\section{Femur (Fig. 17)}

The single known femur (from BMNH P77/1) is incomplete. The proximal end, from the middle of the fourth trochanter, is missing. Assuming that the position of the fourth trochanter along the femoral shaft remained constant throughout ontogeny and the femoral proportions were similar to T. antiquus, the total length of the femur is estimated to have been $72 \mathrm{~mm}$. The steep distal margin of the fourth trochanter indicates that the profile was asymmetrical, like most other early sauropodomorphs except Melanorosaurus readi (Van Heerden \& Galton 1997). The distal shaft is strongly bowed cranially when viewed laterally and slightly bowed medially when viewed cranially. The sinuous nature of the femoral shaft is a plesiomorphic feature found in most early sauropodomorphs (Galton 1990). The space between the distal condyles is distincty hollowed out, suggesting incomplete ossification. A broad but shallow popliteal fossa is developed at the distal end of the caudal surface while the cranial surface remains convex without any trace of an extensor groove. The tibiofibular crest on the caudolateral surface of the distal end is low and is only weakly separated from the fibular condyle by a poorly impressed fibular trochlea. 


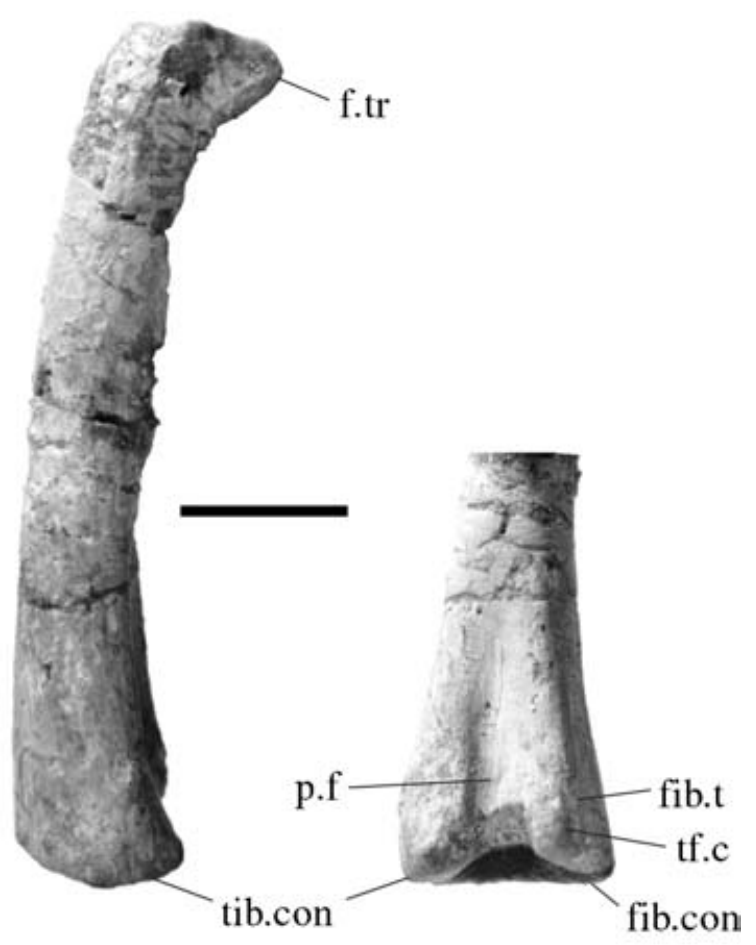

A

B

Figure 17 Thecodontosaurus caducus sp. nov., BMNH P77/1; distal right femur. 17A, medial aspect; 17B, caudal aspect. For abbreviations see Appendix 1. Scale bar $=10 \mathrm{~mm}$.

Tibia (Fig. 18)

If the estimate of the length of the femur is accurate, then the tibia is only slightly shorter than the femur. It is $70 \mathrm{~mm}$ long, which is $97 \%$ of the estimated length of the femur. This is in contrast to other sauropodomorphs where the tibia is much shorter than the femur (e.g. 89\% in Anchisaurus polyzelus: Galton 1976; 65\% in Lufengosaurus huenei: Young 1941a; $62 \%$ in Apatosaurus louisae: Gilmore 1936). The relatively elongate tibia may be due to the small size, and juvenile nature, of the specimen, or it may be a plesiomorphic feature of the species. The proximal head is similar to that of T. antiquus (e.g. BRSMG C4531, note that BMNH 49884, the holotype of Agrosaurus mcgillivrayi, is aberrant and unlike all other tibias assigned to T. antiquus). The triangular, proximal surface is flat and slopes both mediodistally and caudodistally. The low and simple cnemial crest projects cranially from the medial margin of the cranial face, at the proximal end. The fibular condyle forms a low, rounded, lateral projection from the centre of the lateral surface at its proximal end. The tibial shaft is straight, slender and rounded in cross-section. The distal end is only slightly expanded, and is not flared transversely so that the distal surface is squareshaped. The lateral surface of the distal end is gently concave. This concavity is confluent with the notch that separates the caudodistal flange from the facet for the ascending process of the astragulus. Although damaged distally, it is clear that the caudodistal flange was quite low and did not project much further laterally than the craniolateral corner of the distal end.

\section{Fibula (Fig. 19)}

The fibula is a slender, rod-like bone that is $65 \mathrm{~mm}$ long. The proximal end is mediolaterally compressed but craniocaudally expanded. The caudal proximal corner forms a stout pointed process in lateral view, while the cranial proximal corner is rounded. The proximal tibial facet forms a planar surface. The shaft is narrow $(3.5 \mathrm{~mm}$ wide at its midpoint) and has an oval cross-section, with the long axis

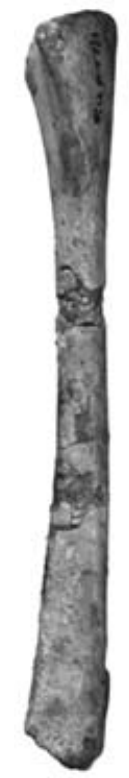

A

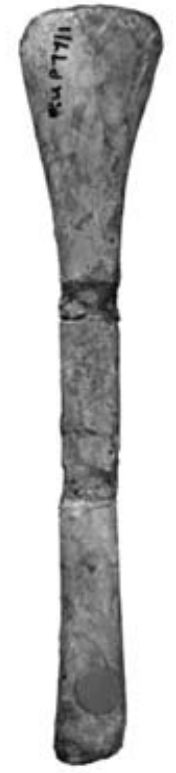

B

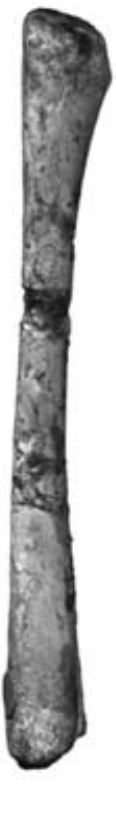

C

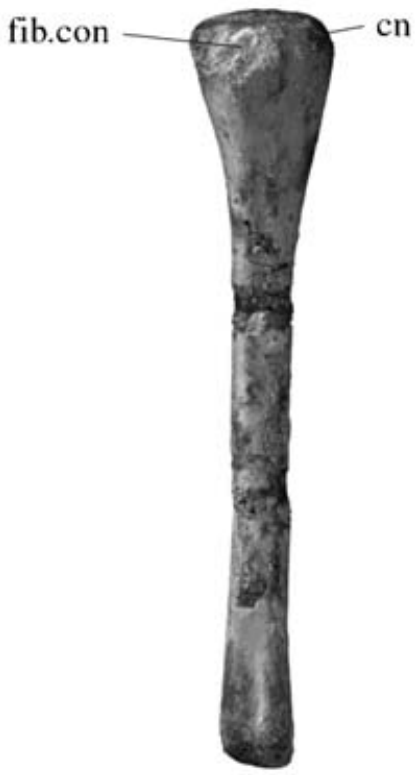

D

Figure 18 Thecodontosaurus caducus sp. nov., BMNH P77/1; right tibia. 18A, cranial aspect; 18B, lateral aspect; 18C, caudal aspect; 18D, medial aspect. fib. $c 0 n=$ fibular condyle, $\mathrm{cn}=$ cnemial crest. Scale bar $=10 \mathrm{~mm}$. 


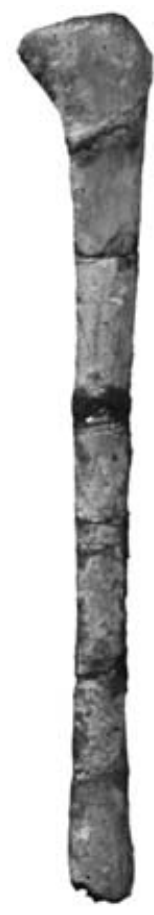

A

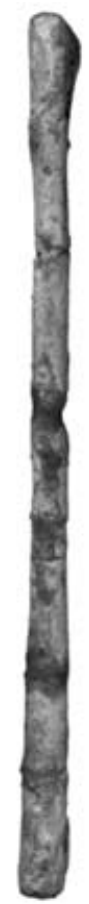

B

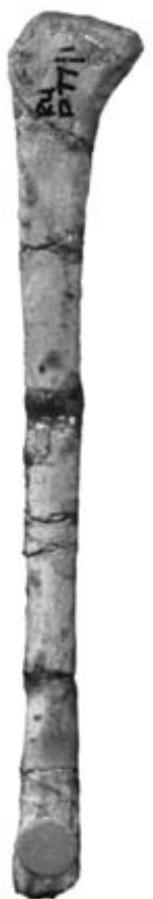

C
Figure 19 Thecodontosaurus caducus sp. nov., BMNH P77/1; right fibula. 19A, lateral aspect; 19B, caudal aspect; 19C, medial aspect. Scale bar $=20 \mathrm{~mm}$.

oriented craniocaudally. There is no trace of a tubercle for the tibiofibularis ligament on the cranial margin of the shaft; this is probably another feature of immaturity. Similarly the expansion at the distal end was not ossified and the fibula is shorter than the tibia.

\section{Pes (Fig. 20)}

The right pes is articulated and almost complete. It is exposed on its plantar surface, although the proximal surface of the metatarsus and the lateral and medial sides of some elements can be observed as well. It is a slender foot, when compared to other basal sauropodomorphs such as Plateosaurus engelhardti (von Huene 1926) and Massospondylus carinatus (Cooper 1981), but this is almost certainly a correlate of the specimen's small size and juvenile nature.

\section{Metatarsal I (Table 2)}

The first is the shortest digit-bearing metatarsal. It is a flattened element that is less than $60 \%$ of the length of metatarsal III, the longest of the metatarsals. It is gently twisted about its long axis so that the dorsal face of the compressed proximal head faces dorsomedially while the transverse axis through the distal articular end is oriented mediolaterally. The proximal head is strongly compressed and has a narrowly elliptical head that fits against the dorsomedial articular facet of metatarsal II. The lateral side remains in contact with metatarsal II for its entire length. In plantar view the distal articular surface is set at an angle so that the medial side is higher than the lateral. This would have enabled the hallux to separate from the rest of the digits of the foot during exten-

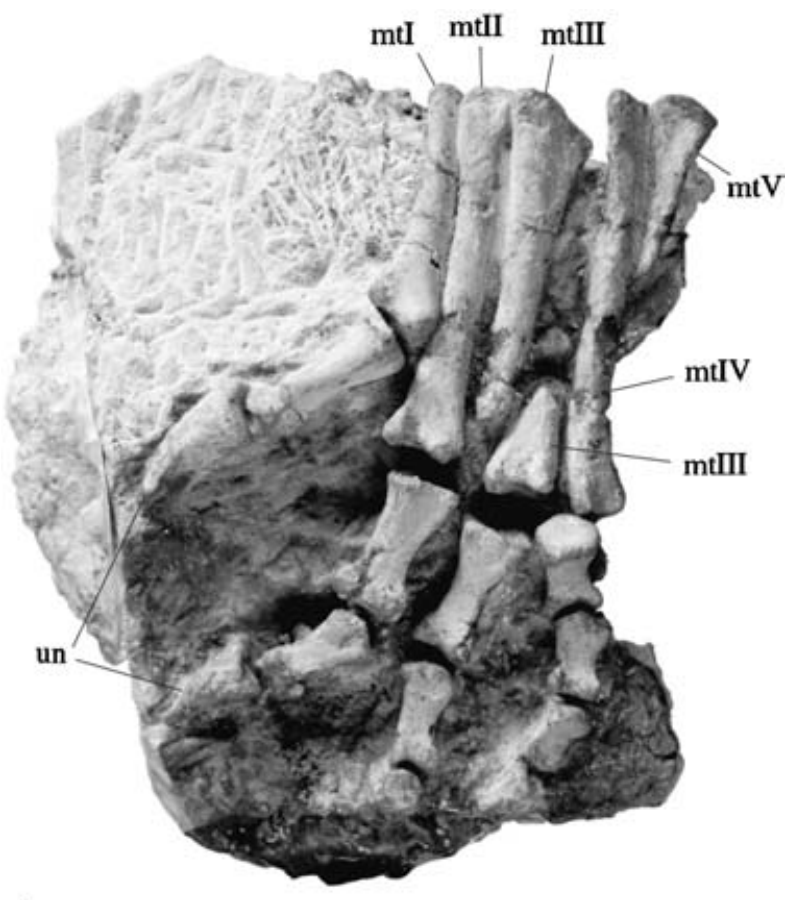

A

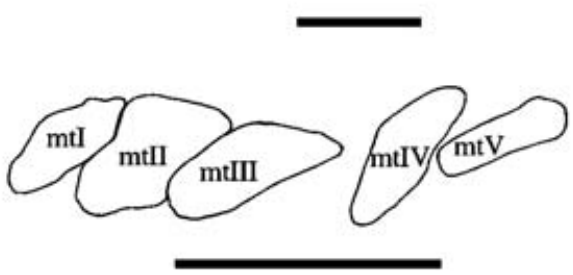

Figure 20 Thecodontosaurus caducus sp. nov., BMNH P77/1; right pes. 20A, plantar aspect; 20B, proximal aspect. For abbreviations see Appendix 1. Scale bars $=20 \mathrm{~mm}$.

sion. This could be correlated with the use of the hallux as a weapon, as is suggested by the enlarged size of the ungual in this digit. A small, weakly developed ligament pit occurs on the lateral side of the distal end, while a weak extensor pit occupies its dorsal face.

\section{Metatarsal II}

This metatarsal is shorter and more robust than metatarsals III and IV. The proximal articular surface is parallelogramshaped, with the transverse width being less than the dorsoplantar depth. The dorsal and plantar faces are straight

Table 2 Dimensions of the metatarsals (in $\mathrm{mm}$ ).

\begin{tabular}{lclll}
\hline & Length & $\begin{array}{l}\text { Distal } \\
\text { width }\end{array}$ & $\begin{array}{l}\text { Maximum } \\
\text { proximal } \\
\text { dimension }\end{array}$ & $\begin{array}{l}\text { Width of } \\
\text { dorsal } \\
\text { proximal face }\end{array}$ \\
\hline Mt I & 20.1 & 5.7 & 5.6 & 3.2 \\
Mt II & 29.0 & 6.3 & 7.3 & 4.1 \\
Mt III & $\sim 35$ & 5.5 & 7.8 & 3.5 \\
Mt IV & 33.3 & 4.3 & 6.8 & 4.2 \\
Mt V & 14.8 & - & 5.8 & - \\
\hline
\end{tabular}

$\mathrm{Mt}=$ Metatarsal 
while the dorsomedial and plantolateral faces (which receive metatarsals I and III, respectively) are slightly concave. Close contact with metatarsal III is maintained in the proximal third of the element. The distal end is slightly widened transversely and has a rectangular shape in distal view. It bears ligament pits on each side. Ossification was not complete, as the distal surface is slightly concave rather than being convex to fit the socket on the proximal surface of the first phalanx.

\section{Metatarsal III}

This is the longest metatarsal of the foot. The proximal articular surface is subrectangular, with the dorso-plantar depth exceeding the mediolateral width. Its dorsal margin is straight, while the plantar margin is rounded. The flat proximolateral facet for the reception of metatarsal IV is angled to face the plantar surface. The poorly ossified distal articular surface forms a transversely elongate rectangle.

\section{Metatarsal IV}

Most dinosaurs have a fourth metatarsal that is subequal to the second in length but, at $33 \mathrm{~mm}$ this specimen is $15 \%$ longer than the second metatarsal. In this respect $T$. caducus is similar to the non-dinosaur Marasuchus lilloensis (Sereno \& Arcucci 1994) but unlike that species, the fourth metatarsal is still shorter than the third. As in other basal sauropodomorphs (e.g. Massospondylus carinatus: Cooper 1981), the proximal head is flattened in the dorsoplantar dimension so that the proximal articular surface is three times wider than it is deep. As the facet for the fourth metatarsal on the third metatarsal faces the plantar side, the former would have extensively underlapped the latter. The distal end is transversely compressed compared to that of metatarsal III, so that the distal articular surface is square-shaped.

\section{Metatarsal V}

The fifth metatarsal is a short splint-like element, that is $15 \mathrm{~mm}$ long, which is less than half the length of the fourth. Its distal end tapers to a point that did not bear a phalanx, unlike some basal sauropodomorphs, e.g. Plateosaurus engelhardti (von Huene 1926) and Massospondylus carinatus (Cooper 1981). The proximal end is transversely expanded, with the transverse width being $40 \%$ of the length. However, unlike many sauropodomorphs (e.g. Lufengosaurus huenei: Young, 1941a; Vulcanodon karibaensis: Cooper 1984), the metatarsal is smoothly tapered and the proximal expansion is not marked by a distinct change in the slope of the lateral and medial margins of the bone.

\section{Pedal digit I (Table 3)}

As in all other dinosaurs, this digit comprises a non-terminal phalanx and an ungual phalanx and is the shortest functional digit of the pes. The first phalanx is longer than those of digits II, III and IV, although it is no broader than the first phalanx of digit II. Its proximal articular surface is subtriangular. There is a ligament pit located centrally on the medial side of the distal end (the lateral side is obscured). The ungual is slightly larger than that of digit II and was almost certainly larger than the missing unguals of III and IV, given the small size of the penultimate phalanges of these digits. The slender ungual is laterally compressed and moderately curved. There is no flexor tubercle on the proximal ventral surface, nor are there neurovascular grooves on each side of the ungual.
Dimensions of the pedal phalanges (in $\mathrm{mm}$ ).

\begin{tabular}{lcc}
\hline & Length & $\begin{array}{l}\text { Proximal width or } \\
\text { height in the case } \\
\text { of unguals }\end{array}$ \\
\hline Digit I & 12.9 & 4.0 \\
Phalanx 1 & 10.6 & 5.5 \\
$\quad$ Phalanx 2 (ungual) & & \\
Digit II & 11.0 & 6.0 \\
Phalanx 1 & 9.4 & 4.8 \\
Phalanx 2 & $\sim 9$ & 4.9 \\
Phalanx 3 (ungual) & & \\
Digit III & 11.2 & 5.1 \\
Phalanx 1 & 9.0 & 4.6 \\
Phalanx 2 & -4 \\
Phalanx 3 & & \\
Digit IV & 8.6 & 4.9 \\
Phalanx 1 & 6.8 & 4.5 \\
Phalanx 2 & 5.6 & 4.3 \\
Phalanx 3 & 5.1 & 3.6 \\
Phalanx 4 & & \\
\hline
\end{tabular}

\section{Pedal digit II}

This digit was shorter than digits III and IV. It comprises two, stout, non-terminal phalanges and a small ungual phalanx. Both of the non-terminal phalanges are about twice as long as they are broad and have flattened ventral surfaces. The first has weakly developed collateral ligament pits while the second does not. The ungual is damaged but it is clear that the proximal articular surface was smaller than that of the first pedal ungual.

\section{Pedal digit III}

The specimen includes two complete non-terminal phalanges and a fragment of the third. With a complete third phalanx and an ungual this would have been the longest digit of the pes. The two proximal phalanges are similar in proportions to those of digit II, being about twice as long as they are broad at the proximal end.

\section{Pedal digit IV}

The preserved portion of this digit consists of four nonterminal phalanges. Unlike the phalanges of the previous digits, these are of stouter proportions with the distal two being almost as wide as they are long. The collateral ligament pits at the distal end of each phalange are well-developed, as is ginglymus at each interphalangeal articulation. Although the ungual is missing, the preserved portion exceeds digit II in length indicating that this was the second longest digit of the pes.

\section{SKELETAL RECONSTRUCTION}

Kermack (1984) reconstructed the skeleton of Thecodontosaurus caducus by combining BMNH P24 with BMNH P77/1. The pelvic, hindlimb and caudal elements of BMNH P77/1 were scaled up so that the reconstructed femur was almost twice as long as the humerus from BMNH P24, thereby bringing the humero-femoral ratio into line with that of other Triassic sauropodomorphs. Kermack (1984) also 


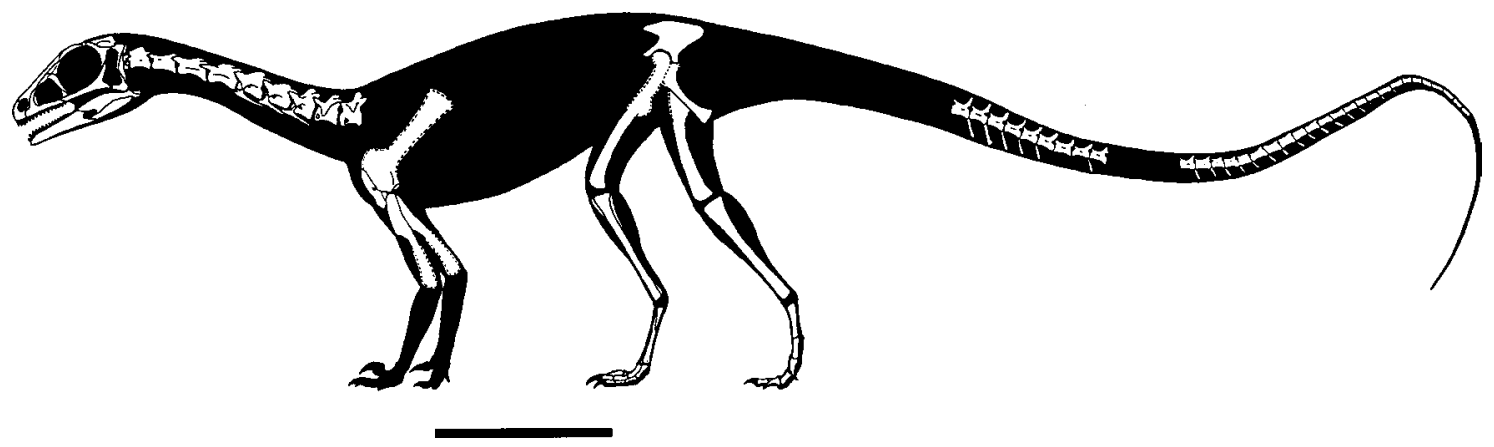

Figure 21 Thecodontosaurus caducus sp. nov., skeletal reconstruction based on BMNH P24, P64/1 and P77/1. Scale bar $=100 \mathrm{~mm}$.

thought that if BMNH P77/1 were not scaled up relative to BMNH P24 then the ilium would appear unrealistically small in comparison to the skull. Two observations are pertinent at this point. Firstly, in a large sample of postcranial bones of $T$. antiquus from Tytherington (uncatalogued BRSUG material) the largest humeri are of similar length to the largest femora (approximately $200 \mathrm{~mm}$ ) suggesting that, at least in this species, the humerus-to-femur ratio was much higher than in other basal sauropodomorphs. Secondly, the skull of the juvenile basal sauropodomorph, Mussaurus patagonicus, was almost certainly longer and taller than its ilium (Bonaparte \& Vince 1979) so we could expect a similar ratio in the present juvenile specimen.

For an alternative reconstruction I have assumed that BMNH P24, P64/1 and P77/1 represent different parts of the same specimen and have restored the specimen accordingly (Fig. 21). There is circumstantial evidence to support the unity of these specimens. All specimens were found in the same spoil heap on the same day (Kermack 1984) and contain no overlapping parts. A small, displaced, ischium (BMNH P24/3) that would fit with the ilium of P77/1 was found in the same slab that contains the skull, neck and pectoral skeleton (P24).

In the new reconstruction the forearms are relatively longer than those in Kermack's (1984) reconstruction and the hindlimbs were not as elongate relative to the trunk length. If these proportions are accurate it is possible that Thecodontosaurus was not an obligate biped as has usually been assumed (e.g. Kermack 1984; Galton 1990, 2000; Van Heerden 1997), but could have progressed using quadrupedal locomotion some of the time. Given that Saturnalia tupiniquim has proportions that are indicative of facultative, rather than obligate, bipedalism (Langer et al. 1999), it is possible that some degree of quadrupedalism is the basal condition for Sauropodomorpha.

\section{CLADISTIC ANALYSIS}

\section{Methods}

Thecodontosaurus caducus was included in a cladistic analysis including 21 ingroup taxa from the Saurischia as well as three outgroup taxa: Crurotarsi, Marasuchus and Ornithischia (Table 4). Amongst the ingroup there are a number of poorly diagnosed taxa based on poor type material. Some explanation as to what material was considered for this analysis is given here. Data for T. antiquus was based on two large collections of disassociated material, one from the type locality, another from a new site some $10 \mathrm{~km}$ to the north. The material was treated as belonging to one species because neither sample showed evidence that more than one type of sauropodomorph was present. The humeri, ilia and proximal caudal vertebrae from both localities display autapomorphies (unpublished results), which indicate that they belong to a single diagnosable species.

All the diagnostic sauropodomorph material from the Newark Supergroup of the Connecticut Valley, North America are treated as a single species united by several autapomorphic features, as assumed by Sereno (1999). These are a narrow, elongate preacetabular blade of the ilium, a narrow pubic apron that is half as wide as the width at the proximal end of the pubes and flattened coplanar ischial shafts. Anchisaurus Marsh, 1885 is used as the oldest available generic name for the material. Sereno used Ammosaurus Marsh, 1891, presumably believing the type species of Anchisaurus, A. polyzelus (Hitchock 1865), to be a nomen dubium. However, the type specimen of A. polyzelus (AM 41/109) clearly shows the diagnostic dorsoventrally flattened, coplanar ischial shafts (Galton 1976), so it is an adequate type specimen. The material from the western United States referred to as Ammosaurus by Galton (1976) is not included in this taxon.

Sellosaurus gracilis from the Early Norian Stubensandstein of Germany was not used as a terminal taxon because the hypodigm of this species is heterogeneous (Galton 1999; pers. obs. of SMNS and GPIT material). Furthermore, the type specimen of Sellosaurus gracilis is indistinguishable from a small specimen of Plateosaurus. The sample from the Stubensandstein of Pfaffenhoffen Quarry appears to represent a taxon that is distinct from Plateosaurus and it is used as a terminal taxon here. 'Efraasia diagnostica' is an available name for this taxon but it is used in quotation marks until a taxonomic restudy of the Stubensandstein prosauropods confirms that this is the correct name for the taxon.

Although Plateosaurus is a very familiar name, the type species, Plateosaurus engelhardti Meyer, 1837, is founded on incomplete remains. The well-known, easily-diagnosed, taxon that is based on many complete skeletons from Europe and Greenland may not be the same species, or indeed genus, as the type of Plateosaurus engelhardti (Galton 2000). Nevertheless it is the former taxon that has been called 
Table 4 Operational Taxonomic Units (OTU) used in the phylogenetic analysis and the sources from which anatomical information was obtained.

\begin{tabular}{|c|c|}
\hline OTU & References \\
\hline Crurotarsi & Walker 1964; Sill 1974; Chatterjee 1978 \\
\hline Marasuchus & Sereno \& Arcucci 1994 \\
\hline Ornithischia $^{1}$ & Thulborn 1972; Santa Luca 1980; Sereno $1991 a$ \\
\hline Herrerasauridae $^{2}$ & Colbert 1970; Novas 1993; Sereno 1993; Sereno \& Novas 1993 \\
\hline Neotheropoda ${ }^{1}$ & Gilmore 1920; Madsen 1976; Welles 1984; Currie \& Zhao 1993 \\
\hline Saturnalia tupiniquim ${ }^{1}$ & Langer et al. 1999 \\
\hline Thecodontosaurus antiquus ${ }^{1}$ & Benton et al. 2000 \\
\hline Anchisaurus polyzelus & Galton 1976 \\
\hline Riojasaurus incertus ${ }^{2}$ & Bonaparte 1972; Bonaparte \& Pumares 1995 \\
\hline 'Efraasia diagnostica' ${ }^{1}$ & Galton 1973, 1984b, 1985b; Galton \& Bakker 1985 \\
\hline Plateosaurus engelhardti ${ }^{1}$ & von Huene 1926; Galton 1984a, $1985 \mathrm{C}$ \\
\hline Massospondylus carinatus ${ }^{2}$ & van Hoepen 1920a,b; Cooper 1981; Gow 1990; Gow et al. 1990 \\
\hline Lufengosaurus huenei & Young 1941a,b \\
\hline Coloradisaurus brevis ${ }^{2}$ & Bonaparte 1978 \\
\hline Yunnanosaurus huangi & Young 1942 \\
\hline 'Euskelosaurus browni' & Van Heerden 1979 \\
\hline Melanorosaurus readi & Van Heerden 1979; Van Heerden \& Galton 1997 \\
\hline Blikanasaurus cromptoni & Galton \& Van Heerden 1998 \\
\hline Vulcanodon karibaensis & Raath 1972; Cooper 1984 \\
\hline Eusauropoda $^{1}$ & $\begin{array}{l}\text { Janensch 1935-36; Gilmore 1936; Bonaparte 1986; He et al. 1988; } \\
\quad \text { Zhang 1988; Madsen et al. } 1995\end{array}$ \\
\hline
\end{tabular}

Plateosaurus for more than 70 years. To invent a new name for this well-known taxon would be confusing and destabilising. In this paper, I provisionally use the name Plateosaurus engelhardti, while recognising that this usage will need to be officially fixed by an appeal to the International Commission for Zoological Nomenclature (ICZN) to conserve the name.

Benton et al. (2000) chose to omit the Chinese taxa Lufengosaurus huenei and Yunnanosaurus huangi from their analysis for the reason that it was impossible to tell which specimens from the Lower Lufeng Formation belonged to which taxon. Here both taxa are included but almost all data is taken from the type specimens alone, thereby eliminating the problem of taxonomic mixing. Some data for Lufengosaurus huenei were taken from the syntypes of 'Gyposaurus' sinensis. The 'Gyposaurus' sinensis specimens do not differ from the type specimen of Lufengosaurus huenei in any of the characters coded in this analysis. They also share with it the autapomorphies of a strongly arched dorsal margin of the ilium and an exceptionally large manual digit I relative to the other manual digits.

The type specimen of Euskelosaurus browni is very fragmentary (Van Heerden 1979). All the data in this analysis were taken from the collection of bones from the Lower Elliott Formation of Kromme Spruit, South Africa that were described by Van Heerden (1979). Since the type specimen of Euskelosaurus browni might be undiagnostic, the name is used for the Kromme Spruit sauropodomorphs with quotation marks, pending taxonomic revision of the sauropodomorphs from the Lower Elliott Formation.

The outgroup taxa were included in the analysis as unconstrained terminal taxa. The final trees were then rooted to these taxa after the analysis. Characters that resolve the relationships between the outgroup taxa, but add nothing to the resolution of ingroup relationships, were not included.
Osteological characters from Galton (1985b, 1990), Gauthier (1986), Novas (1993), Sereno (1993, 1999), Sereno \& Novas (1993), Wilson \& Sereno (1998), Benton et al. (2000) and Rauhut (2000) were reviewed, and all characters that were found to be variable within the ingroup were included, with modifications where necessary. Most modifications involved more precise definitions of character states where they had been previously defined using subjective terms such as 'broad', 'elongated' or 'reduced'. Ordered transformation series were split into discrete characters with binary coding so that all characters in the matrix could be treated as unordered. For example, the progressive enlargement of pedal ungual I is treated as two characters. All taxa where the first pedal ungual is as large as, or larger than, the second pedal ungual are coded as derived in the first of these characters (character 158). Only those in which the first pedal ungual exceeds the second in size are coded as derived in the second of the two characters (character 159). Several novel characters were also included, bringing the total to 164 characters (see Appendix 2).

\section{Results}

Analysis of the matrix using PAUP 4.0, with the branch-andbound search option, produced five most parsimonious trees (Tree Length $=351$, Consistency Index $=0.516$, Homoplasy Index $=0.527$, Retention Index $=0.668$ ). The basal topology of the strict consensus of these trees (Fig. 22) is fully resolved. The Saurischia is monophyletic, with Herrerasauridae and Neotheropoda forming serially closer outgroups to the Sauropodomorpha. The inclusion of Herrerasauridae in the Theropoda (all taxa more closely related to Neotheropoda than to Sauropodomorpha) is contradicted by the analysis. Within Sauropodomorpha, Saturnalia tupiniquim and 

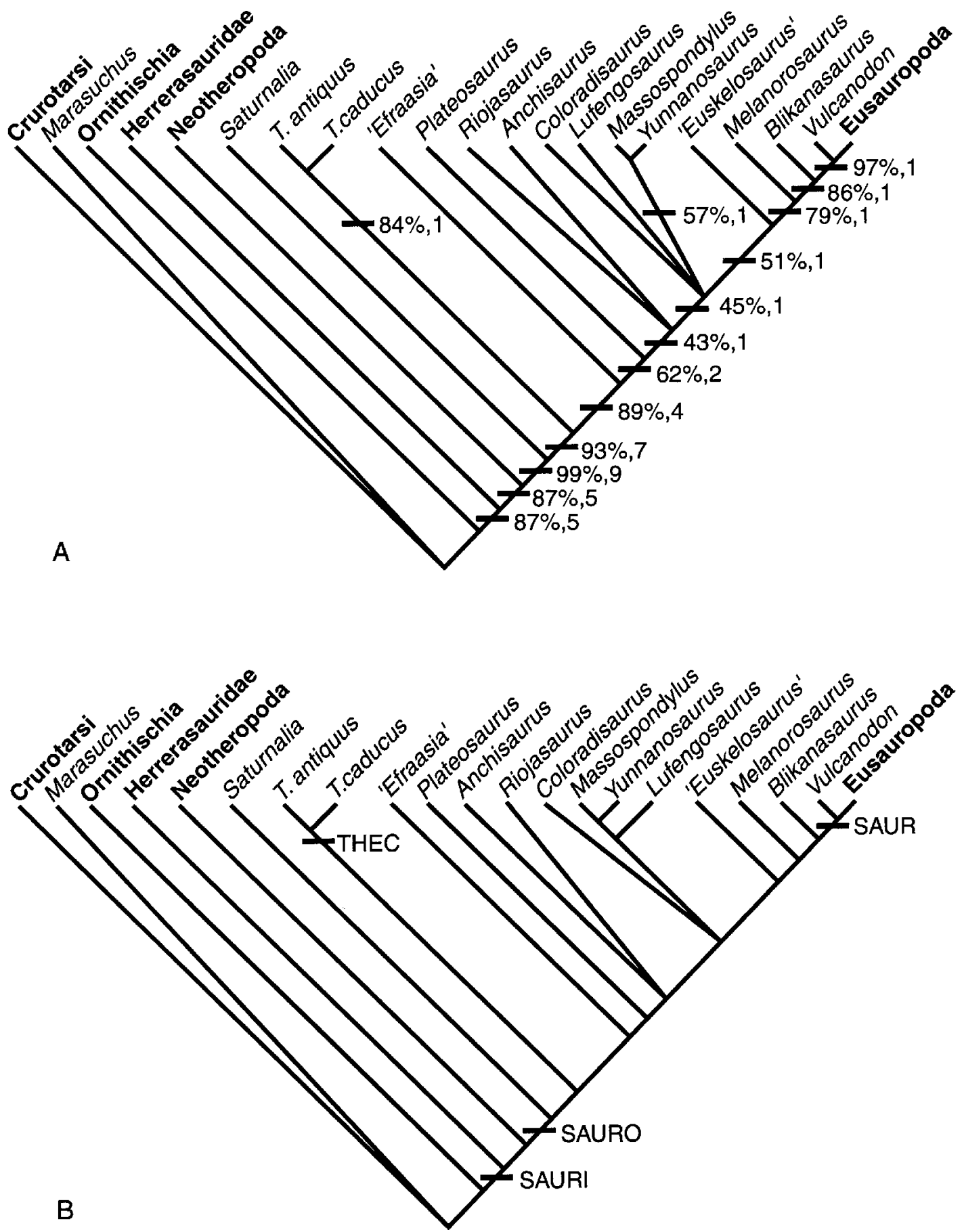

Figure 22 Phylogenetic relationships of early sauropodomorph dinosaurs. 22A, strict consensus of five most parsimonious trees with bootstrap frequency (left) and Bremer support (right) for each node. Each tree has a length of 351 steps, a Consistency Index of 0.516 , a Homoplasy Index of 0.527 and a Retention Index of o.668; 22B, Adams consensus of the five trees with various clades labelled. SAUR $=$ Sauropoda; SAURI = Saurischia; SAURO = Sauropodomorpha; THEC $=$ Thecodontosaurus.

Thecodontosaurus are basal to all other sauropodomorphs. The monophyly of the genus Thecodontosaurus is supported, albeit with a Bremer support of one. All sauropodomorphs more derived than Thecodontosaurus form a well-supported clade. Above this point all clades have a Bremer support of one and many have a bootstrap frequency below $50 \%$. 'Efraasia' and Plateosaurus form serial outgroups to a trichotomy involving Anchisaurus, Riojasaurus and a clade that contains all of the remaining sauropodomorphs. Within this clade, there is a basal polytomy consisting of Lufengosaurus, Coloradisaurus, Massospondylus + Yunnanosaurus and the near-sauropod sauropodomorphs. Within the latter clade, 'Euskelosaurus', Melanorosaurus and Blikanasaurus form serially closer outgroups to the Sauropoda (Vulcanodon + Eusauropoda).

A reduced cladistic consensus tree was produced (Fig. 23), using the method described by Wilkinson (1994). Only Coloradisaurus needed to be removed and this 


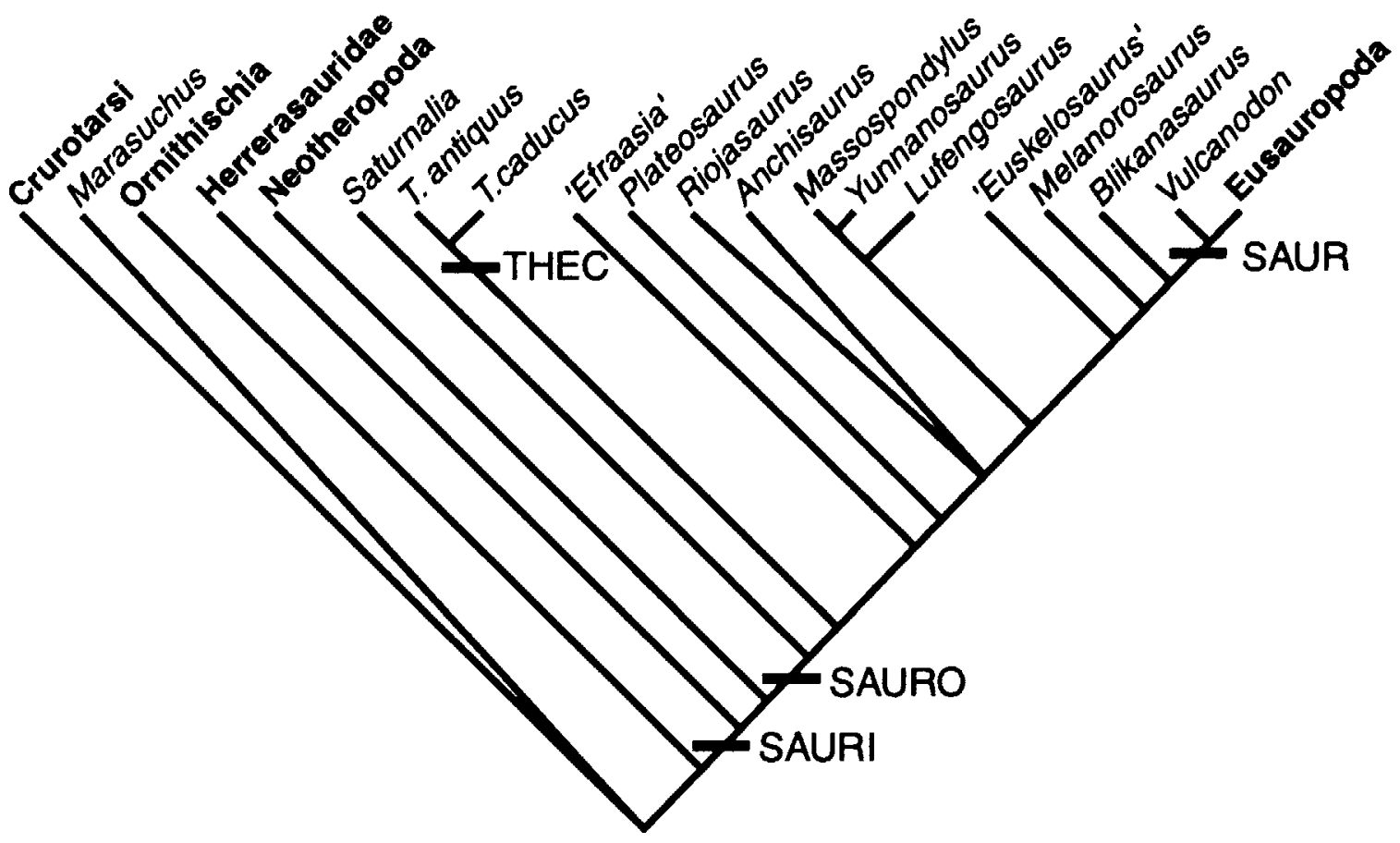

Figure 23 Reduced cladistic consensus of the five most parsimonious trees from Fig. 21. The unambiguous synapomorphies supporting each clade are given in Appendix 3. SAUR = Sauropoda; SAURI = Saurischia; SAURO = Sauropodomorpha; THEC = Thecodontosaurus

resulted in the resolution of Lufengosaurus as the sister group of Massospondylus + Yunnanosaurus. An examination of suboptimal trees one or two steps longer than the most parsimonious trees revealed that the low Bremer support values high up in the cladogram are the result of five unstable terminal taxa. These are: Riojasaurus, Anchisaurus, Coloradisaurus, Yunnanosaurus and 'Euskelosaurus'. Riojasaurus and Anchisaurus are particularly unstable, being able to fall anywhere on the Sauropod stem between Thecodontosaurus and Melanorosaurus with only minimal loss of parsimony. The instability of Coloradisaurus and 'Euskelosaurus' is due to our poor knowledge of these taxa, with only $27.5 \%$ and $29.3 \%$ of the characters being codable for each taxon, respectively. The other taxa are more completely known and their instability is a result of incongruence in character state distributions.

Analysis of a matrix, from which the unstable terminals have been deleted, results in a single most parsimonious tree (Tree Length $=309$, Consistency Index $=0.586$, Homoplasy Index $=0.463$, Retention Index $=0.690$ : Fig. 24). The topology of this tree is identical to that obtained when the unstable terminals are simply pruned from any of the original source trees. From this we can conclude that the unstable terminals exert no influence over the final topology and we can be confident that removing them does not produce an inaccurate result. The robustness of the nodes within this restricted analysis is remarkably good, with the exception of the Massospondylus + Lufengosaurus clade, which is not robust, having a Bremer support of one and a bootstrap frequency of less than $75 \%$.

It is significant that support for the paraphyly of early sauropodomorphs comes from two different sets of taxa, the basal taxa (Saturnalia and Thecodontosaurus) and the derived taxa ('Euskelosaurus', Melanorosaurus and Blikana- saurus). The first support paraphyly of the early sauropodomorphs by combining some of the putative synapomorphies of Prosauropoda with plesiomorphies that strongly indicate that the taxa are basal to the Plateosaurus-Sauropoda dichotomy. Hence these putative synapomorphies of Prosauropoda (e.g. inset first dentary tooth, strap-shaped ventral ramus of the squamosal, strongly asymmetrical distal condyles of metacarpal I and a strongly twisted first phalanx of manual digit I) become symplesiomorphies diagnostic of the more inclusive Sauropodomorpha. The second class of taxa shows the development of some derived characters shared with sauropods (e.g. tall dorsal neural spines, four sacral vertebrae, craniodistally compressed proximal caudal centra and a broad scapula blade) in otherwise 'prosauropod'-like animals.

If both these sets of taxa are deleted from the analysis a monophyletic Prosauropoda is found (three most parsimonious trees, Tree Length $=318$, Consistency Index $=$ 0.563 , Homoplasy Index $=0.481$, Retention Index $=0.660$ : Fig. 25). However, including just one terminal taxon from either group will cause the Prosauropoda to fragment into a paraphyletic array of basal sauropodomorphs on the sauropod stem.

When a monophyletic Prosauropoda (including Saturnalia, Thecodontosaurus antiquus, T. caducus, 'Efraasia', Plateosaurus, Anchisaurus, Riojasaurus, Coloradisaurus, Lufengosaurus, Massospondylus, Yunnanosaurus, 'Euskelosaurus', Melanorosaurus and Blikanasaurus) is placed as a constraint upon the complete matrix, the shortest trees that are recovered are 24 steps longer than the most parsimonious trees. Using a Templeton test this difference is found to be significant $(P=0.0082)$. Thus we can conclude that paraphyly of the 'prosauropods' is a significantly better explanation of the present data than is monophyly. 


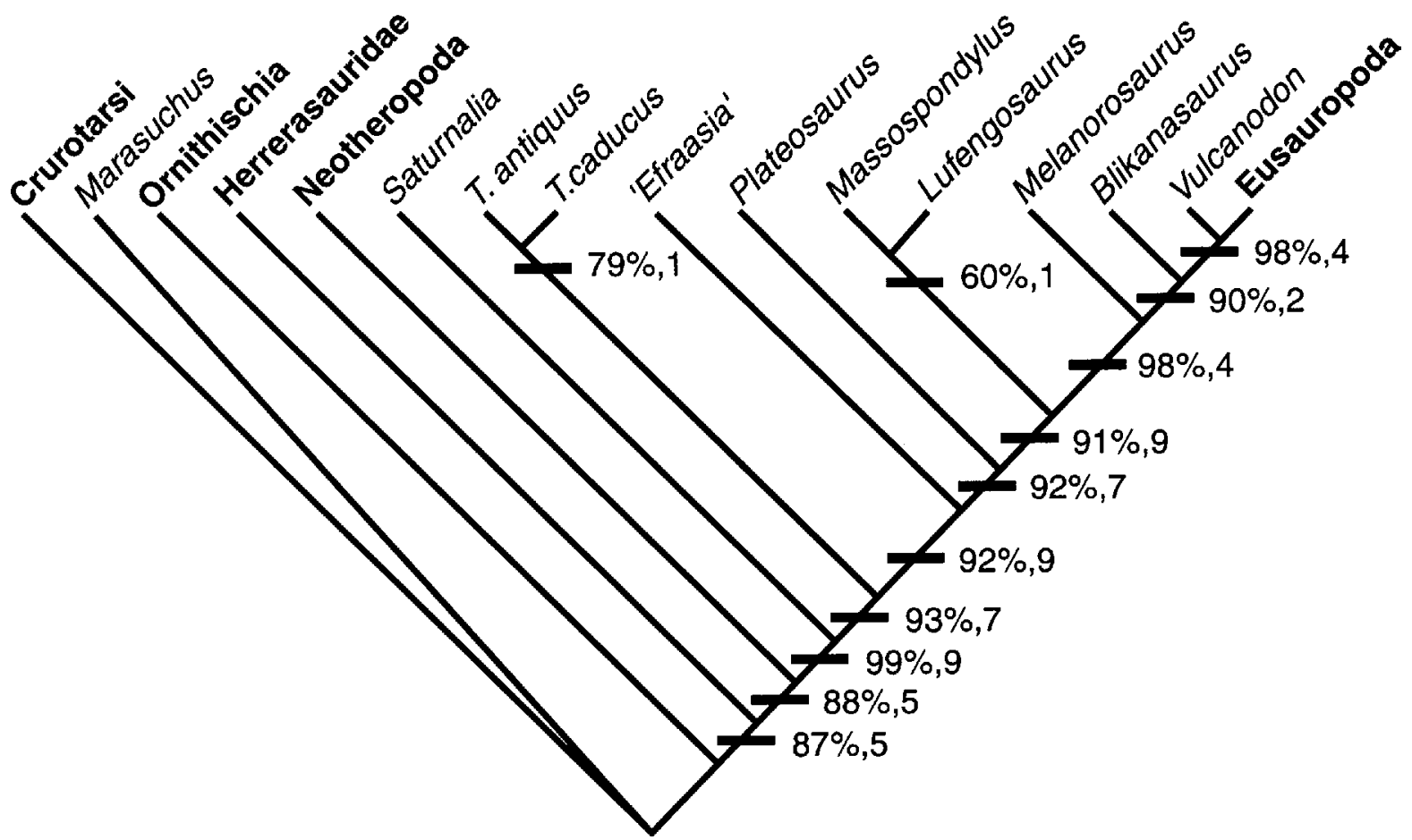

Figure 24 Single most parsimonious tree obtained from a restricted analysis that omits taxa that are unstable at short distances from the most parsimonious trees. Bootstrap frequency (left) and Bremer support (right) are given with each node. The tree has a length of 309 , a Consistency Index of 0.586, a Homoplasmy Index of 0.463 and a Retention Index of 0.690.

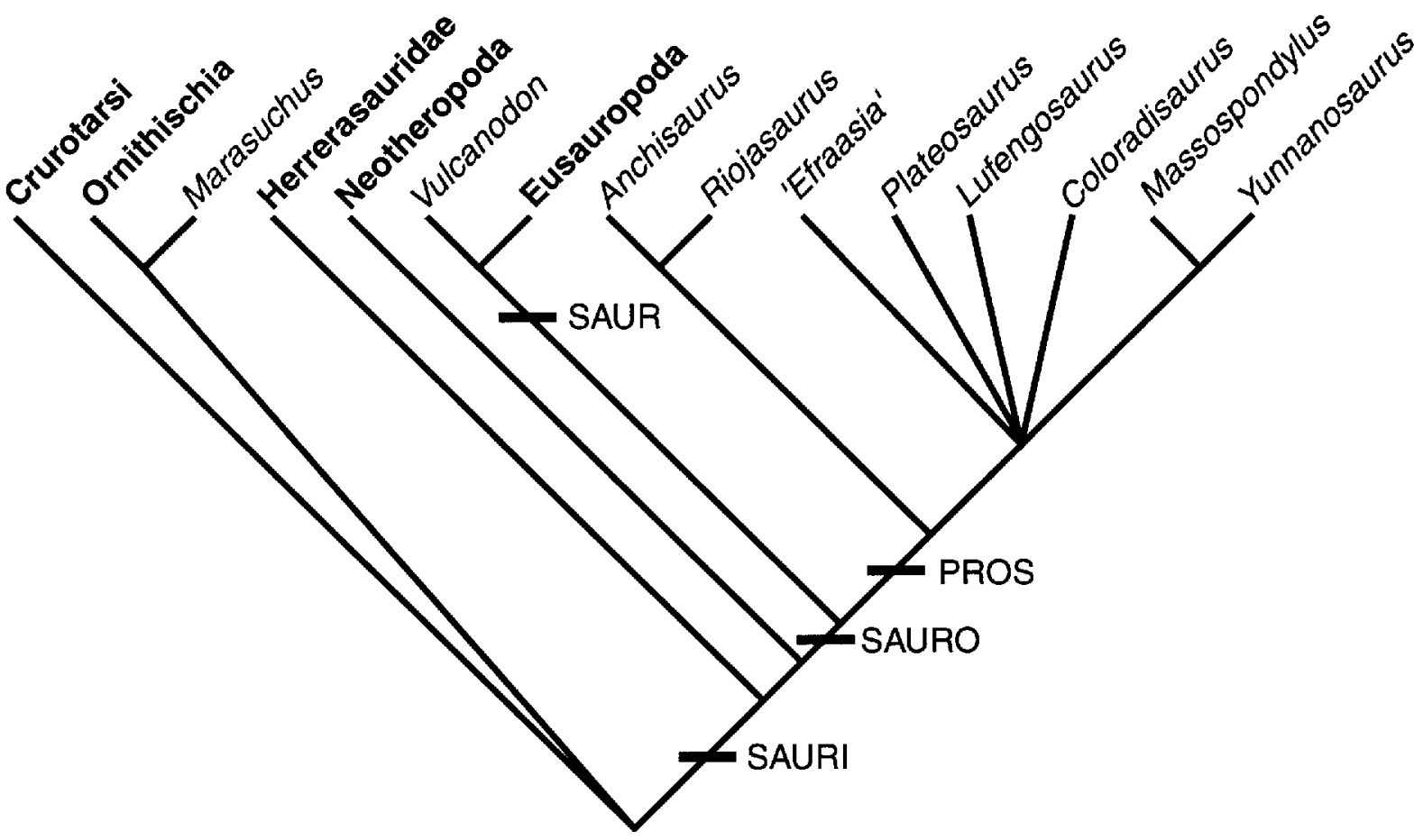

Figure 25 Strict consensus of three most parsimonious trees obtained when basal sauropodomorphs (Saturnalia and Thecodontosaurus) and near-sauropod sauropodomorphs ('Euskelosaurus', Melanorosaurus and Blikanasaurus) are excluded from the analysis. Each tree has a length of 318 steps, a Consistency Index of 0.563 , a Homoplasy Index of 0.481 and a Retention Index of 0.660 . SAUR = Sauropoda; SAURI = Saurischia; SAURO = Sauropodomorpha; PROS = Prosauropoda. 


\section{PROSAUROPOD MONOPHYLY}

Ever since von Huene (1920) named the Prosauropoda and placed it alongside the Sauropoda, within the Sauropodomorpha, people have recognised the similarity between the two groups. The almost mutually exclusive temporal distribution of the two groups strongly hints that the Prosauropoda might contain the ancestor of the Sauropoda and numerous authors have suggested that this is so (e.g. Romer 1956; Cooper 1981; Gauthier 1986). However, this hypothesis has never gained complete acceptance and several authors have objected to it (e.g. Charig et al. 1965; Cruickshank 1975; Van Heerden 1978, 1997; Galton 1990). The objections of Cruickshank, Van Heerden and Galton rest largely upon a single derived character possessed by prosauropods, a reduced fifth digit of the pes, which is deemed to be irreversible. Certainly the re-acquistion of a complicated structure once it has been lost (and the genes coding for its construction have been deleted or degraded) is extremely unlikely. This is demonstrated by the analysis of limb reduction amongst squamates where numerous independent clades evolve progressive limb reduction but do not move back towards the ancestral, limbed condition (Gans 1975). However, the re-enlargement of a structure that is still present, or still genetically coded for, is quite possible. The manual claws of the hoatzin (Parker 1891) and the large hallux contributing to the ankle joint of therizinosauroid coelurosaurs (Perle 1979; Barsbold \& Maryanska 1990; Russell \& Dong 1993) are two good examples of this phenomenon within the Dinosauria.

With the rise of cladistic methodologies in the field of dinosaur phylogenetics, more substantially supported hypotheses supporting the Prosauropoda as a monophyletic group exclusive of the Sauropoda, were proposed (Sereno 1999, Benton et al. 2000). Other authors (Gauffre 1995; Upchurch 1995) reported a similar result but the supporting evidence was not supplied. Importantly, neither of the former stud- ies found that a reduced fifth digit was diagnostic of the Prosauropoda. The atrophy of pedal digit V is, by itself, extraordinarily weak evidence for the monophyly of "prosauropods' with respect to Sauropoda. The four closest outgroups of the Sauropodomorpha (Marasuchus: Sereno \& Arcucci 1994; Ornithischia e.g. Hysilophodon foxi: Galton 1974; Herrerasauridae e.g. Herrerasaurus ischigualastensis: Novas 1993; Neotheropoda e.g. Dilophosaurus wetherilli: Welles 1984) all have a reduced fifth metatarsal that supports only one small phalanx if it supports any at all. Thus, this character is primitive for the Sauropodomorpha and those objections to the 'prosauropod' origins of the Sauropoda based upon this character alone need not be considered further. That leaves the recent cladistic analyses of Sereno (1999) and Benton et al. (2000) to be examined.

Benton et al. (2000) found only weak support for the Prosauropoda in their matrix $(51 \%$ bootstrap support in a reduced analysis). It also appears that one of the characters (character 13) that supports the Prosauropoda is incorrectly coded as plesiomorphic in the sauropod examples of their analysis. The derived state of character 13 , coarse marginal serrations of the teeth angled upwards at $45^{\circ}$ to the long axis of the tooth crown, is found in the teeth of sauropods. These include basal sauropods (e.g. Shunosaurus lii: Zhang 1988) and in those derived sauropods (e.g. Brachiosaurus brancai: Janensch 1935-36) that retain serrations. To examine the effect of this different interpretation, the matrix in Benton et al. (2000) was recoded so that Barapasaurus, Shunosaurus and Brachiosaurus had state 1 for character 13. The modified matrix was then analysed using PAUP 4.0 using the branchand-bound search algorithm. This produced 300 most parsimonious trees (Tree Length $=83$ steps, Consistency Index $=$ 0.651 , Homoplasy Index $=0.349$, Retention Index $=0.736$ : Fig. 26). The Prosauropoda collapses in the strict consensus tree with the base of the Sauropodomorpha as a polytomy including all of the 'prosauropods', Vulcanodon and Eusauropoda (Barapasaurus, Shunosaurus and

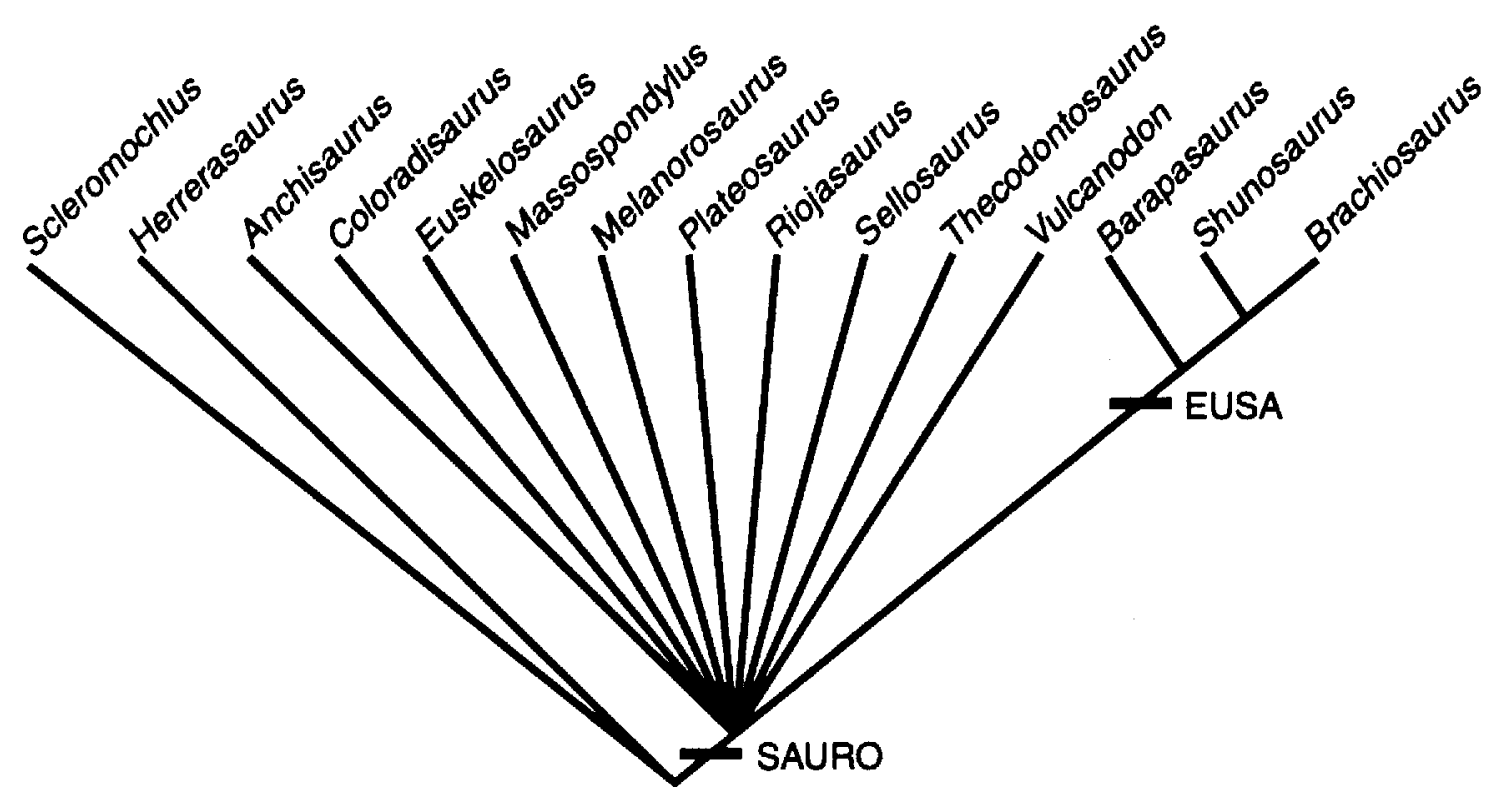

Figure 26 Strict consensus of 300 most parsimonious trees that are obtained when the matrix from Benton et al. (2000) is analysed after recoding one character. Each tree has a length of 83 steps, a Consistency Index of 0.651, a Homoplasy Index of 0.349 and a Retention Index of o.736. SAURO = Sauropodomorpha; EUSA = Eusauropoda. 


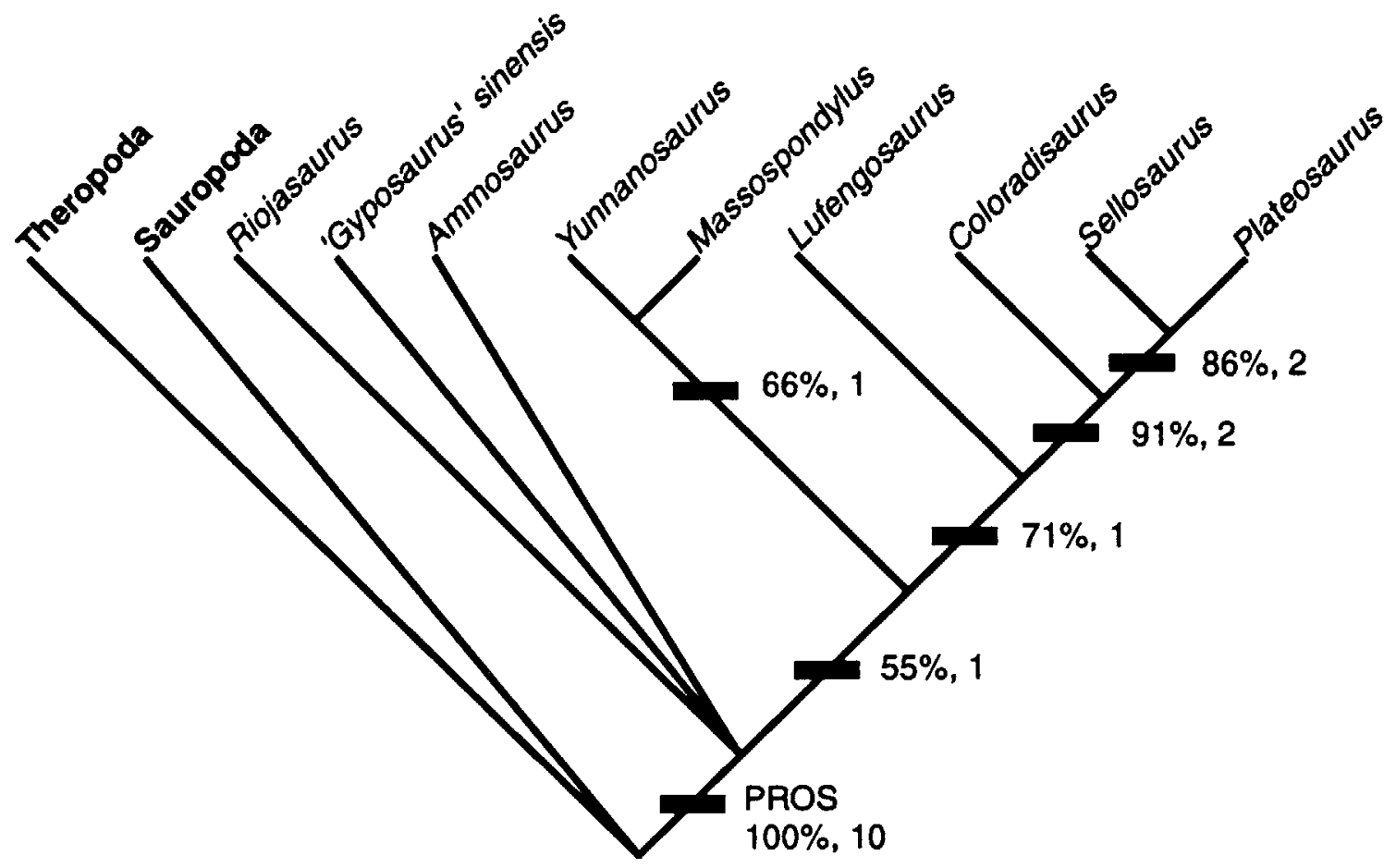

Figure 27 Strict consensus of 8 trees obtained after analysing the data matrix presented in Sereno (1999) with bootstrap support (left) and Bremer support (right) for each node. In this paper 'Gyposaurus' sinensis is regarded as a juvenile of Lufengosaurus, Anchisaurus is taken to be the senior synonym of Ammosaurus, and most of the specimens in the hypodigm of Sellosaurus are taken to belong to 'Efraasia'. Each tree has a length of 34 steps, a Consistency Index of 0.971, a Homoplasy Index of 0.029 and a Retention Index of 0.947.

Brachiosaurus). The fact that one recoding can collapse the Prosauropoda is indicative of the weakness of the support for that clade in this matrix.

Sereno (1999) presented a matrix of 32 characters and nine 'prosauropod' taxa plus two outgroup taxa, Sauropoda and Theropoda, as part of his overall investigation of dinosaur interrelationships. The analysis of this matrix was not presented, beyond a reduced cladogram containing the more stable prosauropod taxa. Analysis of this matrix using PAUP 4.0 produces seven most parsimonious trees (Tree Length $=$ 34 steps, Consistency Index $=0.971$, Homoplasy Index $=$ 0.029, Retention Index = 0.947: Fig. 27). The Prosauropoda is strongly supported with $100 \%$ bootstrap support (1000 replicates in the bootstrap analysis) and a Bremer support of 10. This is hardly suprising given that the matrix contains 19 characters that diagnose the Prosauropoda with virtually no homoplasy and no characters to suggest a conflicting arrangement. On the face of it, it would appear that Sereno has presented a very strong case for 'prosauropod' monophyly that is at odds with the present analysis. However, there are two main problems with this analysis. Firstly, no taxa from the two crucial groups (basal sauropodomorphs and nearsauropod sauropodomorphs) were included. As discussed above, taxa from these two groups provide important evidence regarding the relationships of basal sauropodomorphs. Secondly, many of the characters are not precisely defined or described and many of the codings are debatable. Each of them is examined in detail below.

1. Presence of a premaxillary beak. The snout of Riojasaurus incertus bears a pair of parasagittal ridges on the anterior surface of the premaxillae that define a raised anterior area and may have supported a rhamphotheca (Sereno 1997). Sereno (1997) claimed that a subtle version was also present in Plateosaurus, but most skulls of this taxon do not show the feature (pers. obs. of GPIT Skelett 1, SMNS 12950, HMN mb.1927.19.1). Only one snout from Frick, Switzerland, (Galton 1986: pl. 3, figs $2,3,4$ ) shows easily recognisable parasagittal ridges on the premaxilla. These, however, do not delimit a raised platform as they do in Riojasaurus incertus, instead they just mark the boundary between the rostrallyfacing and laterally-facing regions of the premaxillary body and they may well have been accentuated by lateral compression. No trace of any sort of ridges can be seen on the well-preserved premaxillae of Massospondylus carinatus and an unnamed taxon from the Kayenta Formation (pers. obs. of MCZ 8893), so this character does not stand up as a prosauropod synapomorphy.

2. L-shaped premaxilla-maxilla external suture. Most prosauropods have an external premaxilla-maxilla suture that is shaped like an ' $L$ ' lying horizontally. This shape is caused by the offset of the maxillary ascending ramus from the rostral end of the maxilla and a squareended rostral ramus. Both of these derived conditions are present in most sauropods (e.g. an unnamed basal sauropod from the Lufeng Formation: Barrett 1999; Patagosaurus fariasi: Bonaparte 1986; Brachiosaurus brancai, HMN M.B.2181) although the rostral ramus is shorter and higher than in most 'prosauropods'. The appearance of an L-shaped suture is less apparent in sauropods because the caudolateral process of the premaxilla is 
shortened relative to that of most 'prosauropods'. The character is best interpreted as a single derived character describing the shape of the rostral ramus of the maxilla that is diagnostic of the Sauropodomorpha as a whole.

3. Development of a secondary internal wall of the antorbital fossa. As in most other dinosaurs, the external antorbital fenestra of 'prosauropods' is larger than its internal counterpart (Witmer 1997). This results in a laterally open antorbital fossa that is bounded medially by an internal wall. Such an internal wall is present in all 'prosauropods', ornithischians, herrerasaurids, neotheropods and Marasuchus, so it is certainly primitive for the Dinosauria. Only sauropods lack the internal wall of the antorbital fossa and this must be regarded as a synapomorphy of the clade (Wilson \& Sereno 1998; Upchurch 1998). There is no evidence that the internal wall of 'prosauropods' is secondarily developed, so this character cannot be used as a prosauropod synapomorphy.

4. Regular maxillary vascular foramina with one large caudally directed foramen and five to six anteriorly directed foramina. Primitively dinosaurs have a row of small irregularly spaced neurovascular foramina placed above the ventral margin. At the caudal end of the row in 'prosauropods' (except Thecodontosaurus caducus, unknown in T. antiquus and Saturnalia tupiniquim) there is a distinctly enlarged foramen that exceeds all others in size. Rostrally there are no more than six smaller foramina. Thus the arrangement seen in 'prosauropods' would appear to be derived and would diagnose the group, above Thecodontosaurus. However, sauropods cannot be said to have the primitive condition. There is some variation but most seem to have an irregular group of 3-10 vascular foramina rostral to an enlarged foramen (e.g. Patagosaurus fariasi. Bonaparte 1986; Diplodocus longus: Witmer 1997; Camarasaurus lentus: Madsen et al. 1995). In neosauropods, the caudal foramen is exceptionally enlarged and has been termed the 'preantorbital fenestra' by Wilson \& Sereno (1998). Witmer (1997), Wilson \& Sereno (1998) and Upchurch (1998) have all considered that this fenestra is a pneumatic feature that was produced by outpocketing from, or subdivision of, the antorbital pneumatic sinus. However, an internal canal leads forward from the preantorbital fenestra of Brachiosaurus brancai (pers. obs. of HMN MB.2181) and probably connects with the anterior maxillary neurovascular foramina. Thus the preantorbital fenestra is likely to be of neurovascular origin, although it may have been enlarged by invasion of a pneumatic outpocket of the antorbital fenestra. There are no other neurovascular foramina behind the preantorbital fenestra, which suggests this feature and the enlarged caudal neurovascular foramen of prosauropods are homologous. Some basal sauropods (e.g. Shunosaurus lii: Zhang et al. 1988; Omeisaurus tianfuensis: He et al. 1988; Euhelopus zdanskyi: Wiman 1929), lack an enlarged caudal maxillary foramen. However, this is best interpreted as further evidence that they belong to a clade, the Euhelopodidae (Upchurch 1998), and that they do not represent the basal sauropod condition. In many respects, the arrangement of vascular foramina is quite similar between sauropods and 'prosauropods' and could be coded as a synapomorphy of the two. In any case, if the arrangement seen in 'prosauropods' is treated as a single derived character, the state for Sauropoda cannot be coded as primitive; therefore the character can only be interpreted as an ambiguous synapomorphy of the Prosauropoda, at best.

5. Strap-shaped ventral process of the squamosal. A long, narrow, parallel-sided ventral process of the squamosal (more than four times longer than the width at its midlength) with a pointed end would appear to unambiguously support the monophyly of Prosauropoda.

6. First dentary tooth inset from the anterior margin of the dentary. This character also appears to unambiguously support the monophyly of Prosauropoda.

7. Axial postzygapophyses flush with the caudal centrum face. Primitively in dinosaurs the postzygapophysis overhangs the caudal face of the centrum, so that at least $50 \%$ of the length of the zygapophyseal facet lies caudal to the line that subtends the dorsal and ventral edges of the caudal face of the centrum. Most sauropods, including the basal Patagosaurus fariasi (Bonaparte 1986), display the primitive condition. In contrast, many "prosauropods' (e.g. Plateosaurus engelhardti: von Huene 1926) have cranially-set postzygapophyses that barely overhang the caudal face of the centrum, if at all. Confusing the picture somewhat is the occurrence of the derived state in Euhelopodidae (e.g. Shunosaurus lii: Zhang 1988; Mamenchisaurus sinocanadorum: Russell \& Zheng 1993) and Haplocanthosaurus delfsi (McIntosh \& Williams 1988). More data from basal sauropods will be needed to be sure that the plesiomorphic state was ancestral for the group. If it is found that the derived state was basal for the Sauropoda this character may support the paraphyly of 'prosauropods' with respect to sauropods.

8. Deltopectoral crest more than $50 \%$ of the length of the humerus. The length of the deltopectoral crest of Marasuchus, ornithischians, herrerasaurids, neotheropods and sauropods is usually below $45 \%$ of the length of the humerus, and is certainly so in the basal members of each of these clades. In contrast, many 'prosauropods' have a deltopectoral crest that either approaches, or exceeds, $50 \%$ of the length of the humerus (e.g. Plateosaurus engelhardti: von Huene 1926). However, the deltopectoral crests of Saturnalia tupiniquim (pers. obs. of MCP 3844-PV), Thecodontosaurus antiquus (Benton et al. 2000), Anchisaurus polyzelus (Galton 1976) and 'Euskelosaurus browni' (Van Heerden 1979) are short. If Saturnalia and Thecodontosaurus are accepted as basal to all other 'prosauropods', then this character cannot diagnose the Prosauropoda, although it may diagnose a less inclusive clade within it.

9. Deltopectoral crest deflected $90^{\circ}$ from the transverse axis of the distal condyles. Since the angle of deflection of the deltopectoral crest from the transverse axis of the distal condyles increases with distance from the base of the crest, it is likely that this angle is correlated with the size of the deltopectoral crest (character 8 in this list). Since an extremely low deltopectoral crest is a synapomorphy of Sauropoda it is unlikely that it is possible for them to display a crest that is set at $90^{\circ}$ to the distal condyles even if that was the basal condition of the clade. Given these concerns and the sensitivity 
of the measurement to postmortem distortion by sediment compaction, I prefer not to use this character for phylogenetic analysis of dinosaurs.

10. Distal carpal I is large. Sereno did not specify what he meant by 'large' but when the distal carpal I of 'prosauropods' is compared with distal carpal II it can be seen that the transverse width of the former is at least $20 \%$ greater than that of the latter. Distal carpal proportions are unknown in non-dinosaurian dinosauromorphs, but distal carpal I is less than $10 \%$ wider than distal carpal II in Heterodontosaurus tucki (Santa Luca 1980), the only ornithischian with ossified distal carpals. Distal carpal I is actually smaller than distal carpal II in Herrerasaurus ischigualastensis (Sereno 1993). Thus, a small first distal carpal that is no more than $10 \%$ wider than distal carpal II is taken to be the primitive condition for the Dinosauria. The state of this character in neotheropods is difficult to determine because the two carpals are fused as an apparent synapomorphy of the clade. Nevertheless the fusion is reversed in Alxasaurus elesitaiensis (Russell \& Dong 1993) and possibly Allosaurus fragilis (Madsen 1976) and these show that distal carpal I was enlarged relative to distal carpal II. If the carpal elements of sauropods are distal carpals, which seems to be the most reasonable interpretation, then they also have an enlarged distal carpal I (e.g. Shunosaurus lii: Zhang 1988). Thus, the character is an ambiguous synapomorphy of Saurischia, or an unambiguous synapomorphy of Sauropodomorpha + Theropoda, exclusive of Herrerasauridae. In either case it does not support a monophyletic Prosauropoda.

11. Metacarpal I inset into the carpus. The derived character is a correlate of an extremely large distal carpal I that overlies distal carpal II. This arrangement creates a space in the carpus, under distal carpal I and medial to distal carpal II. This space is filled by an extension of metacarpal I into the carpus. Among 'prosauropods', Massospondylus carinatus (Cooper 1981), Plateosaurus engelhardti (pers. obs. of SMNS 13200), Lufengosaurus huenei (Young 1941a) and possibly 'Efraasia diagnostica' (pers. obs. of SMNS 12667) have the derived state. In other known 'prosauropod' hands (Thecodontosaurus antiquus: Benton et al. 2000; Riojasaurus incertus: Bonaparte 1972; Anchisaurus polyzelus: Galton 1976), the distal carpals do not overlap each other and the proximal end of the first metacarpal remains flush with the other metacarpals. This character could support a less inclusive clade within the 'prosauropods' but it does not support the monophyly of 'prosauropods'.

12. Proximal width of metacarpal I more than $65 \%$ of its maximum length. The proximal width of the first metacarpal of most ornithischians, herrerasaurids and most neotheropods is no more than $55 \%$ of its length. In contrast, Riojasaurus incertus, Anchisaurus polyzelus, 'Efraasia diagnostica', Plateosaurus engelhardti, Massospondylus carinatus, Lufengosaurus huenei and Yunnanosaurus huangi have stout first metacarpals in which the proximal width is greater than $65 \%$ of the length. Thecodontosaurus antiquus retains a primitively elongated first metacarpal (pers. obs. of BRSUG 23629). Neosauropods and their closest outgroups (e.g. Jobaria tiguidensis: Sereno et al. 1999) have elongate first metacarpals (proximal width less than $55 \%$ of the length).
However, the manus of these dinosaurs is highly modified to form an elongate, tubular, weight-supporting device consisting of a colonnade of structurally similar metacarpals. Thus, it is unclear whether neosauropods primitively retain the plesiomorphic state or whether it is secondarily derived. The only basal sauropods with well-preserved forefeet are those of euhelopodids, most of which have stout, 'prosauropod'-like first metacarpals (e.g. Hudiesaurus sinojapanorum: Dong 1997; Shunosaurus lii: Zhang 1988). Thus, the primitive condition for the Sauropoda is ambiguous. If we accept that the state for the Neosauropoda and its allies should be coded as uncertain due to transformation, we are left with accepting that stout metacarpals, present in euhelopodids, are basal for Sauropoda. In this case, the character becomes a synapomorphy of all sauropodomorphs more advanced than Thecodontosaurus.

13. Manual phalanx I of digit I with a proximal heel. The proximal articular surface of the first phalanx of the first digit of crurotarsans and ornithischians is a mildly concave structure of which the palmar lip does not protrude beyond the dorsal lip. This can be regarded as the ancestral condition for the Dinosauria. Sauropods also posses a relatively flat proximal articular surface without any marked protrusion of the palmar lip. In contrast, the palmar lip of herrerasaurids, neotheropods and 'prosauropods' protrudes further back than the dorsal lip. This protrusion, or heel, is especially large and asymmetrical in some of the larger derived 'prosauropods' (e.g. Plateosaurus engelhardti: von Huene 1926; Massospondylus carinatus: Cooper 1981). However, the ventral protrusion of other 'prosauropods' such as Thecodontosaurus antiquus and 'Efraasia diagnostica' is no greater than in Herrerasaurus ischigualastensis (Sereno 1993) or neotheropods such as Dilophosaurus wetherilli (Welles 1984) and Allosaurus fragilis (Madsen 1976). Given that the difference between a large and a small protrusion is slight, I prefer not to draw a distinction and simply regard the presence of the protrusion as a derived character that is probably diagnostic of the Saurischia.

14. First phalanx of manual digit I rotated at least $45^{\circ}$ ventrolaterally. This character apparently supports the monophyly of Prosauropoda. However the lack of twisting in the first phalanx of sauropods may be due to the modification of the hand into a weight-bearing structure, in which case the basal character state for Sauropoda would have to be coded as uncertain. If this is done this character becomes an apomorphy of Sauropodomorpha.

15. Subtriangular preacetabular process of the ilium. In basal dinosaurs (e.g. Herrerasaurus ischigualastensis: Novas 1993) and basal dinosauriforms (e.g. Marasuchus lilloensis: Sereno \& Arcucci 1994) the preacetabular process of the ilium is short and subrectangular in profile. In 'prosauropods' this process is drawn out into a cranially projecting subtriangular blade. The preacetabular process of basal sauropods (e.g. Shunosaurus lii: Zhang 1988; Barapasaurus tagorei: Jain et al. 1977) is not like those of primitive dinosauriforms. It, like the 'prosauropods', bears a pointed termination that projects cranially. They differ from those of 'prosauropods' in projecting well forward of the pubic peduncle and 
having a more strongly arched dorsal margin. However, these are derived characters that represent further modifications of the sauropod ilium. Even if one considers the preacetabular process of 'prosauropods' and sauropods to differ significantly, sauropods cannot be coded as having the primitive state. Thus, at best, this character offers ambiguous support for the monophyly of Prosauropoda, although it is here considered more likely to be a synapomorphy of Sauropodomorpha as a whole.

16. Preacetabular process of the ilium with a scar. The preacetabular process of the ilium of basal dinosauriforms, including basal saurischians, probably bore a cartilaginous extension upon its anterodorsal margin. A strip of rugose bone along the anterior dorsal rim of the ilium in these taxa almost certainly marks the site at which the cartilaginous 'cap' was attached. Such a scar of rugose bone can be seen in Marasuchus lilloensis (Sereno \& Arcucci 1994), Herrerasaurus ischigualastensis (Novas 1993), 'prosauropods' (e.g. 'Efraasia diagnostica': pers. obs. of SMNS 12354; Plateosaurus engelhardti. pers. obs. of GPIT Skelett 1; Massospondylus carinatus: Cooper 1981) and sauropods (e.g. Apatosaurus louisae: Gilmore 1936). Ornithischians and neotheropods appear to have independently lost the cartilaginous cap. The presence of a catilaginous cap and its associated scar in 'prosauropods' are primitive features and do not support monophyly of the group.

17. Distal ischial shaft with a subtriangular cross-section. Apart from 'prosauropods' a subtriangular cross-section of the distal ischial shaft can also be seen in nonmacronarian sauropods (e.g. Vulcanodon karibaensis: Cooper 1984; Dicraeosaurus hansemmani: Janensch 1961) and herrerasaurids (e.g. Herrerasaurus ischigualastensis: Novas 1993). Thus this character is best interpreted as a saurischian synapomorphy. The ovate cross-section of the distal ischial shaft of neotheropods represents a further modification and a synapomorphy of the group. It is interesting to note that the basal saurischian, Guiabasaurus, which has distal ischia with a triangular cross-section (Bonaparte et al. 1999), may be the plesiomorphic sister-group of the Neotheropoda (M. Langer, pers. comm. 2000).

18. Biconcave proximal articular surface of metatarsal II. The typical biconcave shape of the proximal articular surface of metatarsal II of most prosauropods is created by concave facets on either side for the reception of metatarsals I and III, respectively. A rectangular proximal articular surface, with flat contact surfaces on either side, is the basal dinosaur condition. This is seen in non-dinosaurian dinosauromorphs (e.g. Lagerpeton chanariensis: Sereno \& Arcucci 1993; Marasuchus lilloensis: Sereno \& Arcucci 1994) and in Herrerasaurus ischigualastensis (Novas 1993). Like prosauropods, ornithischians have a concave facet for metatarsal I (in those taxa in which metatarsal I is not lost e.g. Hypsilophodonfoxi: Galton 1974; Tenontosaurus tilletti: Forster 1990; Camptosaurus prestwichii: Galton \& Powell 1980). A concave facet for metatarsal III is present in non-iguanodontian ornithischians (e.g. Hypsilophodon foxi: Galton 1974; Stegosaurus armatus: Ostrom \& McIntosh, 1966). In neotheropods metatarsal I does not contact the ankle, so there is no facet for it on the medial side of the proximal end of metatarsal II. Furthermore the facet for metatarsal III is conspicuously convex. Thus neotheropods can be considered too transformed to be regarded as plesiomorphic for this character. Sauropods retain a flat contact with metatarsal III, while the contact with metatarsal I in basal forms is as concave as it is in any 'prosauropod'. Furthermore, there is ingroup variation with Plateosaurus engelhardti exhibiting a plesiomorphic straight contact with metatarsal III (pers. obs. of GPIT Skelett 1, HMN Skelett 45). These distributions suggest that the two contacts should be considered separately in a cladistic analysis. If this approach is taken, a concave facet on metatarsal II for metatarsal I is an ambiguous synapomorphy of Sauropodomorpha, while a concave facet for metatarsal III is an ambiguous synapomorphy of a monophyletic Prosauropoda.

19. Proximal articular surface of metatarsal IV three times broader than dorsoplantar depth. The methods by which these dimensions were measured were not specified. I measure the width as the distance between the medialmost point on the plantar surface to the lateral-most point of the bone and the depth as the maximum dimension orthogonal to this line. Using these measurements dinosaur outgroups and ornithischians are found to have rather squat proximal articular surfaces that are less than twice as wide as they are deep (e.g. 1.79 in Saurosuchus galilei: Sill 1974, table 5; 1.17 in Hypsilophodon foxi: Galton 1974). Eusauropods and neotheropods share similar proportions, whereas Herrerasaurus ischigualastensis (Novas 1993), prosauropods and Vulcanodon karibaensis (Cooper 1984) have proximally widened fourth metatarsals that are more than twice as wide as deep. Among sauropodomorphs, only Massospondylus carinatus reaches the proportion that Sereno regarded as derived (Cooper 1981). A proximal fourth metatarsal that is more than twice as wide as deep is a derived character that has an ambiguous distribution. Since the basal condition for the Sauropoda is ambiguous, the character cannot be used to support 'prosauropod' monophyly.

Thus we can see that of the 19 characters, only three (characters 5, 6 and 14) unambiguously support 'prosauropod' monophyly. Other characters cannot be coded for the immediate 'prosauropod' outgroups (sauropods or theropods) either due to polymorphism or morphological transformation (characters 4, 7, 12, 15, 18 and 19). Thus, these characters can only offer ambiguous support for the monophyly of Prosauropoda. Other characters seem to diagnose clades either less or more inclusive than the proposed Prosauropoda (characters 2, 8, 10, 11, 13, 16 and 17). The three remaining characters (1,3 and 9) are not deemed to be useful for phylogenetic analysis of basal sauropodomorph relationships.

In conclusion, the case for the monophyly of Prosauropoda is not strong and, when the data are incorporated in a more inclusive analysis, such as the one presented here, the Prosauropoda breaks into a paraphyletic array of basal sauropodomorphs. The paraphyly of 'prosauropods' not only solves the problem of the absence of sauropods from all but the latest Triassic (Buffetaut et al. 2000), but also suggests that an organism very like Plateosaurus or Massospondylus 
was directly ancestral to the largest terrestrial animals in Earth's history.

\section{ACKNOWLEDGEMENTS}

I thank Angela Milner and Sandra Chapman for the loan of the material used in this study. Simon Powell kindly assisted with the photography of the specimens. Mike Benton reviewed an earlier version of the paper. Max Langer provided excellent photographs of many of the South American and African taxa used in the phylogenetic analysis and lively discussions on the subject of early dinosaur evolution. I also wish to thank Rainer Schoch and Oliver Rauhut for their hospitality while visiting their respective institutions and Max Langer, Rupert Wild and David Unwin for allowing me to examine specimens in their care. This work was supported by the Leverhulme Trust (Grant No. F/182/BK).

\section{REFERENCES}

Barrett, P. M. 1999. A sauropod dinosaur from the Lower Lufeng Formation (Lower Jurassic) of Yunnan Province, Peoples's Republic of China. Journal of Vertebrate Paleontology 19: 785-787.

Barsbold, R. \& Maryanska, T. 1990. Segnosauria. Pp. 408-415 in Weishampel, D. B., Dodson, P. \& Osmolska, H. (eds) The Dinosauria University of California Press, Berkeley.

Benton, M. J. \& Spencer, P. S. 1995. Fossil reptiles of Great Britain. Chapman and Hall, London, 389 pp.

—, Juul, L., Storrs, G. W. \& Galton, P. M. 2000. Anatomy and systematics of the prosauropod dinosaur Thecodontosaurus antiquus from the Upper Triassic of Southwest England. Journal of Vertebrate Paleontology 20: 77-108

Bonaparte, J. F. 1972. Los tetrapodos del sector Superior de la Formacion Los Colorados, La Rioja, Argentina (Triásico Superior). I Parte. Opera Lilloana 22: 1-183.

- 1978. Coloradia brevis n. g. et n. sp. (Saurischia Prosauropoda), dinosaurio Plateosauridae de la Formacion Los Colorados, Triasico Superior de la Rioja, Argentina. Ameghiniana 15: 327-332.

- 1986. Les Dinosaures (Carnosaures, Allosauridés, Sauropodes, Cétiosauridés) du Jurassique moyen de Cerro Condor (Chubut, Argentine). Annales de Paléontologie 72: 325-386.

- \& Pumares, J. A. 1995. Notas sobre el primer craneo de Riojasaurus incertus (Dinosauria, Prosauropoda, Melanorosauridae) del Triasico Superior de La Rioja, Argentina. Ameghiniana 32: 341-349.

- \& Vince, M. 1979. El hallazgo del primer nido de dinosaurios Triasicos (Saurischia, Prosauropoda), Triasico Superior de Patagonia, Argentina. Ameghiniana 16: 173-182.

—, Ferigolog, J. \& Ribeiro, A. M. 1999. A new early Late Triassic saurischian dinosaur from Rio Grand do Sul State, Brazil. National Science Museum Monographs 15: 89-109.

Brochu, C. A. 1996. Closure of neurocentral sutures during crocodilian ontogeny: implications for maturity assessment in fossil archosaurs. Journal of Vertebrate Paleontology 16: 49-62.

Buffetaut, E., Suteethorn, V., Cuny, G., Tong, H., Loeuff, J. L., Khansubha, S. \& Jongautchariyakul, S. 2000. The earliest known sauropod dinosaur. Nature 407: 72-74.

Carr, T. D. 1999. Craniofacial ontogeny of Tyrannosauridae (Dinosauria, Coelurosauria). Journal of Vertebrate Paleontology 19: 497-520.

Charig, A. J., Attridge, J. \& Crompton, A. W. 1965. On the origin of the sauropods and the classification of the Saurischia. Proceedings of the Linnean Society of London 176: 197-220.

Chatterjee, S. 1978. A primitive parasuchid (phytosaur) reptile from the upper Triassic Maleri Formation of India. Palaeontology 21: 83-127.
Chiappe, L. M., Norell, M. A. \& Clark, J. M. 1996. Phylogenetic position of Mononykus (Aves: Alvarezsauridae) from the Late Cretaceous of the Gobi desert. Memoirs of the Queensland Museum 39: 557582.

Colbert, E. H. 1970. A saurischian dinosaur from the Triassic of Brazil. American Museum Novitates 2405: 1-39.

- 1989. The Triassic dinosaur, Coelophysis. Museum of Northern Arizona Bulletin 57: 1-160.

Cooper, M. R. 1981. The prosauropod dinosaur Massospondylus carinatus Owen from Zimbabwe: its biology, mode of life and phylogenetic significance. Occasional Papers of the National Museums and Monuments of Rhodesia B, Natural Sciences 6: 689-840.

- 1984. A reassessment of Vulcanodon karibaensis Raath (Dinosauria: Saurischia) and the origin of the Sauropoda. Palaeontologia Africana 25: 203-231.

Crompton, A. W. \& Attridge, J. 1986. Masticatory apparatus of the larger herbivores during Late Triassic and Early Jurassic times. Pp. 223-236 in Padian, K. (ed.) The beginning of the age of dinosaurs. Cambridge University Press, Cambridge.

Cruickshank, A. R. 1975. The origin of sauropod dinosaurs. South African Journal of Science 71: 89-90.

Currie, P. J. \& Zhao, X. J. 1993. A new carnosaur (Dinosauria, Theropoda) from the Jurassic of Xinjiang, People's Republic of China. Canadian Journal of Earth Sciences 30: 2037-2081.

Dodson, P. 1975. Taxonomic implications of relative growth in lambeosaurine hadrosaurs. Systematic Zoology 24: 37-54.

Dong, Z. 1997. A gigantic sauropod (Hudiesaurus sinojapanorum gen. et sp. nov.) from the Turpan Basin, China. Pp. 102-110 in Dong, Z. (ed.), Sino-Japanese Silk Road Dinosaur Expedition. China Ocean Press, Beijing.

Forster, C. A. 1990. The postcranial skeleton of the ornithopod dinosaur Tenontosaurus tilletti. Journal of Vertebrate Paleontology, Chicago 10: $273-294$.

Galton, P. M. 1973. On the anatomy and relationships of Efraasia diagnostica (V. Huene) n. gen., a prosauropod dinosaur (Reptilia: Saurischia) from the Upper Triassic of Germany. Paläontologische Zeitschrift 47: 229-255.

- 1974. The ornithischian dinosaur Hypsilophodon from the Wealden of the Isle of Wight. Bulletin of the British Museum (Natural History) Geology 25: 1-152.

- 1976. Prosauropod dinosaurs (Reptilia: Saurischia) of North America. Postilla 169: 2-98.

- 1984a. Cranial anatomy of the prosauropod dinosaur Plateosaurus from the Knollenmergel (Middle Keuper, Upper Triassic) of Germany. I. Two complete skulls from Trossingen/Württ. with comments on the diet. Geologica et Palaeontologica 18: 139-171.

- 1984b. An early prosauropod dinosaur from the upper Triassic of Nordwürttemberg, West Germany. Stuttgarter Beiträge zur Naturkunde, Serie B 106: 1-25.

- 1985a. Diet of prosauropod dinosaurs from the late Triassic and early Jurassic. Lethaia 18: 105-123.

- 1985b. Cranial anatomy of the prosauropod dinosaur Sellosaurus gracilis from the Middle Stubensandstein (Upper Triassic) of Nordwürttemberg, West Germany. Stuttgarter Beiträge zur Naturkunde, Serie B 116: 1-29.

- 1985c. Cranial anatomy of the prosauropod dinosaur Plateosaurus from the Knollenmergel (Middle Keuper, Upper Triassic) of Germany. II. All the cranial material and details of soft-part anatomy. Geologica et Palaeontologica 19: 119-159.

- 1986. Prosauropod dinosaur Plateosaurus (=Gresslyosaurus) (Saurischia: Sauropodomorpha) from the Upper Triassic of Switzerland. Geologica et Palaeontologica 20: 167-183.

- 1990. Basal Sauropodomorpha - Prosauropoda. Pp. 320-344 in Weishampel, D. B., Dodson, P. \& Osmolska, H. (eds) The Dinosauria. University of California Press, Berkeley.

- 1999. Sex, sacra and Sellosaurus gracilis (Saurischia, Sauropodomorpha, Upper Triassic, Germany) - or why the character " two sacral vertebrae", is plesiomorphic for Dinosauria. Neues Jahrbuch für Geologie und Paläontologie, Abhandlungen 213: 19-55. 
- 2000. The prosauropod dinosaur Plateosaurus Meyer, 1837 (Saurischia: Sauropodomorpha). 1. The syntypes of $P$. engelhardti Meyer, 1937 (Upper Triassic, Germany), with notes on other European prosauropods with "distally straight" femora. Neues Jahrbuch für Geologie und Paläontologie, Abhandlungen 216: 237-275.

- \& Bakker, R. T. 1985 . The cranial anatomy of the prosauropod dinosaur "Efraasia diagnostica", a juvenile individual of Sellosaurus gracilis from the Upper Triassic of Nordwürttemberg, West Germany. Stuttgarter Beiträge zur Naturkunde, Serie B 117: 1-15.

— \& Powell, H. P. 1980. The ornithischian dinosaur Camptosaurus prestwichii from the Upper Jurassic of England. Palaeontology 23: 411-443.

— \& Van Heerden, J. 1998. Anatomy of the prosauropod dinosaur Blikanasaurus cromptoni (Upper Triassic, South Africa), with notes on the other tetrapods from the lower Elliot Formation. Paläontologische Zeitschrift 72: 163-177.

Gans, C. 1975. Tetrapod limblessness: evolution and functional corollaries. American Zoologist 15: 455-467.

Gauffre, F.-X. 1995. Phylogeny of prosauropod dinosaurs. Journal of Vertebrate Paleontology 15 (supplement): 31A. (Abstract)

Gauthier, J. A. 1986. Saurischian monophyly and the origins of birds. Memoir of the Californian Academy of Sciences 8: 1-55.

Gilmore, C. W. 1920. Osteology of the carnivorous Dinosauria in the United States National Museum, with special reference to the genera Antrodemus (Allosaurus) and Ceratosaurus. Bulletin of the United States National Museum 110: 1-154.

- 1936. Osteology of Apatosaurus with special reference to specimens in the Carnegie Museum. Memoirs of the Carnegie Museum 11: 175300

Gow, C. E. 1990. Morphology and growth of the Massospondylus braincase (Dinosauria Prosauropoda). Palaeontologia Africana 35: 5975.

—, Kitching, J. W. \& Raath, M. A. 1990. Skulls of the prosauropod dinosaur Massospondylus carinatus Owen in the collections of the Bernard Price Institute for Palaeontological Research. Palaeontologia Africana 27: 45-58.

He, X-L., Li, C. \& Cai, K. J. 1988. The Middle Jurassic dinosaur fauna from Dashanpu, Zigong, Sichuan: sauropod dinosaurs (2) Omeisaurus tianfuensis. Sichuan Publishing House of Science and Technology, Chengdu, $143 \mathrm{pp}$.

Hitchcock, E. 1865. A supplement to the ichnology of New England. Wright and Potter, Boston, $96 \mathrm{pp}$

Hoepen, E. C. N., van 1920a. Contributions to the knowledge of the reptiles of the Karoo Formation. 5. A new dinosaur from the Stormberg Beds. Annals of Transvaal Museum 7: 77-92.

- 1920b. Contributions to the knowledge of the reptiles of the Karoo Formation. 6. Further dinosaurian material in the Transvaal Museum. Annals of Transvaal Museum 7: 93-140.

Huene, F., von 1920. Bemerkungen zur Systematik und Stammesgeschichte einiger Reptilien. Zeitschrift für Indukt. Abstammungslehre und Vererbungslehre 24: 162-166.

- 1926. Vollständige Osteologie eines Plateosauriden aus dem schwäbischen Keuper. Geologische und Paläontologische Abhandlungen. Neue Folge 15: 129-179.

- 1932. Die fossile Reptil-Ordnung Saurischia, ihre Entwicklung und Geschichte. Monographien zur Geologie und Paläontologie. Series 1 4: $1-361$.

Jain, S. L., Kutty, T. S., Roychowdhury, T. \& Chatterjee, S. 1979. Some characteristics of Barapasaurus tagorei, a sauropod dinosaur from the Lower Jurassic of Deccan, India. Proceedings of the IV International Gondwana Symposium 1: 204-216.

Janensch, W. 1935-36. Die Schädel der Sauropoden Brachiosaurus, Barosaurus und Dicraeosaurus aus den Tendaguruschichten Deutsch Ostafrikas. Palaeontographica (Supplement 7) 2: 147-298.

- 1961. Die Gleidmassen und Gleidmaszengürtel der Sauropoden der Tendaguru-Schichten. Palaeontographica (Supplement 7) 3: $177-$ 235

Kermack, D. 1984. New prosauropod material from South Wales. Zoological Journal of the Linnean Society of London 82: 101-117.
Langer, M. C., Abdala, F., Richter, M. \& Benton, M. J. 1999. A sauropodomorph dinosaur from the Upper Triassic (Carnian) of Southern Brazil. Comptes Rendus de l'Académie des Sciences, Paris, Sciences de la Terre et des Planètes 329: 511-517.

Madsen, J. H., Jr 1976. Allosaurus fragilis: a revised osteology. Utah Geological and Mineral Survey Bulletin 109: 1-163.

—, McIntosh, J. S. \& Berman, D. S. 1995. Skull and atlas-axis complex of the Upper Jurassic sauropod Camarasaurus Cope (Reptilia, Saurischia). Bulletin of the Carnegie Museum of Natural History 31: $1-115$.

Marsh, O. C. 1885. Names of extinct reptiles. American Journal of Science (series 3) 29: 169.

- 1891. Notice of new vertebrate fossils. American Journal of Science (series 3) 42: 265-269.

McIntosh, J. S. \& Williams, M. E. 1998. A new species of sauropod dinosaur, Haplocanthosaurus delfsi sp. nov., from the Upper Jurassic Morrison Fm. of Colorado. Kirtlandia 43: 3-26.

Meyer, H., von 1837. Mittheilungen, an Professor Bronn gerichtet (Plateosaurus engelhardti). Neues Jahrbuch für Geologie und Paläontologie, Abhandlungen 1837: 817.

Morris, J. 1843. A catalogue of British fossils. British Museum, London, $222 \mathrm{pp}$

Novas, F. E. 1993. New information on the systematics and postcranial skeleton of Herrerasaurus ischigualstensis (Theropoda: Hererrasauridae) from the Ischigualasto Formation (Upper Triassic) of Argentina. Journal of Vertebrate Paleontology 13: 400-423.

Ostrom, J. H. \& McIntosh, J. S. 1966. Marsh's dinosaurs: the collections from Como Bluff. Yale University Press, New Haven, 388 pp.

Parker, W. K. 1891. On the morphology of a reptilian bird Opisthocomus cristatus. Transactions of the Zoological Society of London 13: 43-85.

Perle, A. 1979. Segnosauridae - a new family of theropods from the Late Cretaceous of Mongolia. Transactions of the Soviet-Mongolian Palaeontological Expedition 8: 45-55. [In Russian].

Raath, M. A. 1972. Fossil vertebrate studies in Rhodesia: a new dinosaur (Reptilia: Saurischia) from near the Triassic-Jurassic boundary. Arnoldia 5: 1-37.

Rauhut, O. W. M. 2000. The Interrelationships and Evolution of Basal Theropods (Dinosauria, Saurischia). Unpublished $\mathrm{PhD}$ thesis. University of Bristol, Bristol, UK.

Riley, H. \& Stutchbury, S. 1836. A description of various fossil remains of three distinct saurian animals discovered in the autumn of 1834, in the Magnesian Conglomerate on Durdham Down, near Bristol. Proceedings of the Geological Society of London 2: 397-399.

Romer, A. S. 1956. Osteology of the reptiles. University of Chicago Press, Chicago, $772 \mathrm{pp}$

Russell, D. A. \& Dong, Z. 1993. The affinities of a new theropod from the Alxa Desert, Inner Mongolia, People's Republic of China. Canadian Journal of Earth Sciences 30: 2107-2127.

- \& Zheng, Z. 1993. A large mamenchisaurid from the Junggar Basin, Xinjiang, People's Republic of China. Canadian Journal of Earth Sciences 30: 2082-2095.

Santa Luca, A. P. 1980. The postcranial skeleton of Heterodontosaurus tucki from the Stormberg of Southern Africa. Annals of the South African Museum 79: 159-211.

Seeley, H. G. 1888. On the classification of the fossil animals commonly named Dinosauria. Proceedings of the Royal Society of London 43 $165-171$.

Sereno, P. C. 1986. Phylogeny of the bird-hipped dinosaurs (Order Ornithischia). National Geographic Society Research 2 234-256.

- 1991a. Lesothosaurus, "fabrosaurids," and the early evolution of Ornithischia. Journal of Vertebrate Paleontology 11: 168-197.

- 1991b. Basal archosaurs: phylogenetic relationships and functional implications. Society of Vertebrate Paleontology Memoir 2: 1-53. [Supplement to Journal of Vertebrate Paleontology 11 (4).]

- 1993. The pectoral girdle and forelimb of the basal theropod Herrerasaurus ischigualastensis. Journal of Vertebrate Paleontology $\mathbf{1 3}$ $425-450$. 
- 1997. The origin and evolution of dinosaurs. Annual Review of Earth and Planetary Sciences 25: 435-489.

- 1999. The evolution of dinosaurs. Science 284: 2137-2147.

- \& Arcucci, A. B. 1993. Dinosaurian precursors from the Middle Triassic of Argentina: Lagerpeton chanarensis. Journal of Vertebrate Paleontology 13: 385-399.

- $\&$ - 1994. Dinosaurian precursors from the Middle Triassic of Argentina: Marasuchus lilloensis, gen. nov, Journal of Vertebrate Paleonto$\operatorname{logy}$ 14: 53-73.

- \& Novas, F. E. 1993. The skull and neck of the basal theropod Herrerasaurus ischigualastensis. Journal of Vertebrate Paleontology 13: 451-476.

—, Beck, A. L., Dutheil, D. B., Larsson, H. C. E., Lyon, G. H., Moussa, B., Sadlier, R. W., Sidor, C. A., Varricchio, D. J., Wilson, G. P. \& Wilson, J. A. 1999. Cretaceous sauropods from the Sahara and the uneven rate of skeletal evolution among dinosaurs. Science $\mathbf{2 8 6}$ 1342-1347.

—, Forster, C. A., Rogers, R. R. \& Monetta, A. M. 1993. Primitive dinosaur skeleton from Argentina and the early evolution of Dinosauria. Nature 361: 64-66.

—, Wilson, J. A., Larsson, H. C. E., Dutheil, D. B. \& Sues, H.-D. 1994. Early Cretaceous dinosaurs from the Sahara. Science 265: 267271.

Sill, W. D. 1974. The anatomy of Saurosuchus galilei and the relationships of the rauisuchid thecodonts. Bulletin of the Museum of Comparative Zoology 146: 317-362.

Thulborn, R. A. 1972. The post-cranial skeleton of the Triassic ornithischian dinosaur Fabrosaurus australis. Palaeontology 15: 29-60.

Upchurch, P. 1995. The evolutionary history of sauropod dinosaurs. Philosophical Transactions of the Royal Society of London B 349: 365-390.

- 1997. Prosauropoda. Pp. 599-606 in Currie, P. J. \& Padian, K. (eds) Encyclopaedia of Dinosaurs. Academic Press, San Diego.

- 1998. The phylogenetic relationships of sauropod dinosaurs. Zoological Journal of the Linnean Society 124: 43-103.

Van Heerden, J. 1978. Herrerasaurus and the origin of sauropod dinosaurs. South African Journal of Science 74: 187-189.

- 1979. The morphology and taxonomy of Euskelosaurus (Reptilia: Saurischia; Late Triassic) from South Africa. Navorsinge van die Nasionale Museum 4: 21-84.

- 1997. Prosauropods. Pp. 242-263 in Farlow, J. O. \& Brett-Surman, M. K. (eds) The Complete Dinosaur. Indiana University Press, Bloomington.
— \& Galton, P. M. 1997. The affinities of Melanorosaurus - a Late Triassic prosauropod dinosaur from South Africa. Neues Jahrbuch für Geologie und Paläontologie, Monatsheft 1997: 39-55.

Walker, A. D. 1964. Triassic reptiles from the Elgin area: Ornithosuchus and the origin of carnosaurs. Philosophical Transactions of the Royal Society of London B 248: 53-135.

Welles, S. P. 1984. Dilophosaurus wetherilli (Dinosauria, Theropoda): osteology and comparisons. Palaeontographica, Abt. A $\mathbf{1 8 5}$ : $85-180$.

Weishampel, D. B. \& Witmer, L. M. 1990. Heterodontosauridae. Pp. 320-344 in Weishampel, D. B., Dodson, P. \& Osmólska, H. (eds) The Dinosauria. University of California Press, Berkeley.

Whiteside, D. I. 1983. A Fissure Fauna from Avon. Unpublished Ph.D. thesis. University of Bristol, Bristol, UK.

Wilkinson, M. 1994. Common cladistic information and its consensus representation: reduced Adams and cladistic consensus trees and profiles. Systematic Biology 43: 343-368.

Wilson, J. A. 1999. A nomenclature for vertebral laminae in sauropods and other saurischian dinosaurs. Journal of Vertebrate Paleontology 19: 639-653.

- \& Sereno, P. C. 1998. Early evolution and higher-level phylogeny of sauropod dinosaurs. Society of Vertebrate Paleontology Memoir 5: 1-68. [Supplement to Journal of Vertebrate Paleontology. 18 (2)].

Wiman C. 1929. Die Kreide-Dinosaurier aus Shantung. Palaeontologia Sinica, Series C 6: 1-67.

Witmer, L. M. 1997. The evolution of the antorbital cavity of archosaurs: a study in soft-tissue reconstruction in the fossil record with an analysis of the function of pneumaticity. Journal of Vertebrate Paleontology Memoir 3: 1-73. [Supplement to Journal of Vertebrate Paleontology 17 (1).]

Young, C. C. 1941a. A complete osteology of Lufengosaurus huenei Young (gen. et sp. nov.) from Lufeng, Yunnan, China. Palaeontologia Sinica (Series C) 7: 1-53.

- 1941b. Gyposaurus sinensis Young (sp. nov.) a new Prosauropoda from the Upper Triassic beds at Lufeng, Yunnan. Bulletin of the Geological Society of China 21: 205-253.

- 1942. Yunnanosaurus huangii Young (gen. et sp. nov), a new Prosauropoda from the red beds at Lufeng, Yunnan. Bulletin of the Geological Society of China 22: 63-105.

Zhang, Y. 1988. The Middle Jurassic dinosaur fauna from Dashanpu, Zigong, Sichuan: sauropod dinosaurs (1) Shunosaurus. Sichuan Publishing House of Science and Technology, Chengdu, 89 pp.

\section{APPENDIX 1: LIST OF ANATOMICAL ABBREVIATIONS}

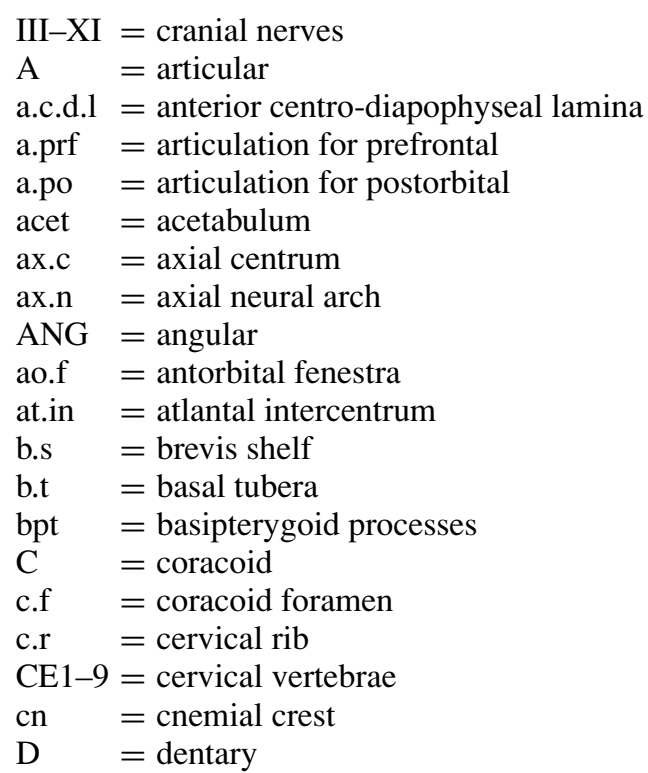

d.c $=$ distal caudal vertebra

d.i.e = distal ischial expansion

d.poz.l = diapo-postzygapohyseal lamina

d.prz.l = diapo-prezygapophyseal lamina

d.l.s $=$ dorsal lateral sulcus

$\mathrm{dp} \quad=$ diapophysis

dp.c = deltopectoral crest

e.m.f. $=$ external mandibular fenestra

ECT = ectopterygoid

en.c = endocranial cavity

ep = epipophysis

EX-OP = exoccipital-opisthotic complex

ext.n = external naris

$\mathrm{F} \quad=$ frontal

$\mathrm{f}$ ? = unidentified foramen

f.ov $=$ fenestra ovalis

f.tr $=$ fourth trochanter

$\mathrm{FE} \quad=$ femur

fib.con = fibular condyle

fib.t = fibular trochlea 


$$
\begin{array}{ll}
\mathrm{gl} & =\text { glenoid } \\
\mathrm{H} & =\text { humerus } \\
\mathrm{h} & =\text { head } \\
\mathrm{hs} & =\text { hyposphene } \\
\mathrm{hy} & =\text { hypantrum } \\
\text { is.ped } & =\text { ischiadic peduncle } \\
\mathrm{J} & =\text { jugal } \\
\mathrm{j} . \mathrm{p} & =\text { jugal process } \\
\mathrm{k} & =\text { keel } \\
\mathrm{L} & =\text { lacrimal } \\
\text { l.(x) } & =\text { left (bone name) } \\
\text { l.f } & =\text { lacrimal foramen } \\
\text { l.t.f } & =\text { lateral temporal fenestra } \\
\text { med.r } & =\text { median ridge } \\
\text { mtI-V } & =\text { metatarsals } \\
\mathrm{MX} & =\text { maxilla } \\
\mathrm{N} & =\text { nasal } \\
\text { n.s } & =\text { neural spine } \\
\text { nc.s } & =\text { neurocentral suture } \\
\text { ne } & =\text { neurapophysis } \\
\text { nv.c } & =\text { neurovascular canal } \\
\text { nv.f } & =\text { neurovascular foramen } \\
\text { o } & =\text { orbit } \\
\text { o.p } & =\text { obturator plate } \\
\text { o.c } & =\text { occipital condyle } \\
\text { od } & =\text { odontoid } \\
\text { ot.c } & =\text { otic capsule } \\
\mathrm{P} & =\text { parietal } \\
\text { p.c.d.l } & =\text { posterior centro-diapophyseal lamina } \\
\text { p.f } & =\text { popliteal fossa } \\
\text { p.ped } & =\text { pubic peduncle } \\
\text { p.r } & =\text { parasphenoid rostrum } \\
&
\end{array}
$$

$$
\begin{array}{ll}
\text { PA } & =\text { palatine } \\
\text { pa.p } & =\text { preacetabular process } \\
\text { par.p } & =\text { paroccipital process } \\
\text { pl.g } & =\text { perilymphatic groove } \\
\text { PMX } & =\text { premaxilla } \\
\text { PO } & =\text { postorbital } \\
\text { po.p } & =\text { postacetabular process } \\
\text { poz } & =\text { postzygapophysis } \\
\text { pp } & =\text { parapophysis } \\
\text { pr.p } & =\text { preacetabular process } \\
\text { PRF } & =\text { prefrontal } \\
\text { PRO } & =\text { prootic } \\
\text { prz } & =\text { prezygapophysis } \\
\text { PS-BS } & =\text { parasphenoid-basisphenoid complex } \\
\text { PT } & =\text { pterygoid } \\
\text { Q } & =\text { quadrate } \\
\text { QJ } & =\text { quadratojugal } \\
\text { r } & =\text { rib } \\
\text { r. }(x) & =\text { right (bone name) } \\
\text { SA } & =\text { surangular } \\
\text { SO } & =\text { supraoccipital } \\
\text { SQ } & =\text { squamosal } \\
\text { st.f } & =\text { supratemporal fossa } \\
\text { su.a } & =\text { supra-acetabular crest } \\
\text { sym } & =\text { symphyseal facet } \\
\text { t } & =\text { tubercle } \\
\text { tf.c } & =\text { tibiofibular crest } \\
\text { tib.con } & =\text { tibial condyle } \\
\text { u.t.f } & =\text { upper temporal fenestra } \\
\text { un } & =\text { ungual } \\
\text { v.f } & =\text { ventral fossa } \\
&
\end{array}
$$

\section{APPENDIX 2: LIST OF CHARACTERS}

1. Skull length exceeds $50 \%$ of the length of the femur $=$ 0 . Skull length is less than $50 \%$ of the length of the femur $=1$ (Benton et al. 2000).

2. Dorsal process of the premaxilla parallel-sided or distally tapered $=0$. Dorsal process is expanded transversely at its distal end $=1$ (Sereno 1999).

3. Premaxilla and nasal form a suture below the external naris $=0$. Premaxilla-nasal in point contact, or not in contact at all, suture absent $=1$ (Gauthier 1986).

4. Premaxilla and nasal in contact below the naris, or almost so, allowing no more than a point contribution from the maxilla to the external narial margin $=0$. Premaxilla and nasal widely separated below the naris, allowing the maxilla to contribute broadly to the narial margin $=1$ (Benton et al. 2000).

5. Maximum diameter of the external naris is less than $50 \%$ of the maximum orbital diameter $=0$. Maximum narial diameter greater than $70 \%$ of the maximum orbital diameter $=1$ (Galton 1990).

6. Rostrocaudal length of antorbital fossa exceeds that of the orbit $=0$. Rostrocaudal length of the antorbital fossa is less than that of the orbit $=1$.

7. Subnarial foramen small (no bigger than the maxillary and premaxillary vascular foramina) with the internal opening just above the tooth row, or absent altogether $=$ 0 . Large subnarial foramen (distinctly larger than the maxillary and premaxillary vascular foramina) on the premaxilla-maxilla suture that opens into the palate, well above the tooth row $=1$ (modified from Sereno \& Novas 1993).

8. Rostral margin of the ascending ramus of the maxilla forms a gently sloping surface that is confluent with the rostral margin of the maxillary body $=$ 0 . Ascending ramus of the maxilla is displaced caudally so that a discrete rostral ramus of the maxilla is formed $=1$ (Rauhut 2000).

9. Rostral ramus of the maxilla is short (dorsoventral height exceeds rostrocaudal length) or absent $=0$. Rostral ramus of the maxilla is elongate (rostrocaudal length exceeds dorsoventral height) $=1$ (Sereno et al. 1994).

10. Caudal-most maxillary vascular foramen is the same size, or smaller than, all other maxillary vascular foramina $=0$. Caudal-most maxillary vascular foramen is larger than all other maxillary vascular foramina $=$ 1.

11. Rostral, medial wall of the antorbital fossa is a narrow and cresentic sheet of the maxilla, with a deeply emarginate caudal margin $=0$. Rostral, medial wall of the antorbital fossa is a broad sheet of the maxilla with an almost straight medial margin $=1$ (Galton 1985b). 
12. Medial wall of the antorbital fossa extends for the full length of the maxilla to form a narrow medial caudal ventral wall of the antorbital fossa $=0$. Medial wall of the antorbital fossa terminates about half way along the length of the caudal ramus of the maxilla so that there is no caudal ventral wall of the antorbital fossa $=$ 1 (Sereno 1999).

13. Neurovascular bundle entering the maxilla through a foramen on the medial or dorsal margin of the maxilla $=0$. Neurovascular bundle entering the maxilla after passing through a dorsally open canal on the caudal floor of the antorbital fossa $=1$.

14. Nasal excluded from the antorbital fossa by an external dorsal contact between the lacrimal and the maxilla $=$ 0 . Nasal contributes to the dorsal margin of the antorbital fossa $=1$ (Sereno 1999).

15. Caudal margin of the conjoined nasals is concave or 'W'-shaped in dorsal view $=0$. Caudal margin of the conjoined nasals is convex in dorsal view $=1$.

16. Lateral margin of the nasal without a posterolateral process $=0$. A caudally projecting, posterolateral process of the nasal overlaps the lacrimal $=1$.

17. Block-shaped or triangular, rostrodorsally sloping lacrimal, with a short ventral ramus $=0$. Tall, erect lacrimal shaped like an inverted ' $L$ ' with an elongate ventral ramus $=1$ (Rauhut 2000).

18. Lacrimal only exposed on the lateral side of the skull $=$ 0 . Lacrimal exposed on the dorsal skull roof $=1$ (Gauthier 1986).

19. Long rostral ramus of the lacrimal forming the dorsal border of a rhomboidal antorbital fossa $=0$. Short to absent rostral ramus of the lacrimal with a triangular antorbital fossa $=1$.

20. Length of the prefrontal is much less than the rostrocaudal diameter of the orbit $=0$. Caudal process of prefrontal is enlarged so that the length of the prefrontal is equal to the rostrocaudal diameter of the orbit $=$ 1 (modified from Galton 1990).

21. Jugal contributes to the caudal ventral margin of the antorbital fenestra $=0$. Jugal excluded from the antorbital fenestra by a lacrimal-maxilla contact $=1$ (modified from Rauhut 2000).

22. Rostral dorsal process of the jugal contributes to the anterior orbital margin $=0$. Rostral end of the jugal without a dorsal process contributing to the anterior orbital margin $=1$.

23. Lower temporal fenestra lies completely behind the orbit $=0$. Lower temporal fenestra partly underlies the orbit $=1$ (Upchurch 1995).

24. Length of quadratojugal ramus of the squamosal is less than four times the rostrocaudal width of the midshaft of the ramus $=0$. Length of the quadratojugal ramus is more than four times the rostrocaudal width of the midshaft $=1$ (modified from Sereno 1999).

25. Angle between the jugal and squamosal rami of the quadratojugal is close to $90^{\circ}=0$. Jugal and squamosal rami of the quadratojugal lie subparallel to each other or are set at an acute angle (less than $\left.45^{\circ}\right)=1$.

26. Quadrate foramen is an elliptical foramen on the quadrate-quadratojugal suture $=0$. Quadrate foramen is deeply incised into, and at least partly enclosed by, the quadrate $=1$ (modified from Rauhut 2000).
27. Pterygoid flange of the quadrate occupies more than $70 \%$ of the length of the quadrate $=0$. Pterygoid flange of the quadrate occupies less than $70 \%$ of the length of the quadrate $=1$.

28. Jugal process of the ectopterygoid projects laterally, with only a weak caudal curvature $=0$. Jugal process of the ectopterygoid strongly curved caudally, producing a hook-like structure $=1$.

29. Ventral side of the main body of the ectopterygoid is a simple planar or gently concave surface $=0$. Ventral surface of the ectopterygoid bears a deep, sharp-edged and medially open fossa $=1$ (Gauthier 1986).

30. Basipterygoid process articulates to the dorsal surface of the pterygoid, near its medial edge, adjacent to the base of the quadrate ramus $=0$. Basipterygoid process fits in a notch, developed on the caudal margin of the pterygoid with a medial pterygoid process wrapping around the anterior and medial surfaces of the basipterygoid process $=1$ (modified from Wilson \& Sereno 1998).

31. Parasphenoid rostrum is a laterally compressed, bladelike structure that is much deeper than it is wide $=0$. Parasphenoid rostrum is as wide as it is deep $=1$.

32. No web of bone spanning the space between the basipterygoid processes $=0$. A web of bones spans the interbasipterygoid space $=1$ (Sereno 1999).

33. The paroccipital processes project laterally or dorsolaterally in caudal view $=0$. The paroccipital processes project ventrolaterally $=1$.

34. Parasphenoid rostrum, basal tubera and occipital condyle roughly in line with one another in lateral view $=$ 0 . Parasphenoid rostrum set distinctly lower than the basal tubera and the occipital condyle $=1$ (Galton 1990).

35. Caudal end of the parabasisphenoid forms a flat surface between the basal tubera $=0$. Caudal end of the parabasisphenoid with a median fossa between the basal tubera $=1$.

36. Stout basipterygoid processes of the parabasisphenoid, where the distance from the top of the parabasisphenoid to the tip of the basipterygoid process is less than the height of the braincase $=0$. Basipterygoid processes are elongate, with the distance from the top of the parabasisphenoid to the tip of the process exceeding the height of the braincase $=1$ (Benton et al. 2000).

37. Basioccipital contribution to the floor of the endocranial cavity is smooth $=0$. A low median crest on the basioccipital portion of the floor of the endocranial cavity $=1$.

38. Post-temporal fenestra bordered by the parietal and the supraoccipital $=0$. Post-temporal fenestra fully enclosed by the supraoccipital $=1$.

39. Jaw joint level with the alveolar margin of the dentary $=$ 0 . Jaw joint depressed well below the alveolar margin of the dentary $=1$ (Sereno 1999).

40. No splenial foramen $=0$. Foramen near the ventral margin of the splenial $=1$ (Rauhut 2000).

41. Lateral surface of the dentary flat or gently convex dorsoventrally, with no buccal emargination $=0$. Thick longitudinal ridge on the lateral surface of the dentary, at its caudal end, demarcating a buccal emargination = 1 (Galton 1990). 
42. Dentary tip not down-turned so that the ventral margin of the dentary is straight or bowed ventrally in lateral view $=0$. Dentary tip down-turned so that the ventral margin of the dentary is arched dorsally in lateral view $=1$ (Sereno 1999).

43. First dentary tooth placed at the anterior apex of the dentary $=0$. First dentary tooth inset for the distance of one alveolus from the dentary tip $=1$ (Sereno 1999).

44. Dentary occupies more than $40 \%$ of the mandibular length and is five times or more as long as its maximum dorsoventral depth $=0$. Dentary is short and deep occupying less than $40 \%$ of the mandibular length is less than five times its maximum depth $=1$ (Benton et al. 2000).

45. Articular with a stout, pointed process projecting medially behind the glenoid $=0$. Medial process of the articular absent $=1$.

46. Retroarticular process of the articular is no longer than the anterocaudal length of the glenoid $=0$. Elongated retroarticular process that exceeds the length of the glenoid $=1$.

47. Maxillary and dentary tooth crowns tapering from their base to their tip $=0$. Maxillary and dentary tooth crowns expanded above their base $=1$ (Sereno 1986).

48. Teeth with fine serrations set at right angles to the margin of the tooth $=0$. Teeth with coarse serrations angled upwards at $45^{\circ}$ from the margin of the tooth $=$ 1 (Sereno 1986).

49. Maxillary and dentary tooth crowns curved caudally = 0 . Maxillary and dentary tooth crowns not curved caudally $=1$ (Sereno 1986).

50. Four premaxillary alveoli $=0$. Five premaxillary alveoli $=1$ (Sereno 1999).

51. Serrations of the maxillary and dentary teeth occur along most of the length of the crowns $=0$. Serrations of the maxillary and dentary teeth restricted to the upper half of the crowns $=1$.

52. Atlantal epipophyses short, not reaching the level of the axial postzygapophyes $=0$. Atlantal epipophyses elongated, extending caudally to the level of the anterior edge of the axial postzygapophyses $=1$.

53. Length of the atlantal intercentrum is greater than that of the axial intercentrum $=0$. Length of the axial intercentrum is greater than that of the atlantal intercentrum $=1$.

54. Axial prezygapophyses and postzygapophyses equidistant from the midline of the axis $=0$. Axial postzygapophyses set wider than the prezygapophyses $=1$ (Gauthier 1986).

55. Axial postzygapophysis overhangs the caudal face of the axial centrum by at least half of the length of the postzygapophysis $=0$. No more than $10 \%$ of the length of the axial postzygapophysis overhangs the caudal face of the axial centrum $=1$ (modified from Sereno 1999).

56. Lengths of the centra of cervical vertebrae 3-6 are less than that of the axial centrum $=0$. Lengths of the centra of cervical vertebrae 3-6 are greater than that of the axial centrum $=1$.

57. Lengths of the centra of cervical vertebrae 7-9 are equal to, or less than, the length of the axial centrum $=$ 0 . Lengths of the centra of cervical vertebrae 7-9 are greater than the length of the axial centrum $=1$ (modified from Gauthier 1986).

58. Length of cervical centrum 3 is less than 2.5 times the height of its caudal face $=0$. Length of cervical centrum 3 is greater than 2.5 times the height of its caudal face $=1$.

59. Strong median ventral keels on the axis and most postaxial cervicals $($ CE3-8) $=0$. Median ventral keels absent from axis and anterior cervical vertebrae $=1$.

60. Diapo-postzygapophyseal lamina and associated caudal chonos present from cervical 4 through to the sacrum $=0$. Diapo-postzygopohyseal laminae and their associated caudal chonae are absent from cervical 4 through to cervical eight $=1$. This character describes a variation in the distribution of the diapopostzygapophyseal lamina along the vertebral column of taxa that have vertebral lamination. This character is not applicable to saurischian outgroups where vertebral lamination is not developed, consequently the outgroup taxa are coded as unknown in the matrix.

61. Atlantal prezygapophyses are flat articular surfaces on each side of the anterior atlantal neural arch $=0$. Atlantal prezygapophyses are mounted on short anteriorly projecting pedicels $=1$.

62. Cervical ribs are no longer than the length of their respective centra and are angled posteroventrally with respect to the long axis of its vertebra $=0$. Cervical ribs are more than twice the length of their respective centra and have their shafts lying parallel to the long axis of their vertebrae $=1$ (Sereno 1999).

63. Epipophyses on the cervical vertebrae form longtitudinal ridges or crests atop the postzygapophyses $=0$. Epipophyses on the cervical vertebrae form horizontal planar sheets above the postzygapophyses $=1$.

64. Presacral vertebrae without extra intervertebral articulations $=0$. Presacral vertebrae with hyposphenehypantra intervertebral articulations supplementing the zygapophyseal intervertebral articulations $=1$ (Gauthier 1986).

65. Presacral neural arches not laminated $=0$. Presacral neural arches impressed with deep semi-conical fossae (chonae of Welles 1984) separated by thin laminae $=$ 1.

66. Dorsoventral height of all dorsal neural spines is no greater than their craniocaudal length $=0$. Dorsoventral height of the middle, and caudal, dorsal neural spines is greater than their craniocaudal length $=1$.

67. Diapo-prezygapophyseal lamina and associated chonos are present on all dorsal neural arches $=0$. Diapoprezygapophyseal and associated anterior chonos are not present in middle dorsal neural arches (presacral $18-23)=1$. As in character 60 this character is not applicable to taxa that lack vertebral lamination.

68. Two sacral vertebrae $=0$. Three or more sacral vertebrae $=1$ (Sereno 1999).

69. Three or less sacral vertebrae $=0$. Four or more sacral vertebrae $=1$ (Galton 1990).

70. First caudal centra at least as long as its maximum height $=1$. First caudal centrum is higher than it is long $=1$ (Benton et al. 2000).

71. Neural spines of proximal caudal vertebrae are more than $30 \%$ of the length of the neural arch with the caudal margin anterior to the postzygapophyses, 
creating a 'U'-shaped interpostzygapophyseal space $=$ 0 . Neural spines of the proximal caudal vertebrae are less than $30 \%$ of the length of the neural arch and are caudally placed, filling the interpostzygapophyseal space $=1$.

72. Distal caudal prezygapophyses not projecting more than $20 \%$ of the length of the preceding vertebra $=$ 0 . Distal caudal vertebra projecting more than $25 \%$ of the length of the preceding vertebra $=1$ (polarity reversed from Chiappe et al. 1996).

73. Middle caudal centra (caudals 15-25) are at least twice as long as their maximum height $=0$. Middle caudal vertebrae are less than twice as long as their maximum height $=1$.

74. Well developed ventral median furrow on the caudal centra of at least the proximal two thirds of the tail = 0 . Weak median ventral furrow present only on the proximal quarter of the tail $=1$.

75. Length of the longest chevron is less than twice the length of the centrum preceding it $=0$. Length of the longest chevron is more than twice the length of the centrum preceding it $=1$.

76. Width of the scapula at the narrowest point of the blade is less than $20 \%$ of the length of the blade and is less than the length of the scapula-coracoid suture $=0$. Width of the scapula blade at its narrowest point is more than $20 \%$ of its length and is close to, if not greater than, the length of the scapula-coracoid suture $=1$.

77. The shoulder of the acromial process arises at a low angle (less than $60^{\circ}$ ) from the long axis of the scapula blade in lateral view $=0$. The shoulder of the acromial process arises at a steep angle (greater than $60^{\circ}$ ) from the long axis of the scapula $=1$.

78. Forelimb less than $50 \%$ of the length of the hindlimb $=$ 0 . Forelimb $50 \%$, or more, of the length of the hindlimb $=1$ (modified from Galton 1990).

79. Distance between the humeral head and the distal end of the deltopectoral crest is less than half the length of the humerus $=0$. Distance between the humeral head and the distal end of the deltopectoral crest is half, or more, of the length of the humerus $=1$ (Sereno 1999).

80. Deltopectoral crest of the humerus is a tall, cranially projecting flange $=0$. Deltopectoral crest is a low rugose ridge $=1$ (Wilson \& Sereno 1998).

81. Humerus more than $60 \%$ of the length of the femur $=0$. Humerus less than $60 \%$ of the length of the femur $=1$.

82. Long axis of the deltopectoral crest of the humerus more or less parallel with that of the humeral shaft so that the leading edge of the crest forms a straight line in anterior view $=0$. Proximal summit of the deltopectoral crest is medially inflected resulting in a sinuous leading edge of the crest in anterior view $=1$.

83. Transverse width of the distal humerus less than $33 \%$ of the length of the humerus $=0$. Transverse width of the humerus is greater than $33 \%$ of the length of the humerus $=1$.

84. Contact for the radius on the medial surface of the proximal end of the ulna is flat or gently concave $=$ 0 . Deep radial fossa is present on the medial side of the proximal end of the ulna $=1$ (Wilson \& Sereno 1998).

85. Ulna with a bony projection, the olecranon process, extending proximal to the humeral articulation $=0$.
Olecranon process of the ulna is absent $=1$ (Wilson $\&$ Sereno 1998).

86. Radius is more than $80 \%$ of the length of the humerus $=0$. Radius is less than $80 \%$ of the length of the humerus $=1$.

87. Ulnare and radiale larger than any of the distal carpals $=$ 0 . Ulnare and radiale smaller than distal carpals I-III = 1 (modified from Sereno 1999).

88. Transverse width of distal carpal I less than $110 \%$ of the width of distal carpal II $=0$. Transverse width of distal carpal I greater than $120 \%$ of the width of distal carpal II = 1 (modified from Sereno 1999).

89. Distal carpal I lies adjacent to, but does not overlap, distal carpal II $=0$. Distal carpal I overlapping the proximal surface of distal carpal II $=1$.

90. Proximal end of metacarpal I is flush with metacarpal II and the medial side of distal carpal II abutts distal carpal $\mathrm{I}=0$. Proximal end of metacarpal $\mathrm{I}$ is inset into the carpus and abutts the medial side of distal carpal II = 1 (Sereno 1999).

91. Maximum dimension of distal carpal II is at least $33 \%$ of that of distal carpal I and covers the entire proximal surface of metacarpal II $=0$. Maximum dimension of distal carpal II is less than $33 \%$ of distal carpal I and fails to cover the entire proximal surface of metacarpal $\mathrm{II}=1$ (modified from Benton et al. 2000).

92. Total length of the manus is less than $45 \%$ of the length of the humerus plus the radius $=0$. Total length of the manus exceeds $45 \%$ of the length of the humerus plus the radius $=1$ (Gauthier 1986).

93. Proximal width of metacarpal I is equal to, or less than, that of metacarpal II $=0$. Proximal width of metacarpal I is greater than that of metacarpal II $=1$ (modified from Galton 1990).

94. Proximal width of metacarpal I is less than $65 \%$ of its maximum length $=0$. Proximal width of metacarpal I is greater than $65 \%$ of its maximum length $=1$.

95. Proximal width of metacarpal $\mathrm{I}$ is less than its maximum length $=0$. Proximal width of metacarpal $\mathrm{I}$ is equal to, or greater than, its maximum length $=1$.

96. Distal condyles of metacarpal I are symmetrical or nearly so $=0$. Distal condyles of metacarpal I are strongly assymetrical with the lateral condyle being larger and shifted towards the extensor side of the manus, relative to the medial condyle $=1$ (modified from Gauthier 1986).

97. Proximal width of metacarpal $\mathrm{V}$ is less than $60 \%$ of its length with a planar proximal surface $=0$. Proximal width of metacarpal $\mathrm{V}$ is greater than $60 \%$ of its length with a strongly convex proximal surface $=1$.

98. Distal ends of metacarpals I-III without deep ligament pits on their extensor surface $=0$. Extensor surface of the distal ends of metacarpals I-III with deep ligament pits $=1$ (Novas 1993).

99. Transverse axis through the distal end of the first phalanx of digit I is untwisted, or slightly twisted ventromedially, relative to the transverse axis proximal end $=0$. Transverse axis through the distal end of the first phalanx of digit I is distinctly twisted ventrolaterally relative to the transverse axis of the proximal end $=1$ (modified from Sereno 1999).

100. Ventrolateral twisting of transverse axis through the distal end of first phalanx of digit $\mathrm{I}$ is less than $50^{\circ}$ 
from the transverse axis through the proximal end $=$ 0 . Ventrolateral twisting of transverse axis through the distal end of first phalanx of digit I is greater than $60^{\circ}$ from the transverse axis through the proximal end $=1$ (modified from Sereno 1999).

101. Digit I shorter than either digit II or III $=0$. Digit I is the longest digit of the manus $=1$.

102. First phalanx of digit $I$ is shorter than metacarpal $I=0$. First phalanx of digit $\mathrm{I}$ is longer than metacarpal $\mathrm{I}=1$ (Sereno 1999).

103. Ungual of digit II is the longest ungual of the manus = 0 . Ungual of digit $\mathrm{I}$ is at least equal in length to the ungual of digit II $=1$ (modified from Gauthier 1986).

104. First phalanges of manual digits II and III are the longest non-terminal phalanges of those digits $=0$. Penultimate phalanges of manual digits II and III are the longest non-terminal phalanges of those digits $=1$ (modified from Gauthier 1986).

105. Non-terminal phalanges of manual digits II and III are at least $20 \%$ longer than their proximal width $=0$. Non-terminal phalanges of manual digits II and III are almost, if not, as proximally wide as they are long $=1$.

106. Manual digit III is longer than digit $\mathrm{II}=0$. Manual digit II is longer than digit III $=1$ (modified from Gauthier 1986).

107. Combined lengths of the non-terminal phalanges of manual digit III exceed those of digit II $=0$. Combined lengths of the non-terminal phalanges of manual digit II exceed those of digit III $=1$.

108. Ungual of manual digit II is greater than $75 \%$ of the ungual of digit $\mathrm{I}$ in all linear dimensions $=0$. Ungual of manual digit II is less than $75 \%$ of the ungual of digit $\mathrm{I}$ in all linear dimensions $=1$ (modified from Benton et al. 2000).

109. Ungual of manual digit II is greater than $50 \%$ of the ungual of digit $\mathrm{I}$ in all linear dimensions $=0$. Ungual of manual digit II is less than $50 \%$ of the ungual of digit I in all linear dimensions $=1$.

110. Manual digits IV and V with at least three and two phalanges, respectively $=0$. Phalangeal formula of manual digits IV and $\mathrm{V}$ is reduced to two and zero, respectively $=1$ (Sereno 1993).

111. Cranial tip of the preacetabular blade of the ilium does not reach the level of the cranial edge of the pubic peduncle $=0$. Cranial edge of the preacetabular blade is located further forward than the cranial edge of the pubic peduncle $=1$.

112. Preacetabular process of the ilium is not supported by a buttress $=0$. A prominent buttress extends from the supra-acetabular crest to the ventral margin of the preacetabular process $=1$.

113. Preacetabular process has a rounded, rectangular, blunt profile $=0$. Preacetabular blade is triangular and pointed in profile $=1$. Preacetabular blade expands dorsoventrally towards its anterior end producing a hatchet-shaped profile $=2$ (modified from Sereno 1999).

114. Acetabulum at least partly closed with a convex to gently concave ventral margin of the internal acetabular wall $=0$. Acetabulaum fully open with a strongly arched ventral margin of the internal acetabular wall = 1 (modified from Galton 1990).
115. Acetabular fossa of the ilium longer than it is tall $=0$. Acetabular fossa of the ilium is taller than it is long $=$ 1 (Benton et al. 2000).

116. Brevis fossa below postacetabular process of the ilium is short, narrow and vaguely defined $=0$. Brevis fossa large and sharply defined by strong ridges $=1$ (Gauthier 1986).

117. Pubic peduncle of the ilium less than twice the length of its distal articular surface $=0$. Pubic peduncle greater than twice the length of its distal articular surface $=1$ (Sereno 1999).

118. Ischial peduncle of the ilium present $=0$. Ischial articular surface not borne on a protruding peduncle $=1$ (Wilson \& Sereno 1998).

119. Supra-acetabular crest of the ilium is at its widest halfway between the pubic and ischial contacts $=0$. Supra-acetabular crest is widest above the base of the pubic peduncle $=1$.

120. Caudal margin of the postacetabular blade is rounded in lateral view $=0$. Caudal margin of the postacetabular blade is square-ended in lateral view $=1$.

121. Ventral plate-like flange extending along the full length of the ischium $=0$. Plate-like ventral flange of the ischium is restricted to the proximal end where it forms an obturator plate $=1$.

122. Pubis as long as, or longer than, the ischium $=0$. Ischium longer than the pubis $=1$ (Wilson $\&$ Sereno 1998).

123. Distal end of the ischium terminates simply, without an expansion $=0$. Distal end of the ischium with an expanded, knob-like termination $=1$ (modified from Sereno 1999).

124. Ischial midshaft with a flat rectangular cross-section $=$ 0 . Ischial midshaft with a triangular cross-section $=1$ (Sereno 1999).

125. Transverse width of the conjoined distal ischial expansions is equal to, or greater than, the length of their symphysis $=0$. Transverse width of the conjoined distal ischial expansions is less than the length of their symphysis $=1$.

126. Ischium without any sulcus developed on the dorsolateral surface of the proximal ischial shaft $=0$. Dorsolateral surface of the proximal ischial shaft with a longitudinal sulcus $=1$.

127. Distal end of the proximal ischial obturator plate is abrupt and proximal to the midpoint of the ischium $=$ 0. Proximal ischial obturator plate with an elongate, gradually tapering distal end that reaches the midpoint of the ischium $=1$. This character is not applicable to those taxa that have the plesiomorphic state for character 123 .

128. Pubis with a knob-like ambiens process projecting laterally from the proximal pubic shaft $=0$. Ambiens process of the pubis is absent $=1$.

129. Pubic apron is straight-sided or distally tapering in anterior view $=0$. Concave lateral margins of the pubes producing a waisted pubic apron in anterior view $=$ 1.

130. Distal ends of the pubes craniocaudally flat $=0$. Distal end of pubes with a craniocaudal expansion, or pubic boot $=1$ (Sereno et al. 1993).

131. Craniocaudal width of the distal end of the pubes is less than $20 \%$ of the length of the pubes $=0$. Craniocaudal 
width of the pubic boot is greater than $20 \%$ of the length of the pubes $=1$.

132. Length of the hind limb is greater than that of the trunk $=0$. Length of the hind limb is less than that of the trunk $=1$ (Galton 1990).

133. Distal two-thirds of the femur bowed medially in anterior view $=0$. Femur straight in anterior view $=1$ (Galton 1990).

134. Femur is gently sigmoid in lateral view with the proximal end bowed caudally and the distal end bowed cranially $=0$. Femur is columnar and straight in lateral view $=1$ (Wilson $\&$ Sereno 1998).

135. Femoral midshaft is subcircular in cross-section with the craniocaudal diameter being equal to the mediolateral diameter $=0$. Femoral midshaft with an elongate oval cross-section, with the mediolateral diameter exceeding the craniocaudal diameter $=1$ (Wilson $\&$ Sereno 1998).

136. Lesser trochanter is a small, rounded, low tubercle $=0$. Lesser trochanter is a proximodistally oriented ridge $=$ 1. Lesser trochanter is absent $=2$ (modified from Galton 1990).

137. Femoral head partially inturned with the long axis of head set at an angle to the transverse axis of the distal condyles of the femur $=0$. Femoral head fully inturned with the long axis of the head parallel to the transverse axis of the distal femoral condyles $=1$.

138. No transverse muscle attachment extending laterally from the lesser trochanter $=0$. Transverse muscle attachment (a sharp ridge, a low rounded ridge or a well-developed scar) extending laterally from the lesser trochanter $=1$.

139. Fourth trochanter is located entirely in the proximal half of the femur $=0$. Fourth trochanter is centrally located so that its distal end occurs in the distal half of the femur $=1$ (Benton et al. 2000).

140. Dorsal and ventral sides of the fourth trochanter are subsymmetrical in lateral view with the summit of the trochanteric crest at its midpoint $=0$. Fourth trochanter asymmetrical in lateral view with the summit of the crest placed distally and the distal margin with a steeper slope than the proximal margin $=1$.

141. In caudal view the fourth trochanter is equidistant from the medial and lateral edges of the shaft $=0$. The fourth trochanter is placed on the medial edge of the femoral shaft in caudal view $=1$ (Galton 1990).

142. Tibia is longer than the femur $=0$. Tibia is equal to, or shorter than, the femur $=1$ (modified from Benton et al. 2000).

143. Length of the tibia is greater than $60 \%$ of the length of the femur $=0$. Length of the tibia is $60 \%$, or less, of the length of the femur $=1$ (modified from Benton et al. 2000).

144. Cranial surface of the distal femur without a longitudinal extensor depression $=0$. Cranial surface of the distal femur with a longitudinal extensor depression $=1$.

145. Transverse width of the distal tibia is equal to its craniocaudal length $=0$. Transverse width of the distal tibia is greater than its craniocaudal length $=1$ (modified from Sereno 1999).

146. Ossified distal tarsals present $=0$. Ossified distal tarsals absent $=1$ (Benton et al. 2000).
147. In cranial view the ascending process of the astragalus arises from the medial end of the bone and slopes continuously upwards to its peak at the lateral end of the process $=0$. In cranial view the ascending process arises abruptly from the centre of the bone and forms a plateau or rounded summit, medial to its lateral edge $=1$.

148. Craniocaudal width of the ascending process of the astragalus in proximal view remains constant along its length $=0$. In proximal view the craniocaudal width of the ascending process of the astragalus increases toward the lateral end of the process $=1$.

149. Caudal margin of the astragalus is straight, or almost so, in proximal view $=0$. Caudal margin of the astragalus strongly convex in dorsal view $=1$.

150. Lateral side of the calcaneum without a horizontal groove $=0$. Calcaneum with a lateral, horizontal groove $=1$.

151. Transverse width of the calcaneum is greater than $30 \%$ of the transverse width of the astragalus $=0$. Transverse width of the calcaneum is less than $30 \%$ of the transverse width of the astragalus $=1$ (modified from Benton et al. 2000).

152. Transverse width of metatarsal $I$ is less than that of metatarsal II $=0$. Transverse width of metatarsal I equal to, or greater than, the transverse width of metatarsal II $=1$ (Wilson \& Sereno 1998).

153. Proximal face of metatarsal II with a straight medial margin $=0$. Proximal face of metatarsal II with a concave medial margin for the reception of metatarsal $\mathrm{I}=$ 1 (modified from Sereno 1999).

154. Proximal face of metatarsal II with a straight lateral margin $=0$. Proximal face of metatarsal II with a concave lateral margin for the reception of metatarsal III = 1 (modified from Sereno 1999).

155. Transverse width of the proximal face of metatarsal IV is less than twice its depth, from the extensor to flexor surfaces $=0$. Transverse width of the proximal face of metatarsal IV is greater than twice its depth, from the extensor to flexor surfaces $=1$ (modified from Sereno 1999).

156. Transverse width of the proximal end of metatarsal $\mathrm{V}$ is less than $25 \%$ of its length $=0$. Transverse width of the proximal end of metatarsal $\mathrm{V}$ is greater than $30 \%$ of its length $=1$ (modified from Sereno 1999).

157. Metatarsal $\mathrm{V}$ more than twice as long as its maximum width $=0$. Metatarsal $\mathrm{V}$ no more than twice as long as its maximum width $=1$.

158. Ungual of pedal digit I shorter than the ungual of pedal digit $\mathrm{II}=0$. Ungual of pedal digit $\mathrm{I}$ is at least as long as the ungual of pedal digit $\mathrm{II}=1$ (Benton et al. 2000).

159. Ungual of pedal digit I no longer than the ungual of pedal digit II $=0$. Ungual of pedal digit I longer than the ungual of pedal digit II = 1 (modified from Sereno 1999).

160. Pedal ungual $I$ is shallow and continuously tapering in lateral view, with a broad flat ventral surface $=0$. Pedal ungual $I$ is deep and abruptly tapering near the distal end with a narrow, rounded ventral surface $=1$ (Wilson \& Sereno 1998). 
161. All linear dimensions of pedal ungual III greater than $90 \%$ of those of pedal ungual II $=0$. Pedal ungual III less than $90 \%$ of pedal ungual II in all linear dimensions $=1$.

162. Pedal digit IV with five phalanges $=0$. Pedal digit IV with three, or fewer, phalanges $=1$ (modified from Benton et al. 2000).
163. Phalanges of pedal digit $\mathrm{V}$ absent $=0$. Pedal digit $\mathrm{IV}$ with at least one phalanx $=1$ (polarity reversed from Gauthier 1986).

164. Pedal digit $\mathrm{V}$ rudimentary, not weight-bearing $=0$. Weight-bearing pedal digit $\mathrm{V}=1$.

\section{APPENDIX 3: LIST OF UNAMBIGUOUS SYNAPOMORPHIES}

This list of synapomorphies applies to the reduced cladistic consensus shown in Fig. 23.

\section{Saurischia}

Lacrimal exposed on the dorsal skull roof; axial postzygapophyses are set further from the midline than the axial prezygapophyses. CE3-6 longer than the axis. Hyposphenehypantra articulations in the presacral vertebrae. Laminated dorsal neural arches. Manus more than $45 \%$ of humerus + radius. First phalanx of manual digit I longer than metacarpal I. Phalangeal formula of manual digits IV and V reduced to 2 and 1, respectively. Prominent supra-acetabularpreacetabular buttress on the ilium. Ischium with a proximal obturator plate.

\section{Neotheropoda + Sauropodomorpha}

Loss of premaxilla-nasal suture below naris. Large subnarial foramen within, or on the border of, the narial fossa. Erect, inverted ' $L$ ' shaped lacrimal. CE7-9 longer than the axis. Radius less than $80 \%$ of the humerus. Distal carpal I at least $120 \%$ wider than distal carpal II. Asymmetric distal condyles of metacarpal I. Ungual of manual digit I at least as long as ungual of manual digit II. Manual digit II longer than digit III. Caudal margin of postacetabular blade of the ilium is squareshaped in lateral view. Large distal ischial expansion. Dorsolateral groove on the proximal ischial shaft.

\section{Sauropodomorpha}

Skull less than $50 \%$ of the length of the femur. Narrow, strap-shaped quadratojugal ramus of the squamosal. Teeth with a constriction between the root and the crown. Diapo-postzygaspophyseal lamina absent in CE3-8. Diapoprezygapophyseal lamina absent in cranial and middle dorsal vertebrae. Forelimb at least $50 \%$ of the length of the hindlimb. Distal humerus is more than three times the width of the humeral midshaft. Hindlimb no longer than the trunk. Tibia no longer than the femur.

\section{Thecodontosaurus + more derived sauropodomorphs}

First dentary tooth inset from the dentary tip. Maxillary and dentary teeth with coarse serrations angled at $45^{\circ}$ from the margins of the tooth. All tooth crowns lack recurvature. Loss of ventral keels in cranial cervical vertebrae. Reversal to the absence of a supra-acetabular-preacetabular buttress. Pubic peduncle of the ilium is greater than twice the length of the pubic articular surface. Supra-acetabular crest is at its widest above the base of the pubic peduncle. Proximal metatarsal
II with a concave medial margin for the reception of metatarsal I. Proximal end of metatarsal V transversely flared.

\section{Thecodontosaurus}

Plate-like epipophyses on the cervical vertebrae with planar dorsal surfaces.

\section{'Efraasia' + (Plateosaurus + (Anchisaurus, Riojasaurus + (Lufengosaurus + (Massospondylus + Yunnanosaurus)) + (Euskelosaurus + (Melanorosaurus + (Blikanasaurus + Sauropoda)))))}

Enlarged caudal vascular foramen on the maxilla. Jaw joint below alveolar margin of the dentary. Caudolateral shelf on the dentary. Pointed medial process of the articular absent. Retroarticular process exceeds glenoid length. Centrum of CE3 is 2.5 times longer than high. Three sacral vertebrae. Centra of middle caudal vertebrae less than twice as long as high. Proximal width of metacarpal I more than $65 \%$ of its length. Reversal to three and two phalanges on manual digits IV and V, respectively. Reversal to the absence of a trochanteric shelf and associated muscle scar on the femur.

\section{Plateosaurus + (Anchisaurus, Riojasaurus + ((Lufengosaurus + Massospondylus) + (Euskelosasurus + (Melanorosaurus + (Blikanasaurus + Sauropoda)))))}

Deeply cleft basal tubera. Five premaxillary alveoli. Reversal to a first phalanx of manual digit I that is shorter than metacarpal I. Manual ungual II is less than $75 \%$ of manual ungual I in all linear dimensions. Fully open acetabulum. Extensor depression on the distal femur.

\section{Anchisaurus, Riojasaurus + ((Lufengosaurus + Massospondylus) + (Euskelosaurus + (Melanorosaurus + (Blikanasaurus + Sauropoda))))}

Reversal to a manus that is less than $45 \%$ of the length of the humerus + radius. Loss of a lateral projecting ambiens process on the proximal pubis. Femur straight in cranial view. Lesser trochanter is a proximodistally elongated ridge. Long axis of the femoral head parallel with the transverse axis of the distal femoral condyles. Fourth trochanter located on the medial margin of the femoral shaft in caudal view. 


\section{Lufengosaurus + ((Massospondylus + Yunnanosaurus) + (Euskelosaurus + (Melanorosaurus + (Blikanasaurus + Sauropoda))))}

Reversal to the loss of exposure of the lacrimal in the dorsal skull roof. Caudorostrally short lacrimal head with a triangular antorbital fossa. Jugal excluded from the margin of the antorbital fenestra by a lacrimal-maxilla contact. Reversal to four premaxillary alveoli. Serrations restricted to the upper half of the crowns of all teeth. Digit I is the longest digit in the manus. Non-terminal phalanges of manual digits II and III are as wide as they are long, or wider. Craniocaudal expansion of the distal pubes. Pedal ungual I longer than pedal ungual II.

\section{Lufengosaurus + (Massospondylus + Yunnanosaurus)}

Enlarged caudal process of the prefrontal. Distal carpal I overlaps distal carpal II. Metacarpal I is inset into the manus. Distal carpal II is less than one-third the width of distal carpal I and fails to cover all of the proximal surface of metacarpal II. Metacarpal I is a wide as it is long. Transverse axis through distal condyles of first phalanx of manual digit I is twisted $60^{\circ}$ ventrolaterally relative to the transverse axis of the proximal facet.

\section{Massospondylus + Yunnanosaurus}

Distally tapering obturator plate of the ischium reaching $50 \%$ of the length of the ischium. Reversal to a femur that is is sinuous in cranial view. Reversal to a fourth trochanter that is inset from the medial margin of the femoral shaft in caudal view.

\section{Euskelosaurus + (Melanorosaurus + (Blikanasaurus + Sauropoda))}

Height of the caudal dorsal neural spines is greater than their craniocaudal length. First caudal centrum is higher than it is long. Reversal to a shallow, narrow and poorly defined brevis shelf.

\section{Melanorosaurus + (Blikanasaurus + Sauropoda)}

Low ridge-like deltopectoral crest. Medial radial fossa on the proximal ulna. Olecranon process of the ulna is absent. Craniocaudally flattened femoral shaft. Distal end of the fourth trochanter is located in the distal half of the femur.

\section{Blikanasaurus + Sauropoda}

Laterally widening ascending process of the astragalus. Caudal margin of astragalus is convex in dorsal view.

\section{Sauropoda}

Distal tarsals not ossified. Proximal end of metatarsal I broader than metatarsal II. Reversal to the absence of a concave lateral margin to the proximal end of metatarsal II. Deep, narrow, pedal unguals. Pedal digit IV with three or fewer phalanges. Weight bearing pedal digit V.

\section{APPENDIX 4: CHARACTER-TAXON MATRIX}

Question marks represent missing data due to incomplete preservation or inapplicable characters. ' $\mathrm{P}$ ' represents polymorphism (0 and 1 in all cases) in the Operational Taxonomic Units(OTU).

\begin{tabular}{|c|c|c|c|c|c|c|c|c|c|c|c|}
\hline OTU & 5 & 10 & 5 & 20 & 25 & 30 & 35 & 0 & 45 & 50 & 5 \\
\hline arsi & $000 \mathrm{P}$ & 0000 & 0000 & 0000 & 0000 & 0000 & 0001 & 0000 & O O OP O & 00000 & ( \\
\hline uchus & ? ? ? ? & ? 000 & ? ? ? & ? ? ? ? & ? ? ? ? & ? ? ? ? & ? ? o & o ?? & ? ? ? ? ? & ? 000 ? & ? 000 \\
\hline ischia & 00000 & 10000 & 0 ? 00 & 00000 & 01000 & PoO o o & 0000 & 0010 & 00101 & $\begin{array}{lllll}11 & 1 & 1\end{array}$ & 0000 \\
\hline . & 00000 & 00000 & $1 ? 00$ & 00100 & 00000 & 10000 & 0101 & ? 00 ? & 00000 & 0000 & 0110 \\
\hline da & 00110 & 01000 & 0000 & 01100 & 01000 & 10111 & 0101 & 00001 & 00000 & 00000 & 110 \\
\hline Saturnalia & 1 ? ? ? ? & ? ? ? ? & $01 ? ? ?$ & ? 1 ? o ? & ? ? ? 1 ? & o ??? & $0 ? 10$ & ?? ?? & $0001 ?$ & $? 100 ?$ & ?? ? \\
\hline T. antiquus & ? ? ? ? & ? ? ? ? & ? ? ? ? ? & ? ? ? ? ? & ? ? ? ? ? & ? ? ? ? ? & 000 & o ?? & $0011 ?$ & ? 11111 ? & ? ? ? ? \\
\hline T. caducus & ? ? ? ? & ? ? ? 0 & ? 111 ? 0 & ? 1100 & ? $10101 ?$ & 00110 & 000 & $1100 ?$ & 110 & 01110 & $01 ?$ \\
\hline & ? ? ? 1 & ? 11 ? & $01 ? ? ?$ & ? 1 ? ? 0 & 01010 & ? o ? ? ? & 101 & o ? o ? ? & 101 & $1 ? ?$ ? 11 & ? 0 ? 1 ? \\
\hline & ? $1 ? 1$ & 11101 & ? 1 ? 0 ? & & 01010 & o o ? ? ? & ? ? o ? 1 & & $1010 ?$ & ? 01111 & 0 ? 11 \\
\hline 'Efrc & 1101 & ? ? 1111 & o ? ? ? ? & ? 111 ? 0 & ? 1 ? ? ? & $100 ? ?$ & 01010 & $1 ? \circ 1 ?$ & 101 & 11110 & 0 ? ? ? 1 \\
\hline & 1101 & $0 \begin{array}{llll}1 & 1 & 1 & 1\end{array}$ & 11111 & 11101 & 01011 & & 01011 & & 101 & & 11 \\
\hline ufe & ? $1 ? 1$ & $1 ? ? 111$ & $01 ? ? 1$ & 011 & 11011 & ? ? o ? 1 & 011 & & ? 01 & & ? ? \\
\hline ondylus & 1111 & 11101 & O 11111 & 011 & 11010 & ? ? ? ? 1 & 10111 & & 101 & 11110 & ?? ? \\
\hline$Y_{u}$ & ? 1111 & $1 ? 10$ ? & 01 ? ? ? ? & ? 1 ? 11 & 100 & ? ? ? ? ? & ? ? 1 ? ? & ? ? ? & ? ० ? ० 1 & 11110 & ? ? 1 \\
\hline 'Eusk & ? ? ? ? & ? ? ? ? & ? ? ? ? ? & ? ? ? ? ? & ? ? ? ? ? & ? ? ? ? ? & ? ? ? ? ? & ??? & ? ? ? ? ? & ? ? ? & ? ? ? ? \\
\hline & ? ? ? ? ? & ? ? ? ? ? & ? ? ? ? & ? ? ? ? ? & ? ? ? ? ? & ? ? ? ? ? & ? ? ? ? ? & ? ? ? ? ? & ? ? ? ? ? & ? ? ? ? ? & ? ? ? ? ? \\
\hline & & ? ? ? ? ? & ? ? ? ? ? & ? ? ? ? ? & ? ? ? ? ? & ? ? ? ? ? & ? ? ? ? ? & ? ? ? ? ? & ? ? ? ? ? & ? ? ? ? ? & ? ? ? ? ? \\
\hline odon & ? ? ? ? ? & ? ? ? ? ? & ? ? ? ? ? & ? ? ? ? ? & ? ? ? ? ? & ? ? ? ? ? & ? ? ? ? ? & ? ? ? ? ? & ? ? ? ? ? & ? ? ? ? ? & ? ? ? ? ? \\
\hline Eusauropoda & 10111 & $11 \mathrm{P} \circ \mathrm{P}$ & 01000 & 01010 & 11100 & 11001 & 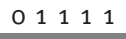 & P 0011 & 00001 & 01110 & $1001 \mathrm{P}$ \\
\hline
\end{tabular}




\begin{tabular}{|c|c|c|c|c|c|c|c|c|c|c|c|}
\hline TU & 60 & 65 & 70 & 75 & 80 & 85 & 90 & 95 & 100 & 105 & \\
\hline si & o o? & $? 00$ & 000 & 0 & 0 & o & ? o? & 00000 & 00000 & 0 & 0 \\
\hline & $00 ?$ & ? ? ० ० & $? 000$ & $0 ? 1$ & 000 & o? 0 & ? ? ? & & & $?$ & ?० ? \\
\hline & o? & 0000 & ? 110 & ० 0 & & & 000 & $0 \circ 0$ & & 000 & 00 \\
\hline & 00 & 011 & 0001 & ? ? & & & 000 & 00 & & & 01 \\
\hline & 00 & 011 & 0110 & ० 0 & & & 100 & & & & 01 \\
\hline & ? 01 & 1011 & 1000 & ?? ? & 01110 & 100 & ? ? ? & ? ? ? & ? & ? ? ? ? & ? ? ? \\
\hline & ? 11 & 111 & 1000 & $1 ?$ & & & o & & & & 01 \\
\hline & 011 & 11 & ? ? ? ? & $1 ?$ & & ? ? & ? ? ? & ? ? ? & & & \\
\hline & $0 ?$ & $? 1$ & 01100 & o? & 10 & 00 & $11 ? 00$ & 110 & r & & 00 \\
\hline & 011 & 011 & 01100 & ? ? & & & 00 & & & & 00 \\
\hline & 111 & 1011 & 1100 & 11 & 10 & 00 & $? 11110$ & 10 & $1001 ?$ & 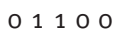 & 00 \\
\hline & 111 & 1011 & 1100 & $? 1$ & 10 & 00 & $11 ? 11$ & 10 & 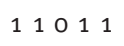 & 0 & 100 \\
\hline & & 11 & & & & & 11 & & & & 0 \\
\hline & 01 & ? ? & ? ? ? ? ? & ? ? & & & ? ? ? & ? ? & & & $?$ \\
\hline & 1 & 11 & 10 & o ? & & & 11 & 11 & 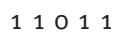 & 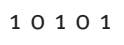 & 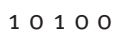 \\
\hline & ? 0 & $? 1$ & 00 & & & & & & & & 1 ? \\
\hline & 01 & ? ? 11 & $\begin{array}{llll}11 & 1\end{array}$ & o? & 10 & 00 & ? ? ? & ?? & $?$ & ? ? ? & ? ? ? ? \\
\hline & ? 1 & 11 & 11 & $?$ & & & ? ? & ? ? & ? & $?$ & ? ? ? \\
\hline & & & ? ? ? ? ? & & & & & & & & 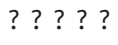 \\
\hline & ? ? ? & ? ? ? ? ? & ? ? 1111 & 01 & 01 & $00 ? 11$ & ? ? ? ? ? & ? ? ? & ? ? ? ? ? & ? ? ? ? & ? ? ? ? ? \\
\hline Eusauropoda & 11010 & 01011 & 10111 & 00100 & $111 \mathrm{P}_{1}$ & 00011 & 01100 & $000 \mathrm{Po}$ & 10000 & $101 ? 1$ & ?? ? 110 \\
\hline
\end{tabular}

\begin{tabular}{|c|c|c|c|c|c|c|c|c|c|c|c|c|c|}
\hline OTU & & & & 120 & 125 & 130 & 135 & 140 & 145 & 150 & 155 & 160 & 1 \\
\hline si & - & & - & . & $000 ?$ & $0 ? ? 000$ & 1000 & $2 ? 000$ & (- & $0 ? ? 00$ & 1000 & 0000 & . \\
\hline & o c & & 00 & 00 & ० ० ? & ? 000 & 0000 & 0100 & 000 & 0000 & 0000 & 0000 & ? 00 \\
\hline & 1 & & 000 & 00 & $0000 ?$ & ? o ? o & 0000 & $\begin{array}{lllll}0 & 1 & 0 & 0 & 1\end{array}$ & $\circ \circ \mathrm{P}$ & 0000 & 0110 & 0000 & 000 \\
\hline (E) & 100 & & 0000 & 00 & 1001 ? & 00000 & 00000 & 00101 & 0000 & 00000 & 0001 & 0000 & 0010 \\
\hline & 21 & & 1000 & 01 & 10100 & 10101 & 0000 & 00100 & 00000 & 00000 & $0 ? ?$ & 0000 & 0000 \\
\hline & 10 & & 000 & 01 & 10110 & 0000 & 1000 & 00101 & 1000 & 00000 & 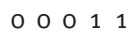 & o ? ? o & 1000 \\
\hline & 10 & & $\begin{array}{llll}1 & 1 & 0 & 1\end{array}$ & 11 & ? ? ? ? ? & ? ? ० ० ? & $? 000$ & 00101 & $? 000$ & ? ० ? ० ? & ? $\begin{array}{lll}1 & 1 & 1\end{array}$ & ? ? ? ? & ? ? ? \\
\hline & 010 & & $? \begin{array}{lll}1 & 0 & 1\end{array}$ & 11 & $1 ? ? 110$ & 10 ? ? ? & ? ? 000 & ? ? ? 01 & 01000 & ? ? ? ? ? & ? $\begin{array}{lllll}0 & 1 & 1 & 1\end{array}$ & 10100 & $? 000$ \\
\hline urus & 011 & & $\begin{array}{llll}110 & 1\end{array}$ & $1 ?$ & 10100 & $? 0100$ & 01100 & 11001 & $\begin{array}{lllll}1 & 1 & 0 & 1\end{array}$ & $0 ? ?$ & o ? ? ? & 10100 & 0000 \\
\hline & 11 & & $\begin{array}{llll}11 & 0 & 1\end{array}$ & 10 & 10110 & 10100 & 1101 & 11001 & 1010 & 01000 & 0 ? ? 1 & $11 ? 00$ & $? \circ 00$ \\
\hline & 010 & & 1101 & 11 & 10110 & 10000 & 01000 & 00001 & $0100 ?$ & 00001 & $0 ? ? 1$ & 10100 & 0000 \\
\hline aurb & $\begin{array}{lll}0 & 1 & 1\end{array}$ & & $\begin{array}{llll}1 & 1 & 0 & 1\end{array}$ & 10 & 10111 & 10001 & 01000 & 00001 & 01010 & 00001 & $\begin{array}{llll}0 & 0 & 1 & 0\end{array}$ & 10100 & 0010 \\
\hline at & $\begin{array}{lll}0 & 1 & 1\end{array}$ & & $\begin{array}{llll}1 & 1 & 0 & 1\end{array}$ & 10 & 10110 & 10111 & 011100 & 11001 & $\begin{array}{llll}1 & 0 & 1 & 1\end{array}$ & $\begin{array}{lllll}0 & 1 & 0 & 0 & 1\end{array}$ & $\begin{array}{llll}0 & 1 & 1 & 1\end{array}$ & $\begin{array}{lllll}11 & 1 & 1 & 0\end{array}$ & 1010 \\
\hline isaur & ? ? ? & & ? ? ? ? & ? ? & ? ? ? ? ? & ? ? ? ? ? & ? ? ? ? ? & ? ? ? ? ? & ? ? ? ? ? & ? ? ? ? ? & ? ? ? ? & ? ? ? ? & ? ? ? ? \\
\hline ond & $\begin{array}{llll}0 & 0 & 1 & 1\end{array}$ & & $\begin{array}{llll}0 & 1 & 0 & 1\end{array}$ & 11 & $\begin{array}{lllll}1 & 0 & 1 & 1 & 1\end{array}$ & ? $\begin{array}{llll}1 & 1 & 1 & 1\end{array}$ & 01000 & $\begin{array}{lllll}1 & 1 & 0 & 0 & 1\end{array}$ & $\begin{array}{lllll}0 & 1 & 0 & 1 & 1\end{array}$ & $\begin{array}{lllll}0 & 1 & 0 & 0 & 1\end{array}$ & $\begin{array}{lllll}0 & 0 & 1 & 1 & 1\end{array}$ & $\begin{array}{lllll}11 & 1 & 1 & 0\end{array}$ & 1010 \\
\hline 259 & $\begin{array}{llll}0 & 0 & 1 & 1\end{array}$ & & $\begin{array}{llll}1 & 1 & 0 & 1\end{array}$ & 11 & 10110 & $\begin{array}{lllll}11 & 1 & 0 & 1\end{array}$ & $1 ? 000$ & 11001 & $\begin{array}{lllll}0 & 1 & 0 & 1 & 1\end{array}$ & $\begin{array}{lllll}? & 1 & ? & 0 & 1\end{array}$ & 0 ? $\begin{array}{llll} & 1 & 1\end{array}$ & ? ? ? ? ? & ? ? ? ? \\
\hline & 0011 & & 0101 & 11 & $1 ? ? 110$ & ? o ? ? ? & ? ? 100 & 00001 & $\begin{array}{lllll}0 & 1 & 0 & 0 & 1\end{array}$ & ? ? ? ? ? & ? ? ? ? ? & ? ? ? ? ? & ? o ? ? \\
\hline 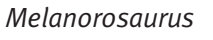 & $\begin{array}{llll}0 & 0 & 1 & 1\end{array}$ & & ? 1001 & 11 & ? ? ? ? ? & ? ? $\quad 101$ & ? ? 100 & 11010 & $\begin{array}{llll}1 & 1 & 0 & 1\end{array}$ & ? ? 0 ० ? & ? ? ? ? & ? ? ? ? ? & ? ? ? ? \\
\hline saurus & ? ? ? ? & & ? ? ? ? & ? ? & ?？？？？ & ? ? ? ? ? & ? ? ? ? ? & ? ? ? ? ? & ? ? ? ? 1 & $\begin{array}{lllll}0 & 1 & 1 & 1 & 0\end{array}$ & $1011 ?$ & $\begin{array}{lllll}11 & 1 & 1 & 0\end{array}$ & 1010 \\
\hline & ? ? ? 1 & & ? $\begin{array}{lll}1 & 1 & 1\end{array}$ & $1 ?$ & $\begin{array}{lllll}11 & 1 & 1 & 0\end{array}$ & ? 010101 & $1 ? ? \begin{array}{llll}1 & 1 & 1\end{array}$ & $\begin{array}{llll}11011 & 1\end{array}$ & $\begin{array}{llll}1 & 1 & 1\end{array} ?$ ? & $\begin{array}{lllll}1 & 1 & 1 & 1\end{array}$ & ? $\begin{array}{llll}1 & 1 & 0 & 1\end{array}$ & $\begin{array}{lllll}1 & 1 & 1 & 1 & 1\end{array}$ & $\begin{array}{lll}1111 & 1\end{array}$ \\
\hline usauropoda & 1021 & & $\begin{array}{llll}0 & 1 & 1 & 1\end{array}$ & 10 & $\begin{array}{lllll}11 & 1 & 1 & 0\end{array}$ & $\begin{array}{lllll}10 & 1 & 1 & 1\end{array}$ & $\begin{array}{lllll}1 & 1 & 1 & 1 & 1\end{array}$ & $210 \mathrm{P} 0$ & $\begin{array}{lllll} & 1 & 1 & 1 & 1\end{array}$ & $\begin{array}{lllll}11 & 110\end{array}$ & 11100 & $\begin{array}{lllll}1 & 1 & 1 & 1 & 1\end{array}$ & $\begin{array}{llll}1 & 1 & 1 & 1\end{array}$ \\
\hline
\end{tabular}

